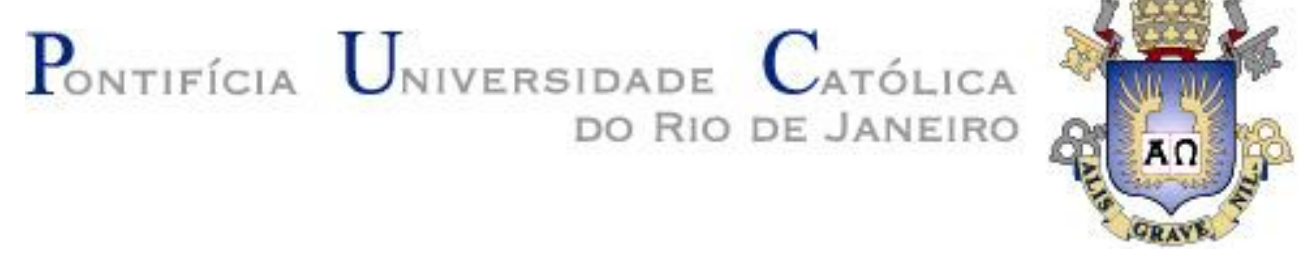

Allícia Sthel Santos de Oliveira

Análise Probabilística de Estabilidade de Poços de Petróleo

Dissertação de Mestrado

Dissertação apresentada como requisito parcial para obtenção do grau de Mestre pelo programa de PósGraduação em Engenharia Civil do Departamento de Engenharia Civil e Ambiental da PUC-Rio.

Orientador: Dr. Sérgio Augusto Barreto da Fontoura Co-orientadora: Dra. Vivian Rodrigues Marchesi

Rio de Janeiro Novembro de 2020 


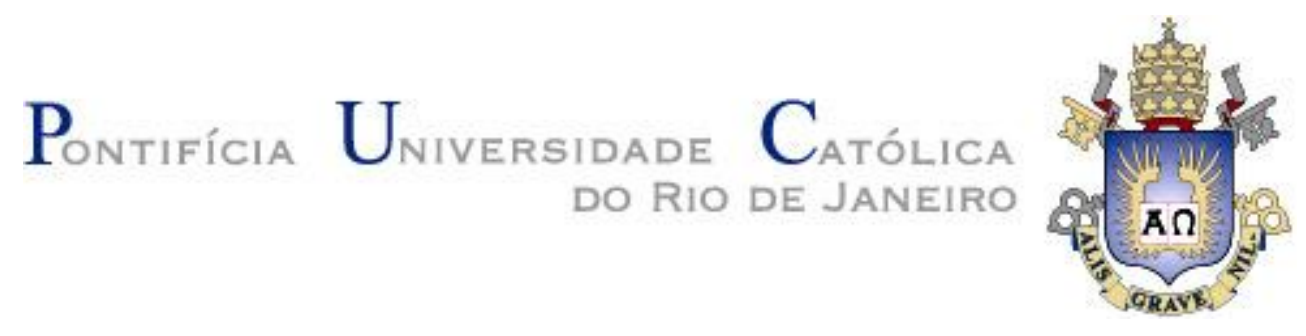

Allícia Sthel Santos de Oliveira

\section{Análise Probabilística de Estabilidade de Poços de Petróleo}

Dissertação apresentada como requisito parcial para obtenção do grau de Mestre pelo programa de PósGraduação em Engenharia Civil da PUC-Rio. Aprovada pela Comissão Examinadora abaixo.

Dr. Sérgio Augusto Barreto da Fontoura

Orientador

Departamento de Engenharia Civil - PUC Rio

Dra. Vivian Rodrigues Marchesi

Co-orientadora

GTEP - PUC-Rio

Dr. Alberto de Sampaio Ferraz Jardim Sayão

Departamento de Engenharia Civil - PUC Rio

Dr. João Carlos Plácido

Departamento de Engenharia Mecânica - PUC Rio

Rio de Janeiro, 26 de novembro de 2020 
Todos os direitos reservados. É proibida a reprodução total ou parcial do trabalho sem a autorização da universidade, da autora e do orientador.

\section{Allícia Sthel Santos de Oliveira}

Graduou-se em Engenharia de Petróleo pela Universidade Federal Fluminense em 2017. Em 2014 foi aluna de Intercâmbio Internacional na Universidade Estadual do Kansas nos Estados Unidos e atualmente trabalha no Grupo de Tecnologia em Engenharia de Petróleo na PUCRio como engenheira pesquisadora participante da equipe de desenvolvimento de software de análise de estabilidade. Principais áreas de interesse: Engenharia de Petróleo, Geomecânica do Petróleo e Mecânica das Rochas.

Ficha Catalográfica

Oliveira, Allícia Sthel Santos de

Análise probabilística de estabilidade de poços de petróleo / Allícia Sthel Santos de Oliveira ; orientador: Sérgio Augusto Barreto da Fontoura ; co-orientadora: Vivian Rodrigues Marchesi. - 2020.

132 f. : il. color. ; $30 \mathrm{~cm}$

Dissertação (mestrado)-Pontifícia Universidade Católica do Rio de Janeiro, Departamento de Engenharia Civil e Ambiental, 2020.

Inclui bibliografia

1. Engenharia Civil e Ambiental - Teses. 2. Análise de estabilidade de poços. 3. Métodos probabilísticos. 4. Probabilidade de falha. 5. Incertezas associadas. 6. Eventos de perfuração. I. Fontoura, Sérgio Augusto Barreto da. II. Marchesi, Vivian Rodrigues. III. Pontifícia Universidade Católica do Rio de Janeiro. Departamento de Engenharia Civil e Ambiental. IV. Título. 
Para meus muito amados: pais, irmã e irmão, pelo apoio, confiança e torcida sempre. 


\section{Agradecimentos}

Aos meus pais, Josi e Elço, pelo amor incondicional, por estarem sempre ao meu lado, me apoiarem diariamente, compreender todos os altos e baixos dessa caminhada, por me transmitirem os valores que me tornaram o ser humano que sou hoje, por sempre incentivarem meu crescimento profissional e pelo enorme investimento que fizeram nos meus estudos com muito esforço.

À Allana, que além de ser minha irmã, também é minha melhor amiga, por todo o amor que sempre recebi, por todo apoio emocional, por ouvir meus desabafos, ajudar a me concentrar, passar dicas de organização, por ser meu ponto de calma e clareza e por ser um exemplo de mulher e profissional.

Agradeço também ao meu irmão Átila, que não é de sangue, mas é de todo o coração, por trazer descontração mesmo nos momentos mais estressantes, por me mostrar uma visão mais simples e objetiva nos meus momentos de tempestade no copo d'água, por todo amor, carinho e proteção que um irmão poderia proporcionar.

Ao meu orientador, Sérgio A. B. da Fontoura, a quem dedico profundo respeito e admiração profissional. Por todos os conhecimentos transmitidos, pela confiança, pela oportunidade de desenvolver esse trabalho no GTEP, por cobrar de mim o meu melhor desempenho e pela grande contribuição para o meu crescimento profissional.

À minha coorientadora Vivian R. Marchesi, a quem admiro profundamente, pela valiosa amizade, pelo apoio emocional ao longo desse período em que estamos trabalhando juntas, pela enorme contribuição para o meu crescimento profissional e no desenvolvimento deste trabalho, pelos ensinamentos, pelo exemplo de profissional e por mostrar que delicadeza, firmeza e força são características altamente harmoniosas.

Ao meu amigo Cristhian, pela amizade, pelas brincadeiras, por deixar o ambiente de trabalho sempre mais leve, pela importante contribuição no desenvolvimento deste trabalho, pelos ensinamentos passados sempre de maneira prática, pela paciência, pelas palavras de conforto e pela forte contribuição - até hoje - no desenvolvimento da minha autoconfiança.

Agradeço à Carla, pela ajuda fundamental no início dessa caminhada, por todo o apoio e carinho, por sempre acreditar em mim e pelos ensinamentos passados com tanta doçura.

Agradeço aos amigos do GTEP, em especial à Renata, Bianca e Araken - com quem compartilhei a sala, o conhecimento, o dia a dia e as risadas por meses e que me apoiaram ao longo do mestrado - ao Roger, Roberto, Gabriel Valle, Gabriel Pinheiro, Emanuel e Vanessa - que trabalham diretamente comigo e sempre torceram e festejaram cada vitória minha - e ao Michel - por sempre trazer uma solução inteligente, 
prática e imediata e nunca permitir que eu perdesse horas de trabalho feito desta dissertação quando ocorria alguma falha operacional na minha máquina.

A todos os professores e funcionários do Departamento de Engenharia Civil pelos ensinamentos, esclarecimentos e apoio ao longo de todo o mestrado.

À Petrobras pelo fornecimento dos dados utilizados para este estudo.

Ao CNPq, à PUC-Rio e ao GTEP pelos auxílios concedidos, sem os quais esse trabalho não poderia ter sido realizado.

Finalmente e mais importante, agradeço a Deus, por me cercar de todas as pessoas citadas, por planejar minha vida com tantas oportunidades, por estar sempre ao meu lado, me ajudando a superar momentos difíceis e valorizar os momentos de vitórias e por sempre ouvir minhas orações e retribuir com o melhor para mim.

O presente trabalho foi realizado com apoio da Coordenação de Aperfeiçoamento de Pessoal de Nível Superior - Brasil (CAPES) - Código de Financiamento 001. 


\section{Resumo}

Oliveira, Allícia Sthel Santos; Fontoura, Sérgio Augusto Barreto. Análise Probabilística de Estabilidade de Poços de Petróleo. Rio de Janeiro, 2020. 132p. Dissertação de Mestrado - Departamento de engenharia Civil, Pontifícia Universidade Católica do Rio de Janeiro.

A análise de estabilidade de poços de petróleo é um passo importante para uma previsão do comportamento geomecânico de poços que ainda serão perfurados e para o entendimento de problemas que possam ter acontecido em perfurações anteriores (a fim de evitar que os problemas se repitam). Muitas complicações que ocorrem ao longo da perfuração de um poço são devido a um dimensionamento falho do peso de fluido de perfuração a ser utilizado. Algumas dessas complicações podem gerar a necessidade da interrupção da perfuração, o que provoca o tempo não produtivo e, consequentemente, o acréscimo de milhões de dólares na soma final dos gastos da operação, devido ao aluguel de equipamentos que são subutilizados nesse momento. As análises de estabilidade são amplamente realizadas de maneira determinística, o que pode acarretar incertezas aos resultados. Este trabalho propõe a análise de estabilidade probabilística de poços de petróleo baseada em dois métodos diferentes: FOSM e SEAM, com o objetivo de fornecer uma janela operacional mais realista para a análise de estabilidade ao longo de toda a trajetória de um poço. As metodologias FOSM e SEAM foram implementadas em código MATLAB@ $\subset$ pela autora desse trabalho e então foi possível obter os gradientes de colapsos e fratura para um projeto de um poço de petróleo (ao longo de toda sua trajetória). No estudo de caso proposto, foi possível observar que os resultados probabilísticos obtidos - para uma probabilidade de falha da formação de $10 \%$ - apresentaram uma previsão mais coerente para o comportamento dos gradientes de colapsos e fratura desse poço do que os resultados determinísticos, de onde se conclui que alguns problemas observados durante a perfuração poderiam ter sido evitados com a utilização dos métodos probabilísticos.

\section{Palavras-chave}

Análise de estabilidade de poços; métodos probabilísticos; probabilidade de falha; incertezas associadas; eventos de perfuração. 


\section{Abstract}

Oliveira, Allícia Sthel Santos; Fontoura, Sérgio Augusto Barreto. Probabilistic analysis of oil wellbore stability. Rio de Janeiro, 2020. 132p. Dissertação de Mestrado - Departamento de engenharia Civil, Pontifícia Universidade Católica do Rio de Janeiro.

The stability analysis of a wellbore is an important step to predict the geomechanical behavior of wellbores that will be drilled and for understanding problems that may have occurred in wellbores already drilled (in order to prevent problems from happening again). Many unwanted events that occur during the drilling of a wellbore are due to a bad dimensioning of the mud weight used. Some of these complications can bring on the need to interrupt drilling operation, which causes nonproductive time and, consequently, the addition of millions of dollars in the final sum of the expenses of the drilling operation, due to the daily rental of equipment that are not used during the non-productive time. The stability analyzes are widely performed with deterministic methods, which can lead to uncertainties in the final results. This paper proposes a probabilistic wellbore stability analysis based on two different methods: FOSM and SEAM, with the purpose of providing a more realistic mud weight window for the stability analysis along the trajectory of the wellbore. The FOSM and SEAM methodologies were developed in MATLAB $\subset$ code by the author of this study and then it was possible to obtain the collapses and fracture gradients for a project of a wellbore (along its entire trajectory). In the case study proposed, it was possible to observe that the probabilistic results - for a failure probability of $10 \%$ - presented a more coherent prediction of the behavior of the wellbore's collapses and fracture gradients than the deterministic results, and hence it can be concluded that some of the problems observed during drilling operation could have been avoided with the use of probabilistic methods.

\section{Keywords}

Wellbore stability analysis; probabilistic methods; failure probability; associated uncertainties; drilling events. 


\section{Sumário}

1. Introdução 22

1.1. Objetivos Gerais 24

1.2. Objetivos Específicos 24

1.3. Estrutura da dissertação 25

2. Revisão Bibliográfica 27

2.1. Análise Probabilística 27

2.2. Análise de Risco 31

2.3. Eventos de Perfuração 36

2.3.1. Perda de circulação 38

2.3.2. Prisão diferencial 39

2.3.3. Desmoronamento/Alargamento do poço 41

2.3.4. Kick 42

2.3.5. Fechamento do poço 43

2.4. Tempo não produtivo e custos associados 44

3. Metodologia 48

3.1. Análise Determinística de Estabilidade de Poços 48

3.1.1. Parâmetros de entrada para o cálculo da Janela Operacional50

3.1.2. Cálculo dos gradientes em estabilidade de poços 57

3.2. Análise Estatística dos Parâmetros de Entrada 62

3.2.1. Distribuição Normal 63

3.2.2. Distribuição Uniforme 65

3.3. Análise Probabilística de Estabilidade de Poços 67

3.3.1. Método da Análise Estatística de Erro (Statistical Error Analysis Method, SEAM) 69 
3.3.2. Método do Segundo Momento de Primeira Ordem (First Order Second Moment Method, FOSM) 71

4. Estudo de Caso 74

4.1. Poço de Correlação 75

4.2. Poço de Projeto - Montagem 80

4.3. Poço Retroanalisado 83

5. Resultados e Discussões 89

5.1. Análise Determinística de Estabilidade de Poços para o Projeto 89

5.2. Análise Estatística dos Parâmetros de Entrada 93

5.3. Análise Probabilística de Estabilidade de Poços para o Projeto 94

5.3.1. Validação dos Métodos Probabilísticas Implementadas no MATLABC 95

5.3.2. Comparação entre resultados obtidos por FOSM e SEAM para o Poço de Projeto $\quad 97$

5.3.3. Análise Integrada com Resultados Reais Pós Perfuração 108

5.3.4. Análise de Sensibilidade 113

6. Conclusões e Recomendações para Trabalhos Futuros 121

6.1. Conclusões e comentários finais 121

6.2. Recomendações para trabalhos futuros 123

Referências $\quad 125$

Apêndice A - Equivalência Amostral entre os Métodos Estatísticos 128

Apêndice B - Metodologia geral do Código Desenvolvido em MATLABC)

para Aplicação dos Métodos Probabilísticos 


\section{Lista de Figuras}

Figura 1 - Análise de sensibilidade dos parâmetros de entrada no resultado de A) colapso inferior; B) fratura. O eixo y denota a variação observada no gradiente a partir de uma pequena variação dos parâmetros listados no eixo x. (Adaptado de Fontoura et al., 2010)

Figura 2 - Resultados obtidos no estudo de Gholami et al. (2015).

Figura 3 - Resultados da análise de sensibilidade dos parâmetros de entrada no gradiente de colapso. O eixo y denota a valor do observado no gradiente de colapso em relação aos diferentes valores dos parâmetros de entrada apresentados nos eixos $x$. apresentado por (Adaptado de Moos et al., 2003).

Figura 4 - a) Janela obtida com pressão de poros e gradiente de fratura e b) Janela obtida com pressão de poros, gradiente de fratura e gradiente de colapso. (Moos et al., 2003, adaptado)

Figura 5 - Resultados da análise de sensibilidade dos parâmetros de entrada no gradiente de colapso para o segundo modelo de disposição de sapatas, apresentado na Figura 4 b). O eixo y denota a valor do observado no gradiente de colapso em relação aos diferentes valores dos parâmetros de entrada apresentados nos eixos x. apresentado por (Adaptado de Moos et al., 2003).

Figura 6 - Ilustração: Perda de circulação. (adaptado de Oilfield Review, 1999)

Figura 7 - Ilustração: prisão diferencial. (Oilfield Review, 1999)

Figura 8 - Ilustração: desmoronamento/alargamento de poço. (Oilfield Review, 1990)

Figura 9 - Ilustração: kick. (Guimarães, 2010)

Figura 10 - Poços em Blowout. (Guimarães, 2010)

Figura 11 - Ilustração: fechamento do poço. (Oilfield Review, 1999)

Figura 12. Comparação entre tempo não produtivo associado aos eventos de perfuração e tempo produtivo (adaptado de Reid et al., 2006). 
Figura 13. Porcentagem de tempo não produtivo relacionado a cada evento de perfuração. (Adaptado de Reid et al., 2006).

Figura 14. Comparação entre custos relacionados ao tempo produtivo e não produtivo. (Adaptado de Reid et al., 2006).

Figura 15 - Fluxo de cálculos para análise de estabilidade.

Figura 16 - Exemplo de perfil de imagem corrido para a observação de ocorrência de breakouts. As setas vermelhas indicam onde é possível verificar a ocorrência de breakouts no perfil de imagem e as setas verdes indicam a representação desses breakouts na sessão transversal do poço. (Modificado de Zoback, 2003) 56

Figura 17 - Distribuição de tensões em coordenadas cilíndricas. (Fjaer, 2008)

Figura 18. Histograma apresentando uma distribuição normal de frequência de um perfil raios gama ${ }^{4}$. (SESTC)

Figura 19 - Distribuição de amostragem ao longo da função de densidade de um distribuição normal. (Portal Action, acesso em 20/09/2020)

Figura 20. Histograma apresentando uma distribuição uniforme de frequência de dados de pressão de poros. (SESTC)

Figura 21 - Função densidade de uma distribuição uniforme. (Pinheiro et al., 2012)

Figura 22 - Perfis iniciais utilizados para a retroanálise do poço de correlação para o estudo de caso. $\Delta t c$ é o tempo de trânsito compressional da onda, $\Delta t s$ é o tempo de trânsito cisalhante, $\rho b$ é a densidade da formação e GRAY é o perfil de raios gama para as camadas (A) pós sal e (B) pré-sal. (SESTC)

76

Figura 23 - Propriedades mecânicas estimadas nas camadas (A) pós sal e (B) pré-sal para o poço de correlação para o estudo de caso. (SESTC)

Figura 24 - Propriedades mecânicas estimadas nas camadas (A) pós sal e (B) pré-sal para o poço de correlação para o estudo de caso. (SESTC)

Figura 25 - Dados de breakout observados na camada pré-sal do poço de correlação utilizados para a estimativa da tensão horizontal maior. (GTEP, 2016) 
Figura 26 - Janela Operacional obtida a partir da retroanálise do poço de correlação nas camadas $(A)$ pós sal e $(B)$ pré-sal para o estudo de caso. (SEST@)

Figura 27 - llustração do processo de correlação entre um poço correlato e um poço de projeto. (A) correlação entre litologias interpretadas de poços de correlação e litologia prevista para o projeto a partir do quadro de previsão geológico; (B) correlação entre os perfis iniciais de poços de correlação para a criação dos perfis adaptados para o projeto.

Figura 28 - Perfis iniciais para o projeto do Poço PUC obtidos nas camadas (A) pós sal e (B) pré-sal a partir do poço de correlação. (SEST TR 2.0C)

Figura 29 - Perfis iniciais corridos nas camadas (A) pós sal e (B) pré-sal do Poço PUC. (SEST TR 2.0@)

Figura 30 - Estimativa dos parâmetros elásticos durante a retroanálise do Poço PUC, nas camadas (A) pós sal e (B) pré-sal. (SEST TR 2.0@)

Figura 31 - Estimativa das propriedades mecânicas durante a retroanálise do Poço PUC, nas camadas (A) pós sal e (B) pré-sal. (SEST TR 2.0@)

Figura 32 - Janela operacional estimada nas camadas (A) pós sal e (B) pré-sal a partir da retroanálise do Poço PUC. (SEST TR 2.0@)

Figura 33 - Propriedades elásticas estimadas deterministicamente nas camadas (A) pós sal e (B) pré-sal. (SEST TR 2.0@)

Figura 34 - Propriedade mecânicas estimadas deterministicamente nas camadas (A) pós sal e (B) pré-sal. (SEST TR 2.0 (C)

Figura 35 - Estado de tensões estimado deterministicamente nas camadas (A) pós sal e (B) pré-sal. (SEST TR 2.0 (C)

Figura 36 - Gradientes de fratura superior e colapsos superior e inferior estimados deterministicamente nas camadas (A) pós sal e (B) pré-sal. (SEST TR 2.0 (C))

Figura 37 - Gradientes de fratura e colapso obtidos a partir dos métodos probabilísticos FOSM e SEAM nas camadas (A) pós sal e (B) pré-sal para as probabilidades de falha: $P F=10 \%, P F$ $=50 \%$ e PF $=90 \%$ - com distribuição normal dos parâmetros de entrada. (SEST TR 2.0@) 99 
Figura 38 - Janelas operacionais obtidas a partir do método FOSM, nas camadas (A) pós sal e (B) pré-sal, para as diferentes probabilidades de falha (PF) - com distribuição normal dos parâmetros de entrada. (SEST TR 2.0@).

Figura 39 - Janelas operacionais obtidas a partir do método SEAM, nas camadas (A) pós sal e (B) pré-sal, para as diferentes probabilidades de falha (PF) - com distribuição normal dos parâmetros de entrada. (SEST TR 2.0@).

101

Figura 40 - Gradientes obtidos a partir dos métodos probabilísticos FOSM e SEAM, nas camadas (A) pós sal e (B) pré-sal, para as diferentes probabilidades de falha (PF) - com distribuição uniforme dos parâmetros de entrada. (SEST TR 2.0 @) 102

Figura 41 - Gradientes obtidos a partir da metodologia FOSM, nas camadas (A) pós sal e (B) pré-sal, com distribuição uniforme dos parâmetros de entrada. (SEST TR 2.0 C) 103

Figura 42 - Gradientes obtidos a partir da metodologia FOSM, nas camadas (A) pós sal e (B) pré-sal, com distribuição uniforme dos parâmetros de entrada. (SEST TR 2.0๑) 104

Figura 43 - Distribuição acumulada referente a uma produndidade na camada pós-sal. O eixo $\mathrm{y}$ refere-se a probabilidade de falha acumulada e o eixo $\mathrm{x}$ refere-se aos valores de gradientes obtidos para cada probabilidade em Ib/gal.

106

Figura 44 - Distribuição acumulada referente a uma profundidade na camada pré-sal. O eixo y refere-se a probabilidade de falha acumulada e o eixo $\mathrm{x}$ refere-se aos valores de gradientes obtidos para cada probabilidade em lb/gal.

107

Figura 45 - Comparação entre as janelas operacionais obtidas deterministicamente, nas camadas (A) pós sal e (B) pré-sal, no projeto e retroanálise do estudo de caso. (SEST TR 2.0@)

Figura 46 - Comparação entre gradientes obtidos deterministicamente e gradientes obtidos probabilisticamente para uma probabilidade de falha de 10\%, nas camadas (A) pós sal e (B) pré-sal. (C) denota a comparação em detalhe na camada pré-sal. (SEST TR 2.0@)

Figura 47 - Análise de sensibilidade dos parâmetros que mais influenciam o resultado para gradiente de fratura nas camadas (A) pós sal e (B) pré-sal. GFRATD é o gradiente de fratura obtido deterministicamente. GFRAT $\left(\mathrm{X}^{+}\right)$é o resultado para o gradiente de fratura quando é imposta uma variação positiva no parâmetro X. GFRAT(X') é o resultado para o gradiente de fratura quando é imposta uma variação negativa no parâmetro X. (SEST TR 2.0@) 114 
Figura 48 - Análise de sensibilidade dos parâmetros que mais influenciam o resultado para gradiente de colapso superior nas camadas $(A)$ pós sal e $(B)$ pré-sal. GCOLSD é o gradiente de fratura obtido deterministicamente. $\mathrm{GCOLS}\left(\mathrm{X}^{+}\right)$é o resultado para o gradiente de fratura quando é imposta uma variação positiva no parâmetro X. GCOLS(X) é o resultado para o gradiente de fratura quando é imposta uma variação negativa no parâmetro X. (SEST TR 2.0๑)

Figura 49 - Análise de sensibilidade dos parâmetros que mais influenciam o resultado para gradiente de colapso superior nas camadas (A) pós sal e (B) pré-sal. GCOLID o gradiente de fratura obtido deterministicamente. $\mathrm{GCOLI}\left(\mathrm{X}^{+}\right)$é o resultado para o gradiente de fratura quando é imposta uma variação positiva no parâmetro $X$. GCOLI(X') é o resultado para o gradiente de fratura quando é imposta uma variação negativa no parâmetro $X$. (SEST TR 2.0@)

Figura 50 - Esquema para definição do intervalo da distribuição uniforme que abrange $68.3 \%$ da amostragem. (Pinheiro et al., 2012, modificada) 


\section{Lista de Tabelas}

Tabela 1 - Principais eventos de perfuração associados a suas causas e efeitos. (Tavares, 2008)

Tabela 2. Média de preços do aluguel diário de diferentes sondas (adaptado de Condol \& Corrêa, 2012).

Tabela 3 - Valores médios dos parâmetros de entrada utilizados no estudo de Fontoura et al. para a aplicação dos métodos probabilísticos. (Modificado de Fontoura et al., 2002) 95

Tabela 4 - Comparação entre os resultados obtidos em Fontoura et al. (2002) e o código desenvolvido para esta dissertação a partir da aplicação dos métodos FOSM e SEAM para a estimativa do gradiente de fratura.

Tabela 5 - Comparação entre os resultados obtidos em Fontoura et al. (2002) e o código desenvolvido para esta dissertação a partir da aplicação dos métodos FOSM e SEAM para a estimativa do gradiente de colapso superior.

Tabela 6 - Comparação entre os resultados obtidos em Fontoura et al. (2002) e o código desenvolvido para esta dissertação a partir da aplicação dos métodos FOSM e SEAM para a estimativa do gradiente de colapso inferior.

Tabela 7 - Comparação entre nível de conservadorismo entre os métodos FOSM e SEAM considerando distribuição uniforme dos parâmetros de entrada.

Tabela 8 - Faixa de valores de gradiente de fratura (GFRAT) obtido em psi a partir do incremento positivo e negativo do parâmetro de entrada. GFRATD denota o gradiente de fratura médio em psi.

Tabela 9 - Faixa de valores de gradiente de colapso superior (GCOLS) obtido em psi a partir do incremento positivo e negativo do parâmetro de entrada. GCOLSD denota o gradiente de colapso superior médio em psi. 
Tabela 10 - Faixa de valores de gradiente de colapso inferior (GCOLI) obtido em psi a partir do incremento positivo e negativo do parâmetro de entrada. GCOLID denota o gradiente de colapso inferior médio médio em psi.

Tabela 11 - Resumo de análise de sensibilidade desse estudo de caso para os gradientes de fratura superior, colapso superior e colapso inferior. 


\section{Lista de Símbolos}

$\Delta \mathrm{t}_{\mathrm{C}_{\text {Normal }}} \quad$ Tempo de trânsito da onda compressional para o trend de compactação normal

$\Delta \mathrm{t}_{\mathrm{Cbs}} \quad$ Tempo de trânsito da onda compressional

$\mathrm{C}_{\mathrm{B}} \quad$ Parâmetro auxiliar para o cálculo da coesão

$\mathrm{D}_{\mathrm{W}} \quad$ Espessura da lâmina d'água

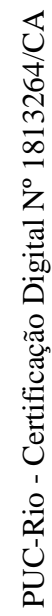

$\overline{\mathrm{FS}}$

Valor médio do fator de segurança

$\mathrm{FS}_{\mathrm{I}}^{-} \quad$ Fator de segurança obtida a partir da variação negativa de um parâmetro

$\mathrm{FS}_{I}^{+} \quad$ Fator de segurança obtida a partir da variação positiva de um parâmetro

$\overline{\mathrm{P}}$

Pressão média de ruptura

$\mathrm{P}_{\mathrm{F}} \quad$ Pressão interna do poço

$\mathrm{P}_{\mathrm{H}} \quad$ Pressão hidrostática

$\mathrm{P}_{\mathrm{I}}^{-} \quad$ Pressão de ruptura obtida a partir da variação negativa de um parâmetro

$\mathrm{P}_{\mathrm{I}}^{+} \quad$ Pressão de ruptura obtida a partir da variação positiva de um parâmetro

$\mathrm{P}_{\mathrm{P}} \quad$ Pressão de poros

$\mathrm{S}_{\mathrm{A}}, \mathrm{S}_{\mathrm{B}}, \mathrm{S}_{\mathrm{C}} \quad$ Tensões auxiliares para o cálculo das tensões principais 


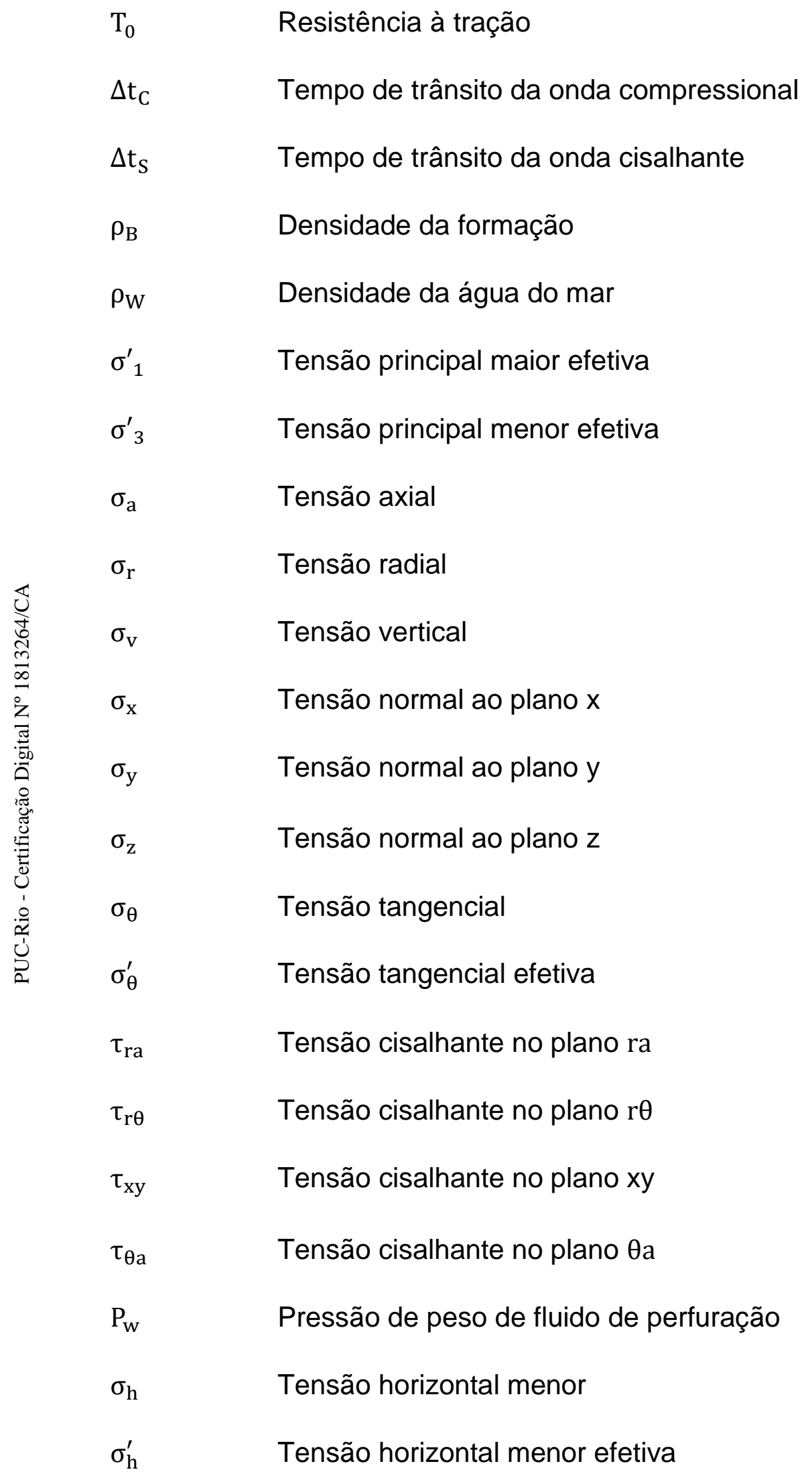




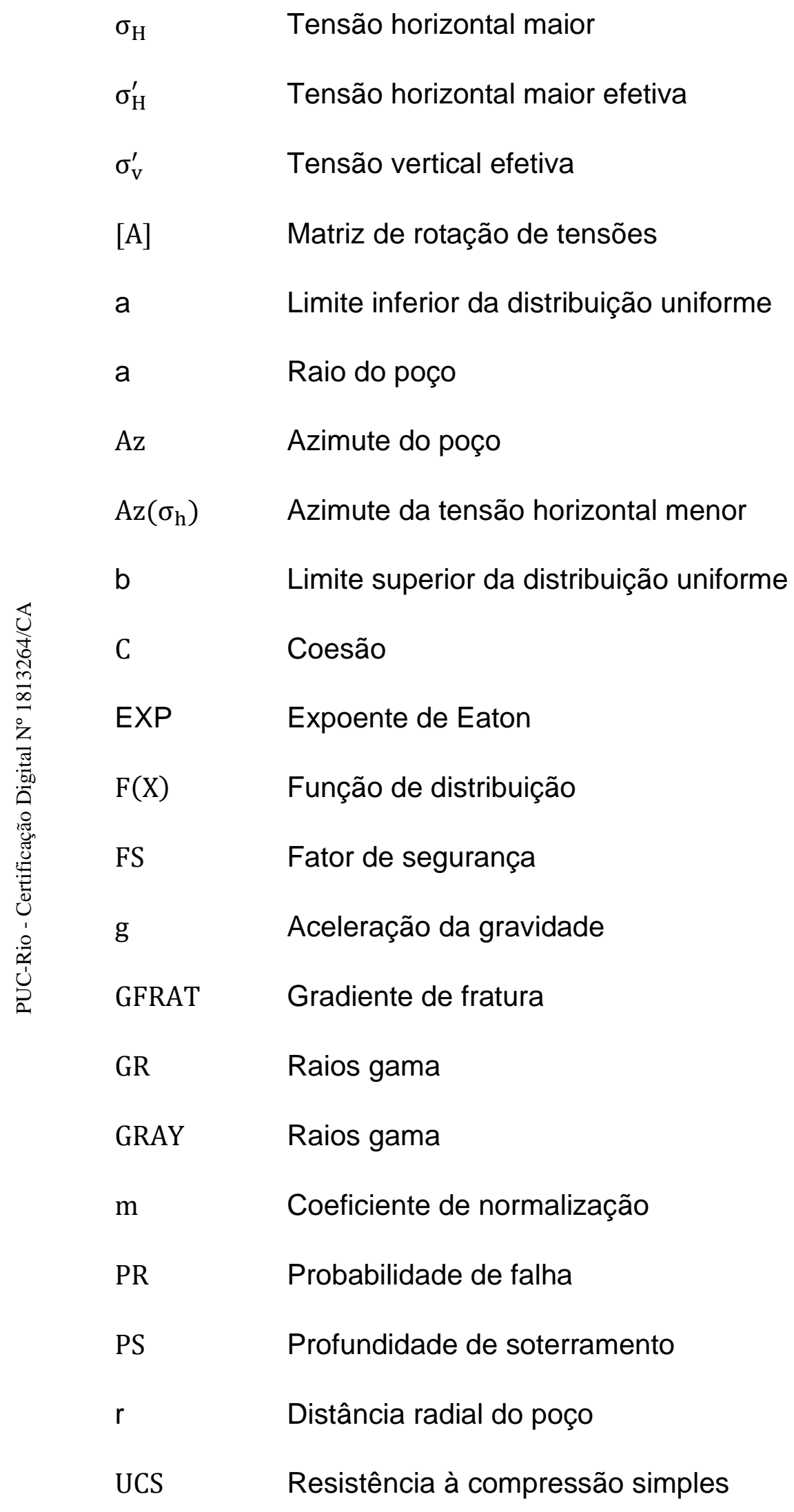




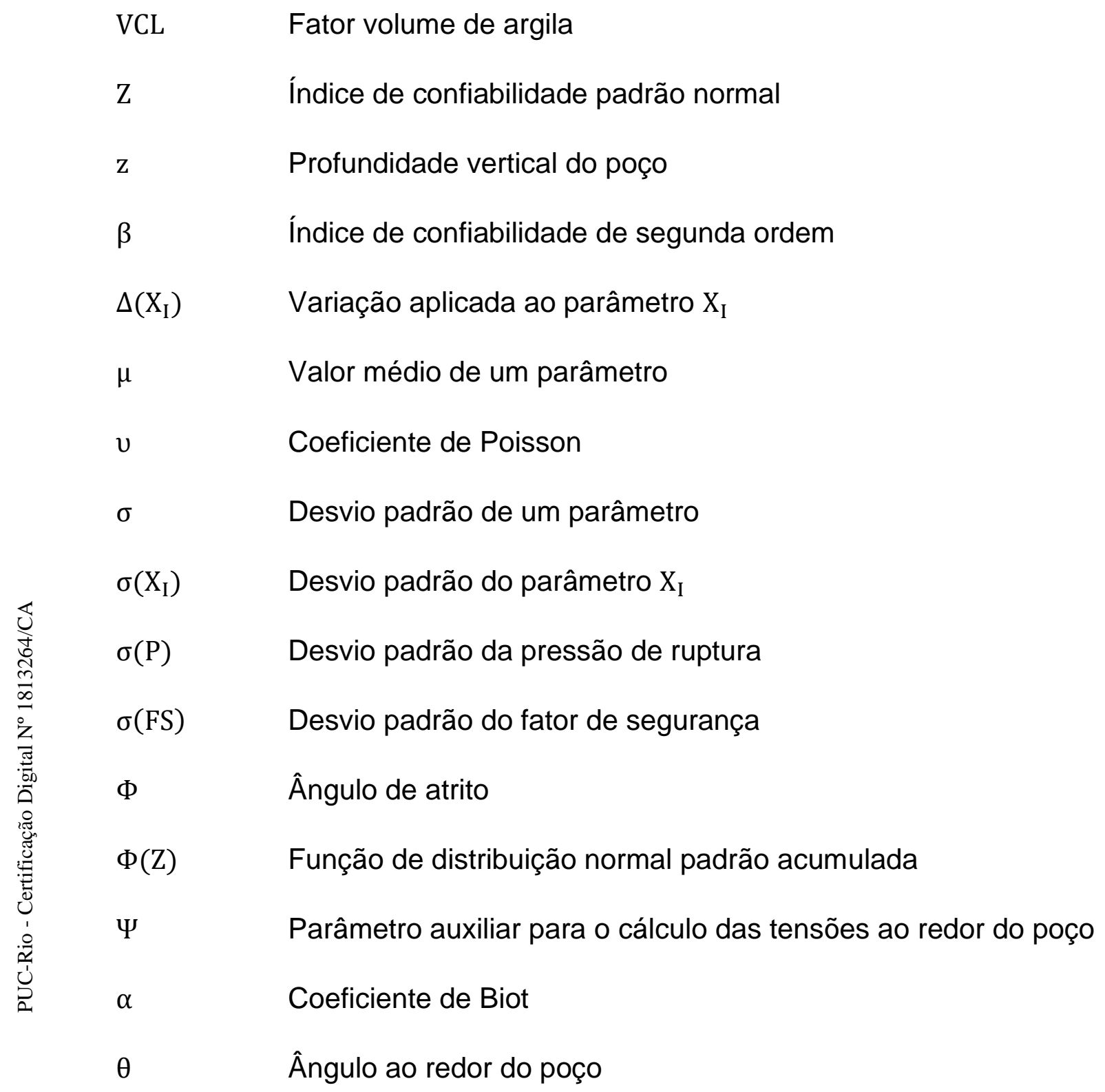




\section{1. Introdução}

Ao desenvolver um projeto de análise de estabilidade de um poço de petróleo, é importante ter acesso à maior quantidade de informações possível a respeito da área a ser perfurada, isto devido à importância da acurácia dos dados para a construção da janela de estabilidade. A janela de estabilidade, ou janela operacional, é um resultado de grande importância na sequência de um projeto de perfuração de poços. Nessa janela, estão representados os limites superiores e inferiores que a densidade do fluido de perfuração pode assumir a fim de preservar a estabilidade do poço ao longo da perfuração.

Os componentes básicos de uma janela de estabilidade são os gradientes de colapso e fratura superiores, gradientes de tensões horizontais (limites superiores), gradientes de colapso e fratura inferior e gradiente de pressão de poros (limites inferiores). Uma calibração inapropriada da densidade de fluido de perfuração pode resultar em eventos de perfuração indesejados que, geralmente, implicam em custos extras e maior tempo gasto na operação de perfuração do poço, por isso, é importante que seja aplicado um modelo geomecânico bem calibrado para a estimativa dos parâmetros utilizados no cálculo dos gradientes da janela operacional - que serão referidos como parâmetros de entrada nesse trabalho - tais como propriedades mecânicas e estado de tensões.

De uma maneira geral, a fim de evitar a ocorrência de problemas de perfuração, dados de poços adjacentes (poços correlatos) àquele que se quer perfurar são utilizados para estimar deterministicamente os gradientes de fratura e colapso e estabelecer um intervalo de peso de fluido que assegura a integridade do poço ao longo de sua trajetória. $O$ método determinístico consiste em utilizar os valores médios estimados de cada parâmetro empregado nos cálculos e aplicar correlações e hipóteses simplificadoras para a obtenção dos gradientes da janela operacional. Apesar da sua alta aplicação na indústria do petróleo, esse método pode carregar incertezas associadas e por fim, acarretar erros significativos nos resultados. 
Uma análise mais abrangente destes gradientes para diminuir os riscos de ocorrência de eventos indesejados consiste no uso de métodos probabilísticos, uma vez que essas metodologias englobam o efeito das incertezas associadas a cada parâmetro de entrada e fornecem resultados baseados em diferentes cenários e sua probabilidade de ocorrência. As incertezas podem ser provenientes de diferentes fontes ao longo da análise de estabilidade, por exemplo: leitura indireta dos dados, uso de correlações da literatura para a estimativa das propriedades mecânicas, hipóteses simplificadoras para as estimativas de tensões e pressões e hipóteses simplificadoras dos critérios de ruptura.

Apesar da análise probabilística produzir resultados mais abrangentes, este não é um método comumente utilizado para estimar os gradientes de colapsos e fratura ao longo da trajetória, mas sim a análise determinística de estabilidade de poços. Isso se deve ao fato de que, além de serem necessárias mais informações - nem sempre disponíveis - para a aplicação de métodos probabilísticos, estes muitas vezes demandam um tempo de processamento computacional alto - como por exemplo, as simulações de Monte Carlo. Dessa forma, muitas vezes opta-se por calcular de maneira determinística os gradientes ao longo da trajetória e, de maneira probabilística, apenas alguns pontos de profundidade para calibração.

Tendo em vista a compreensão das incertezas das estimativas determinísticas, vê-se a necessidade da utilização de metodologias probabilísticas para a análise de estabilidade ao longo de toda a trajetória de um poço. Este trabalho apresenta um projeto de análise de estabilidade de poço baseada em dois métodos probabilísticos diferentes: Método de Análise Estatística de Erro (FOSM) e Método do Segundo Momento de primeira Ordem (SEAM). As duas metodologias, já existentes na literatura, são implementadas em código MATLAB® para a aplicação ao longo de toda a trajetória de um poço.

A seleção das metodologias abordadas neste trabalho é feita com base no software comercial SESTC. Esse software permite ao usuário calcular os gradientes de colapsos e fraturas probabilisticamente a partir dos métodos FOSM e SEAM citados. Entretanto, esse cálculo é feito somente de maneira pontual. Portanto, para garantir a padronização da ferramenta já utilizada, opta-se por evoluir a implementação dessas mesmas metodologias para o cálculo dos gradientes ao longo de todas as profundidades do poço. 
Um estudo de caso é utilizado para ilustrar a aplicação das metodologias. Este estudo de caso é feito para um poço denominado Poço PUC e inicialmente é apresentada a retroanálise (análise após a perfuração) de estabilidade do poço correlato ao poço PUC, é detalhado também o projeto de estabilidade para o poço PUC com base na litologia e perfis adaptados a partir do poço correlato e posteriormente, é apresentada a retroanálise de estabilidade do poço PUC com base na litologia interpretada e perfis corridos após a sua perfuração.

Em seguida, os métodos probabilísticos são aplicados ao projeto feito para o poço PUC. Dessa forma, é possível comparar os diferentes resultados obtidos probabilisticamente com aqueles apresentados deterministicamente para o projeto e por fim, verificar que a utilização de métodos probabilísticos pode conferir resultados mais confiáveis e próximos do comportamento real no poço PUC.

\section{1. \\ Objetivo Geral}

Esse trabalho tem por objetivo apresentar duas metodologias de cálculo probabilístico dos gradientes de colapso (superior e inferior) e fratura (superior) e implementá-las em código MATLABC, com a finalidade de evoluir a ferramenta já existente, SESTC, fornecendo uma janela operacional mais realista para a análise de estabilidade de poços ao longo de toda a trajetória de um poço.

\section{2.}

\section{Objetivos Específicos}

Os objetivos específicos são:

- Encontrar métodos probabilísticos aplicáveis á análise de estabilidade de poços com baixo custo operacional, de forma a permitir sua aplicação ao longo de toda a trajetória de um poço;

- Testar a aplicação desses métodos em um poço real e verificar o custo operacional de sua aplicação; 
- Comparar resultados entre os métodos probabilísticos selecionados e resultados determinísticos, testando sua aplicabilidade para casos reais;

- Comparar resultados com evidências de problemas após a perfuração do poço projetado.

\section{3. \\ Estrutura da dissertação}

Este documento está dividido em 6 capítulos:

O capítulo 1 apresenta a introdução e os objetivos gerais e específicos desse estudo, além de descrever a estrutura do trabalho.

O capítulo 2 refere-se à revisão bibliográfica. Neste capítulo serão apresentados estudos anteriores de autores que abordaram as temáticas análise de estabilidade de poços a partir de métodos probabilísticos e utilização de métodos probabilísticos para fins de perfuração de poços, assim como os eventos de perfuração consequentes de instabilidades nas paredes do poço e sua influência no tempo não produtivo de perfuração.

O capítulo 3 apresenta a metodologia utilizada para o seguimento do estudo. Neste capítulo são apresentados todos os cálculos e correlações utilizadas para o cálculo determinístico dos gradientes de fratura e colapso, as correlações utilizadas para obter os parâmetros de entrada do cálculo determinístico e também a descrição da análise estatística que será utilizada para a caracterização das incertezas associadas aos parâmetros de entrada. Este capítulo introduz a metodologia de cálculos para a realização de dois tipos diferentes de análise probabilística (SEAM e FOSM).

O capítulo 4 apresenta o estudo de caso. Neste capítulo são apresentadas as informações referentes ao poço de correlação que será utilizado no projeto, inclusive a sua retroanálise, mostra também como é feita a montagem dos dados iniciais do poço de correlação para serem utilizados no projeto do poço a ser perfurado (poço do estudo de caso) e por fim apresenta todos os dados reais do poço do estudo de caso, inclusive a sua janela operacional calculada deterministicamente. 
No capítulo 5 serão apresentados os resultados das análises determinísticas, estatísticas e probabilísticas obtidos a partir da metodologia descrita no capítulo 3. Neste capítulo, os resultados determinísticos e probabilísticos serão comparados.

O capítulo 6 retrata as conclusões, considerações finais e recomendações para trabalhos futuros. 


\section{2. Revisão Bibliográfica}

Esse capítulo é dividido em duas partes: a primeira apresenta uma revisão bibliográfica sobre metodologias probabilísticas e a contabilização das incertezas associadas a parâmetros para a estimativa da janela operacional com o objetivo de auxiliar na tomada de decisões durante a perfuração, obter resultados mais seguros e diminuir riscos associados a uma operação. A segunda parte apresenta uma revisão sobre os principais problemas de perfuração possivelmente associados a problemas geomecânico (má previsão da janela operacional).

\section{1. \\ Análise Probabilística}

A avaliação da janela operacional obtida por meio de métodos probabilísticos tem sido abordada para variados tipos de estudos relacionados às diferentes áreas da indústria do petróleo. Isso porque as metodologias que se baseiam em probabilidade permitem a análise de um cenário mais amplo e completo de cada problema. Cada parâmetro utilizado possui um valor médio, porém assume-se a possibilidade desse valor flutuar dentro de um intervalo de incerteza definido por uma análise estatística.

A seguir serão apresentados trabalhos que abordam a análise probabilística da janela operacional para diferentes aplicações na engenharia, como por exemplo a análise de estabilidade em taludes de mineração (Vecci \& Sayão, 2019), a verificação da sensibilidade dos diferentes critérios de ruptura utilizados para o cálculo dos gradientes de colapso (Al-Ajmi \& Al-Harthy, 2010), a comparação de métodos probabilísticos alternativos, com menor custo operacional quando comparado ao método de Monte Carlo - que é referência no que diz respeito a métodos probabilísticos e amplamente utilizado - onde se destaca o estudo de Fontoura et al. (2002), a verificação do nível de incertezas associadas ao valor final do cálculo da janela operacional com foco em trechos horizontais (Morita, 1995), além da 
importante aplicação das metodologias probabilísticas também para a análise de risco, a fim de analisar os riscos associados ao processo de perfuração, e evitar a ocorrência de eventos de perfuração e seus custos associados, como abordado por Gholami et al. (2015) e Moos et al. (2003).

Al-Ajmi \& Al-Harthy (2010) por exemplo, calculam os gradientes de colapso probabilisticamente com a finalidade de comparar os resultados para diferentes critérios de ruptura. Os autores fazem uma análise de sensibilidade dos parâmetros de entrada para o cálculo do gradiente de colapso visando a posterior análise probabilística deste gradiente. Os parâmetros de entrada analisados foram: tensão horizontal maior, tensão horizontal menor, tensão vertical, pressão de poros, ângulo de atrito, coesão e coeficiente de Poisson.

A metodologia apresentada no artigo define de maneira determinística cada parâmetro e posteriormente, com os resultados obtidos deste primeiro cálculo, é feita uma análise estatística assumindo uma distribuição normal para obter os parâmetros estatísticos: valor máximo e valor mínimo. Este procedimento foi realizado para os três regimes de falha: normal, reversa e transcorrente.

Após determinação dos parâmetros estatísticos, foram utilizados os critérios de ruptura de Mohr-Coulomb e Mogi Coulomb para o cálculo do gradiente de colapso em cada regime de falha. O método probabilístico adotado foi o de Monte Carlo (10000 iterações) aplicado pontualmente para uma profundidade específica. Os resultados obtidos após a análise mostraram que os gradientes de colapso se apresentam menores para o critério de Mogi-Coulomb do que para o critério de Mohr-Coulomb e a análise de sensibilidade, feita para os regimes de falha normal e transcorrente, mostrou que os três parâmetros mais influentes para estes resultados são tensão horizontal maior, ângulo de atrito e coesão.

Neste estudo, Al-Ajmi e Al- Harthy utilizaram o método probabilístico mais notório, Monte Carlo. Já nos artigos apresentados por Vecci \& Sayão (2019), Fontoura et al. (2002) e Morita (1995), são abordados métodos probabilísticos alternativos a fim de ampliar as opções para análise de um cenário mais completo sem um custo de tempo operacional tão elevado quanto o Monte Carlo. Os métodos probabilísticos abordados foram: First Order Second Moment (FOSM), First Order Reliability Model 
(FORM) e Statistical Error Analysis Method (SEAM) e esses estudos serão melhor detalhados a seguir.

A metodologia FOSM foi inicialmente introduzida por Christian et al. (1992) e posteriormente foi amplamente aplicada na engenharia. Vecci \& Sayão (2019) apresentaram um estudo abordando o método FOSM para a análise de estabilidade de um talude na Mina do Cauê em Minas Gerais. As propriedades do solo (parâmetros de entrada para a análise de estabilidade) consideradas com incertezas associadas foram densidade natural, densidade saturada, coesão, tangente do ângulo de atrito e pressão de poros.

A partir da aplicação do método de FOSM, foi observado que a influência das densidades natural e saturada são irrelevantes para a análise de estabilidade do talude da Mina do Cauê, enquanto que a variável de maior influência foi o ângulo de atrito. A aplicação do método probabilístico foi associada a 3 métodos de equilíbrio limite (Bishop, Spencer e Morgenstern-Price) considerando dois cenários: fixação ou não da superfície de ruptura crítica.

A partir dos resultados, concluiu-se que, para um mesmo método de equilíbrio limite, o cenário de superfície de ruptura crítica fixa simplifica a aplicação do método e fornece resultados muito similares àqueles obtidos para a superfície livre. Já a comparação entre os resultados obtidos considerando diferentes método de equilíbrio limite e o cenário de superfície de ruptura crítica fixo, mostra uma variação significativa nos resultados de probabilidade de falha do talude.

Fontoura et al. (2002) fazem uma breve descrição de cada um dos métodos, esclarecendo que a principal motivação para a sua abordagem é o fato de que as simulações apresentadas demandam um tempo expressivamente menor para apresentar resultados quando comparados ao método de Monte Carlo. Isso se deve ao fato de que Monte Carlo prevê um número muito alto de simulações enquanto os três métodos destacados no artigo demandam um total de $(2 n+1)$ simulações, onde n é o número de entradas com incertezas associadas.

No artigo, foi feito um estudo de caso para um poço vertical onde os parâmetros de entrada, com suas respectivas incertezas associadas, foram: azimute da tensão horizontal menor, tensões in situ, pressão de poros, coeficiente de Biot, coeficiente de Poisson, ângulo de atrito, resistência à compressão simples e coesão. 
Em uma mesma profundidade, a simulação de Monte Carlo foi associada a 16 valores diferentes de pressão interna do poço. Foram feitas 50000 simulações. Posteriormente, foram feitas simulações pelos métodos FORM, FOSM, e SEAM associados aos mesmos 16 valores de pressão interna de poço. Para estes, foram 21 simulações cada método.

Os resultados obtidos mostraram que as estimativas foram bem similares independentemente do método usado (FOSM, SEAM, FORM ou Monte Carlo). Para ruptura por colapso superior, as diferenças entre os métodos são abaixo de $5 \%$ e para colapso inferior, as diferenças não superam $10 \%$. Para a curva de fratura, os resultados foram ainda mais similares.
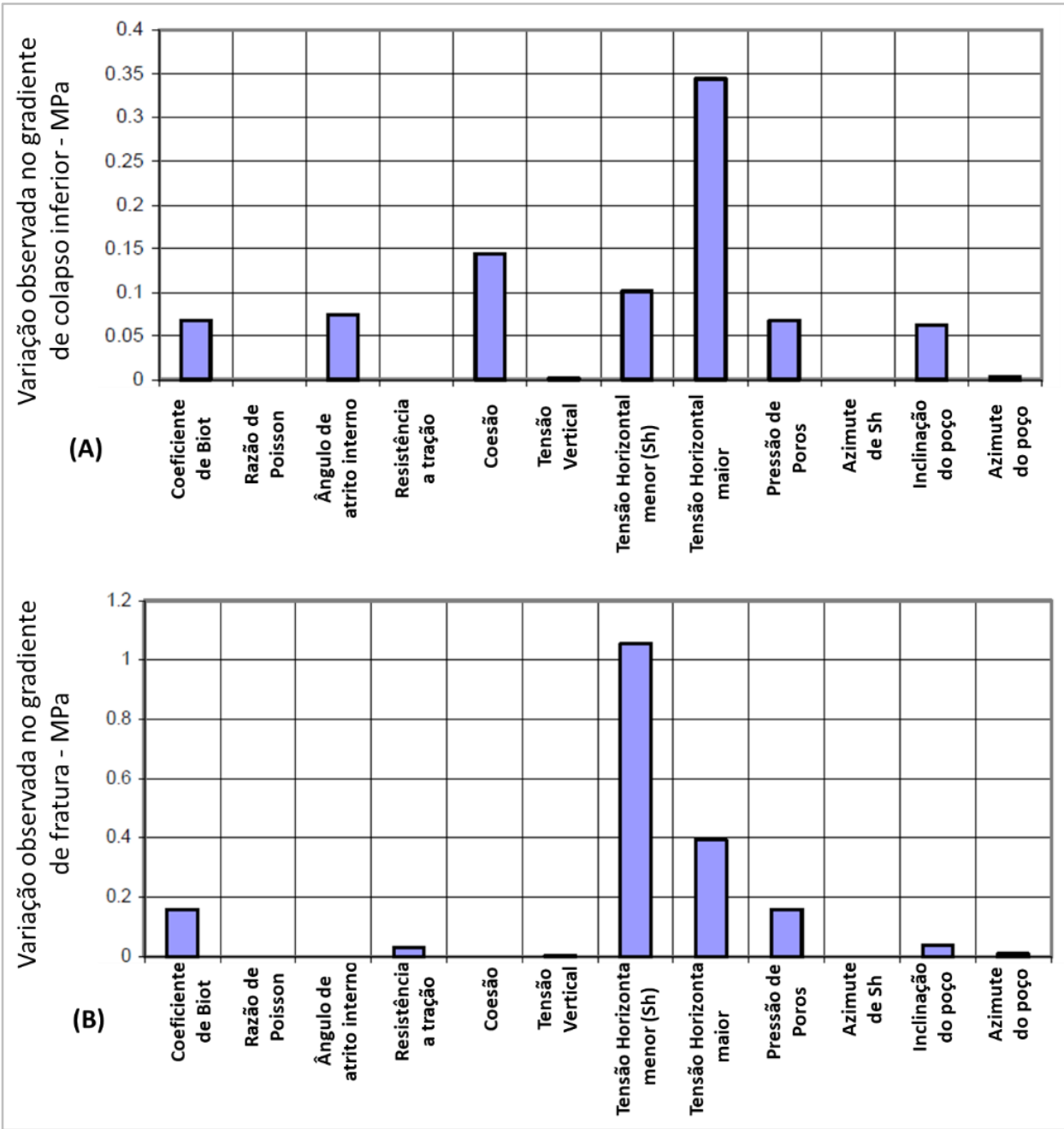

Figura 1 - Análise de sensibilidade dos parâmetros de entrada no resultado de A) colapso inferior; B) fratura. O eixo y denota a variação observada no gradiente a partir de uma pequena variação dos parâmetros listados no eixo x. (Adaptado de Fontoura et al., 2010) 
Para esse estudo, a análise de sensibilidade mostrou que para o cálculo do gradiente de colapso inferior, a tensão horizontal maior foi o parâmetro que apresentou a maior influência quando submetido a uma variação (Figura 1 (A)). Por outro lado, o parâmetro que mais influenciou o resultado final para o gradiente de fratura foi a tensão horizontal menor (Figura 1 (B)).

Em 1995, Morita aborda, também, o uso da metodologia SEAM. Nesse estudo é verificada da influência de incertezas associadas a um modelo geomecânico adotado para a análise de estabilidade especificamente em trechos horizontais de poços. Essa análise abordou os resultados obtido para a perfuração em dois tipos de formações: arenosas e argilosas. Como a análise foi focada em trechos horizontais, os resultados mostraram que a incerteza associada ao resultado final da pressão de fratura apresenta magnitude consideravelmente maior quando o poço está orientado em direção paralela à menor tensão in situ do que aquela apresentada para poços horizontais perpendiculares à menor tensão in situ.

Neste estudo foi observado também, que a janela operacional encontrada para o trecho de formação arenosa é significativamente menor do que aquela obtida para trechos de formações argilosas. Dessa forma, as incertezas associadas às pressões de colapso e fratura em formações argilosas também apresentam magnitude superior. Por fim, Morita (1995) conclui na análise de sensibilidade que o parâmetro de maior influência para o cálculo da pressão de fratura foi a tensão horizontal maior, para a formação arenosa, enquanto que para a formação argilosa, foi o efeito de inchamento consequente da interação desse tipo de formação com o fluido de perfuração. Já no cálculo do colapso, o parâmetro de maior influência foi a coesão para ambos os tipos de formação.

\section{2.}

\section{Análise de Risco}

Outra aplicação importante de métodos probabilísticos para o cálculo dos gradientes da janela operacional é a análise de risco. O conceito de análise de risco pode ser utilizado em variados cenários a fim de contribuir para a tomada de decisão na engenharia de petróleo e a análise probabilística é uma etapa fundamental ao considerar uma avaliação de risco quantitativa. 
Murtha (2000) define risco como o potencial de ganho ou perda associados a cada resultado específico, enquanto Houtchens (2007) complementa o conceito afirmando que o risco é uma composição de dois segmentos:

(i) A probabilidade de ocorrência de um evento e;

(ii) As consequências econômicas associadas à ocorrência deste evento.

Houtchens (2007) também define a análise de risco como o estudo do risco visando integrar esses segmentos e suas causas, ou seja, uma avaliação que correlaciona os eventos indesejados com suas possíveis causas, sua probabilidade de ocorrência e os gastos associados à sua ocorrência.

Gholami et al. (2015) utilizam o método de análise quantitativa de risco (QRA) para considerar os efeitos das incertezas associadas aos parâmetros de entrada para a estimativa do cálculo da janela operacional utilizando diferentes critérios de falha. Para esta análise, os parâmetros de entrada com incertezas associadas foram: parâmetro elástico (Young), coeficiente de Biot, resistência à compressão simples, tensões in situ, pressão de poros e azimute e inclinação do poço.

Após a análise de sensibilidade de cada parâmetro isoladamente, as incertezas foram tratadas a partir de interações pelo método de Monte-Carlo aplicadas a diversos critérios de ruptura: Mohr-Coulomb, Hoek-Brown, Lade modificado e Mogi-Coulomb. Nesse estudo, concluiu-se que, para uma probabilidade de falha de $90 \%$, por exemplo, os critérios de Hoek-Brown e Mogi-Coulomb forneceram a melhor estimativa para o valor mínimo aceitável para evitar breakouts, ou seja, apresentaram uma estimativa mais próxima aos resultados reais observados.

No que diz respeito a pressão de colapso superior, o critério de Mogi-Coulomb apresentou resultados levemente mais coerentes, embora a diferença apresentada entre esse critério e os de Hoek-Brown e Lade modificado tenha sido insignificante. Esses resultados podem ser verificados na Figura 2, que apresenta os limites de densidade de fluido de perfuração obtidos para diferentes probabilidades de falha para cada critério de ruptura.

Durante a análise de sensibilidade foi possível concluir também, com o auxílio de um gráfico do tipo tornado, que as variações de tensão horizontal maior e de 
pressão de poros são os parâmetros que mais e menos influenciam nos cálculos de limites da janela operacional, respectivamente.

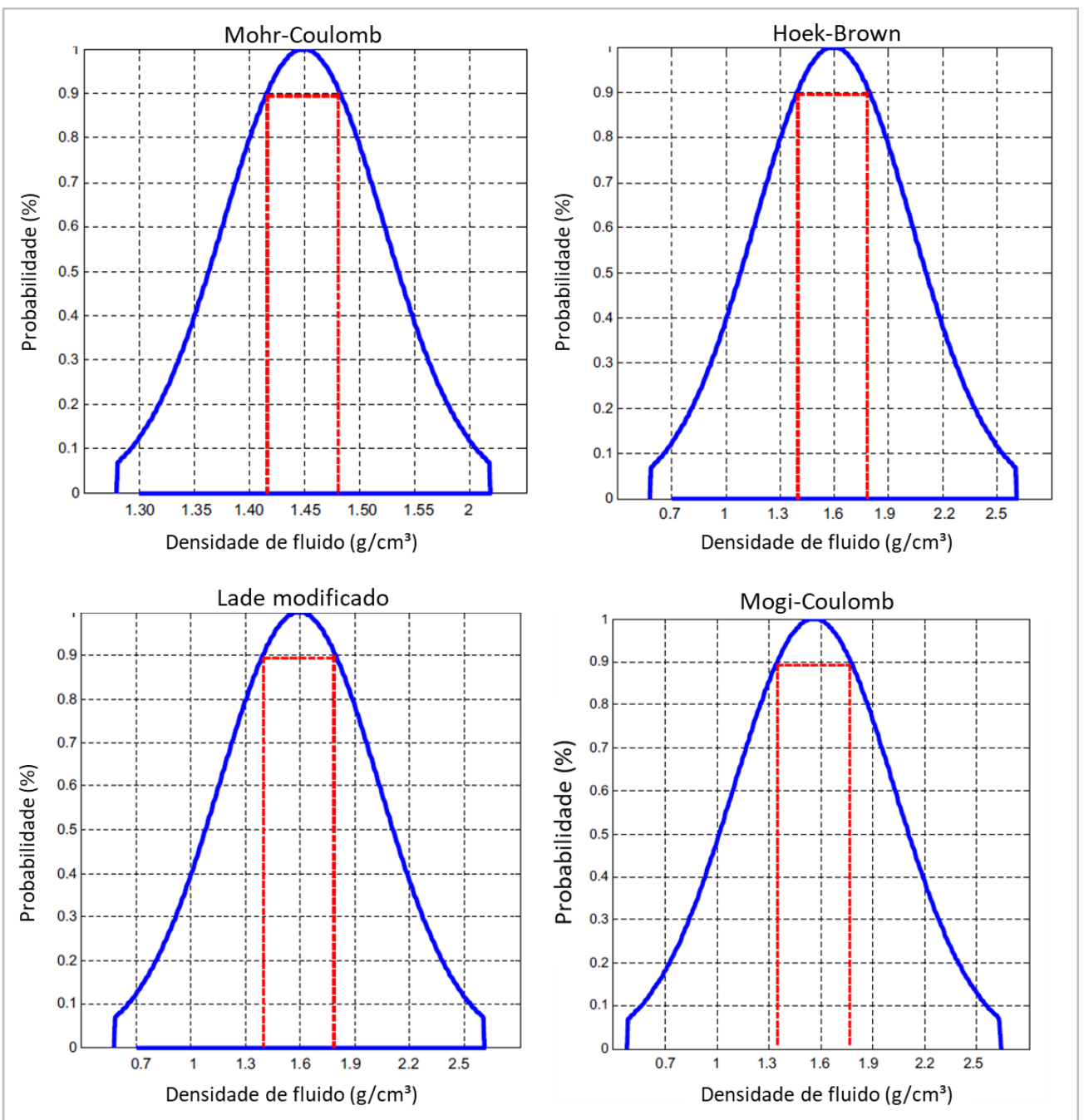

Figura 2 - Resultados obtidos no estudo de Gholami et al. (2015).

Enquanto Gholami et al. (2015) utilizaram a análise de risco aplicada a janela operacional para comparar os resultados obtidos a partir de quatro critérios de ruptura diferentes, Moos et al. (2003) foram mais específicos e aplicaram a QRA em dois estudos de caso diferentes:

i. Viabilidade de perfuração sub-balanceada de poço horizontal e completação com poço aberto 
ii. Efeito das incertezas para o modelo de revestimento em poço vertical de águas profundas

No estudo de caso i, inicialmente definiu-se de maneira determinística os valores médios dos parâmetros de entrada (resistência à compressão simples, tensão horizontal maior, tensão horizontal menor, tensão vertical e pressão de poros), posteriormente foram determinadas as incertezas associadas a esses parâmetros e aplicado a um critério de falha baseado na abertura de breakout.

Nesta aplicação os autores concluíram que a perfuração sub-balanceada do poço é possível, apesar dos riscos apresentados, porém recomendam uma análise mais profunda para a tomada de decisão a respeito da completação a poço aberto. Além disso, a análise de sensibilidade deste estudo mostrou que o parâmetro mais influente para os resultados foi a resistência da rocha, como indicado na Figura 3.

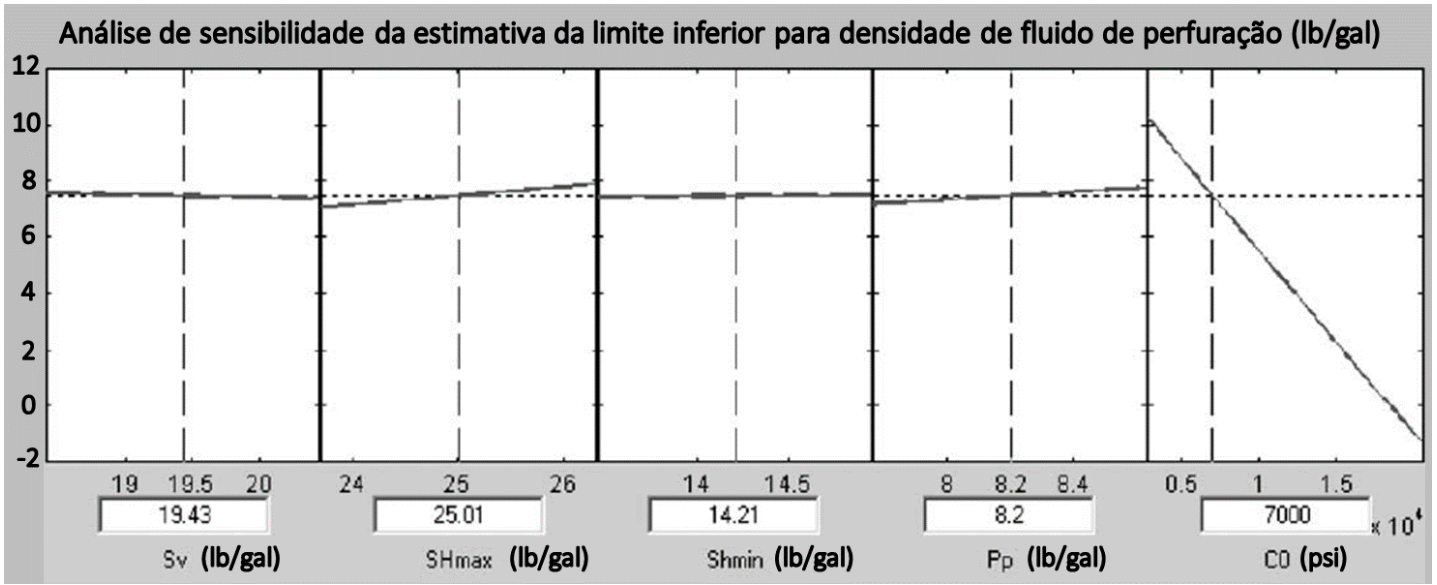

Figura 3 - Resultados da análise de sensibilidade dos parâmetros de entrada no gradiente de colapso. O eixo y denota a valor do observado no gradiente de colapso em relação aos diferentes valores dos parâmetros de entrada apresentados nos eixos x. apresentado por (Adaptado de Moos et al., 2003).

Já para o estudo de caso ii, inicialmente, a pressão de poros foi calculada a partir de velocidade sísmica e o gradiente de fratura ${ }^{[1]}$ com base em valores de pressão do leak-off test (teste de absorção). As duas curvas foram plotadas e então determinou-se o peso de fluido e a profundidade de assentamento das sapatas de

[1] A pressão de fratura denota a pressão necessária dentro do poço para a iniciação de umå4 fratura induzida. Os resultados de teste de absorção, que são amplamente utilizados para estimar o valor da tensão horizontal menor, denotam a pressão exercida no interior do poço suficiente para a abertura de fissuras préexistentes na formação e podem ser considerados, para fins de análises, como um gradiente de fratura conservador. 
modo a haver $1 \mathrm{lb} / \mathrm{gal}{ }^{[2]}$ de janela para os trechos. Para este modelo, foram estimadas 6 sapatas ( 6 fases de perfuração), como mostrado na Figura 4 a).

Para o cálculo de gradiente de colapso, foram também estimados os valores de resistência à compressão simples, tensões horizontais maior e menor e tensão vertical. Após a inserção das três curvas (gradientes de pressão de poros, colapso e fratura), determinou-se o peso de fluido e a profundidade de assentamento das sapatas de modo a haver $0.5 \mathrm{lb} / \mathrm{gal}$ de janela entre os gradientes de fratura e colapso. Neste caso, foram estimadas 5 sapatas, como mostrado na Figura 4 b).

a)

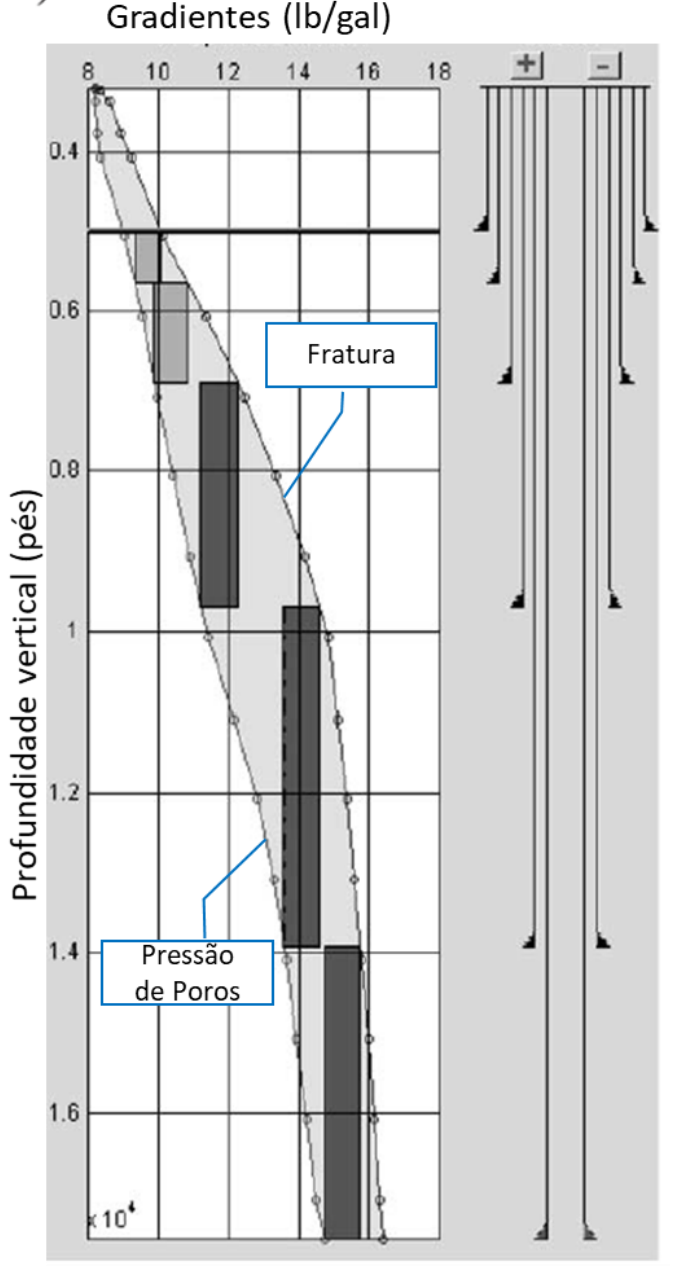

b) Gradientes (lb/gal)

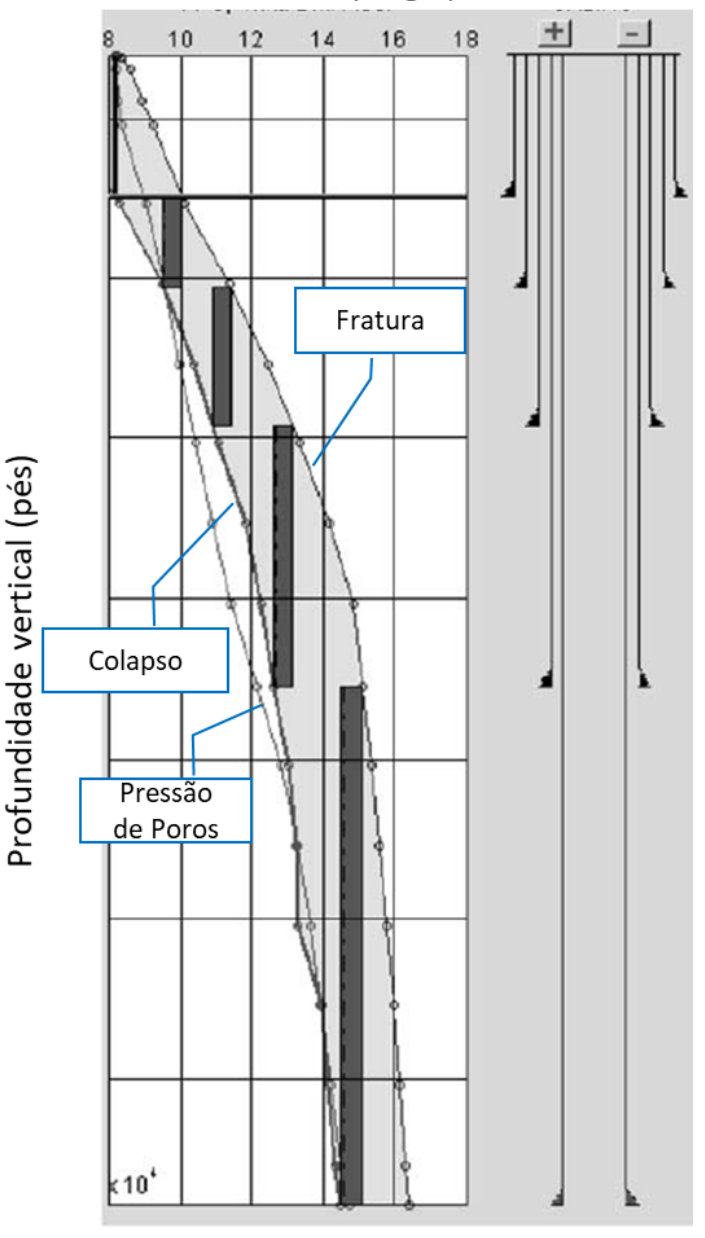

Figura 4 - a) Janela obtida com pressão de poros e gradiente de fratura e b) Janela obtida com pressão de poros, gradiente de fratura e gradiente de colapso. (Moos et al., 2003, adaptado) 
Aplicou-se o método QRA para a probabilidade de sucesso de $50 \%$ e o resultado obtido para a faixa segura de peso de lama foi de $9.3 \mathrm{lb} / \mathrm{gal}$ a $9.8 \mathrm{lb} / \mathrm{gal}$. A análise de sensibilidade feita para os resultados de gradiente de colapso indicou que o parâmetro que mais afeta os resultados para o cálculo do gradiente de colapso foi a pressão de poros, enquanto para o cálculo do gradiente de fratura, foi a tensão horizontal menor, como mostrado na Figura 5.

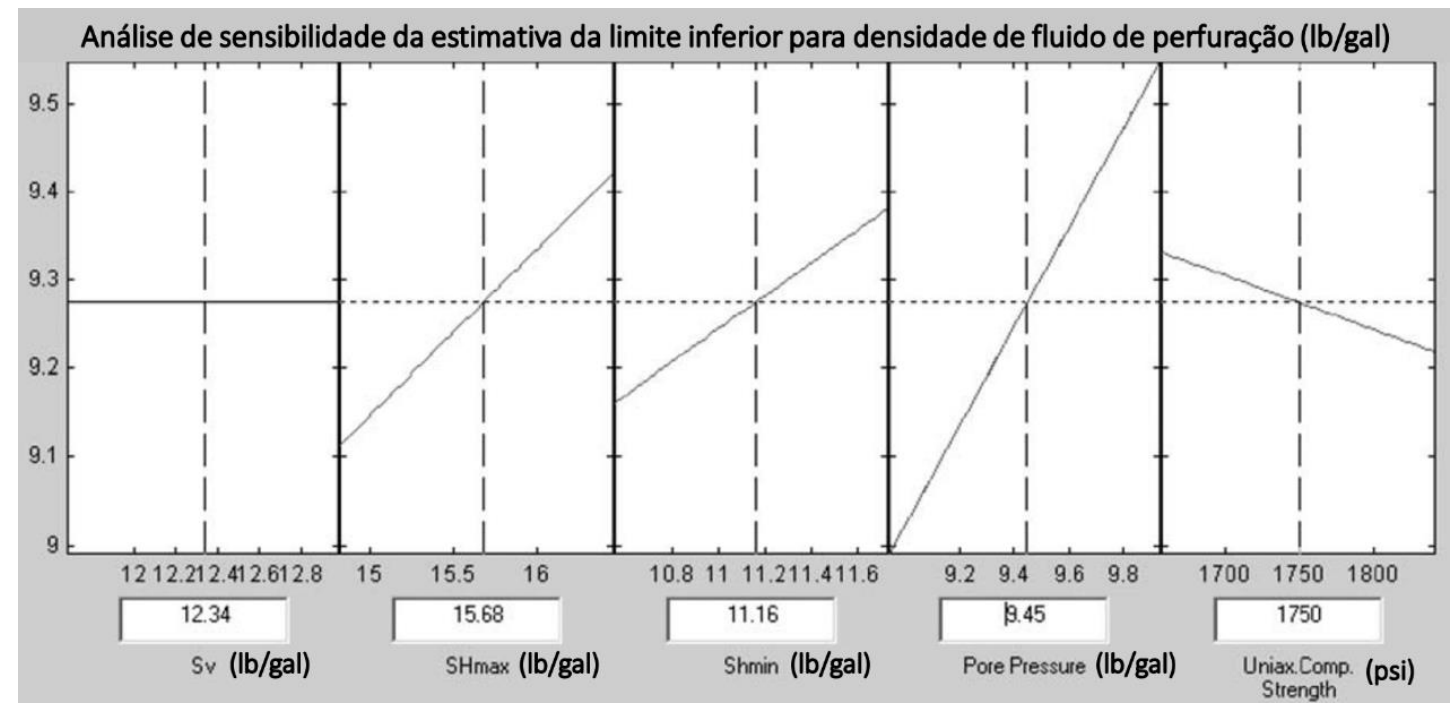

Figura 5 - Resultados da análise de sensibilidade dos parâmetros de entrada no gradiente de colapso para o segundo modelo de disposição de sapatas, apresentado na Figura 4 b). 0 eixo y denota a valor do observado no gradiente de colapso em relação aos diferentes valores dos parâmetros de entrada apresentados nos eixos x. apresentado por (Adaptado de Moos et al., 2003).

\section{3.}

\section{Eventos de Perfuração}

Muitos problemas podem ocorrer durante uma operação de perfuração devido ao dimensionamento falho do fluido de perfuração. Esses eventos indesejados podem ter causas diferentes e cada um deles pode apresentar consequências negativas e levar ao tempo não produtivo (non-productive time - NPT), durante as operações de perfuração. Além do NPT, eventos descontrolados podem acarretar em danos mais 
sérios, como acidentes ambientais, danos à plataforma ou mesmo a perda de vidas humanas.

A Tabela 1 apresenta um resumo dos principais problemas de perfuração, seus agentes causadores e efeitos consequentes desses eventos. Verifica-se que vários deles são gerados pelo dimensionamento equivocado do fluido de perfuração.

Tabela 1 - Principais eventos de perfuração associados a suas causas e efeitos. (Tavares, 2008)

\begin{tabular}{|c|c|c|}
\hline PROBLEMAS & CAUSAS & EFEITOS OBSERVADOS \\
\hline Alargamento & $\begin{array}{l}\text { - Pressão hidráulica excessiva (vazão de bombeio) } \\
\text { - Ação mecânica da coluna (BHA) } \\
\text { - Reatividade da formação x fluido (tipo de fluido) } \\
\text { - Desmoronamentos (regime de tensões) }\end{array}$ & $\begin{array}{l}\text { - Topadas durante manobras } \\
\text { - Maior volume de retorno de } \\
\text { cascalho }\end{array}$ \\
\hline Batentes & $\begin{array}{l}\text { - Intercalações entre formações moles e duras de } \\
\text { pequena espessura (litologia) }\end{array}$ & $\begin{array}{l}\text { - Choques na passagem da } \\
\text { coluna pelo trecho } \\
\text { - Dificuldade de descida de } \\
\text { revestimentos }\end{array}$ \\
\hline Chavetas & $\begin{array}{l}\text { - Atrito da coluna com a parede do poço em } \\
\text { trechos com desvio acentuado (inclinação) }\end{array}$ & $\begin{array}{l}\text { - Dificuldade na manobra do } \\
\text { BHA }\end{array}$ \\
\hline Desmoronamento & $\begin{array}{l}\text { - Pressão hidrostática insuficiente (peso de } \\
\text { fluido/regime de tensões) } \\
\text { - Ação mecânica da coluna (BHA) } \\
\text { - Pressão hidráulica excessiva (vazão de bombeio) } \\
\text { - Dissolução de domos salinos (litologia) }\end{array}$ & $\begin{array}{l}\text { - Maior volume de retorno de } \\
\text { cascalho } \\
\text { - Drags elevados na manobra } \\
\text { - Cascalhos com tamanho } \\
\text { maior que o normal } \\
\end{array}$ \\
\hline Fechamento & $\begin{array}{l}\text { - Reatividade da formação x fluido (tipo de fluido) } \\
\text { - Formações com mobilidade (ex: sais) (litologia) } \\
\text { - Pressão hidrostática insuficiente (peso de fluido) }\end{array}$ & $\begin{array}{l}\text { - Drags elevados na manobra } \\
\text { - Dificuldade na descida do } \\
\text { revestimento } \\
\text { - Ameaças de prisão }\end{array}$ \\
\hline Kick & $\begin{array}{l}\text { - Pressão hidrostática insuficiente (peso de } \\
\text { fluido/pressão da formação) } \\
\text { - Pistoneio (operação) } \\
\text { - Perda de circulação (característica da } \\
\text { formação/peso de fluido) }\end{array}$ & $\begin{array}{l}\text { Indícios primários: } \\
\text { - Aumento do volume de lama } \\
\text { nos tanques } \\
\text { - Aumento da vazão de retorno } \\
\text { - Fluxo com bombas } \\
\text { desligadas }\end{array}$ \\
\hline $\begin{array}{l}\text { Perda de } \\
\text { circulação }\end{array}$ & $\begin{array}{l}\text { - Existência de fraturas na formação (característica } \\
\text { da formação) } \\
\text { - Formaçôes com alta permeabilidade e } \\
\text { porosidade (característica da formação) } \\
\text { - Peso de fluido excessivo em zonas depletadas } \\
\text { ou com baixo gradiente de fratura (peso de fluido) }\end{array}$ & $\begin{array}{l}\text { - Redução do volume de lama } \\
\text { nos tanques }\end{array}$ \\
\hline $\begin{array}{l}\text { Prisão por } \\
\text { diferencial }\end{array}$ & $\begin{array}{l}\text { - Grande diferencial de pressão lama } x \text { formação } \\
\text { (permeável). É preciso ainda que a coluna esteja } \\
\text { em contato com a parede do poço (peso de } \\
\text { fluido/pressão da formação) } \\
\text { - Tipo de fluido inadequado (com grande } \\
\text { quantidade de filtrado) (tipo de fluido) }\end{array}$ & $\begin{array}{l}\text { - Aumento do drag e torque } \\
\text { - Perda do movimento da } \\
\text { coluna }\end{array}$ \\
\hline
\end{tabular}

Cardoso Junior (1992), Tavares (2006), Rabelo (2008), Chipindu (2010), Chieza (2011) e Argote (2012) apresentam revisão e estudos de caso realçando vários problemas que podem ocorrer durante uma perfuração de poço, suas causas e 
consequências. Dos problemas abordados pelos autores, os principais que são ocasionados pelo mau dimensionamento do peso de fluido de perfuração são listados e descritos nos tópicos 2.3.1 a 2.3.5.

\subsection{1.}

\section{Perda de circulação}

A perda de circulação (Figura 6) é o influxo de fluido para dentro da formação a qualquer profundidade durante a perfuração. Quando ocorre a perda de circulação e não há retorno para a superfície, define-se a perda total de circulação. Porém, se houver retorno de alguma quantidade à superfície, ocorre a perda de circulação parcial (Rabelo, 2008; Tavares, 2006; Chieza, 2011).

Esse problema é verificado quando a formação é muito porosa e permeável ou também quando a formação é naturalmente fraturada e ocorre quando a densidade equivalente de circulação ${ }^{[3]}$ (ECD) supera a pressão de poros existente nas formações. Pode ocorrer perda de circulação também quando a pressão exercida pelo fluido na parede do poço é alta a ponto de abrir as microfissuras já fechadas ou até induzir fraturas na formação (Tavares, 2006).

A perda do fluido para a formação provoca a redução do volume de fluido no anular entre a coluna de perfuração e a parede do poço (ou do revestimento acima). Consequentemente, há queda da pressão hidrostática exercida na parede do poço, acarretando outros problemas como desmoronamento das paredes e influxo de fluido de dentro da formação para o poço (kick) (Chipindu, 2010; Rabelo, 2008).

[3] Densidade equivalente de circulação (equivalent circulating density, ECD) equivale a soma da pressão hidrostática no fundo do poço com as perdas de carga por fricção no espaço anular. 38 


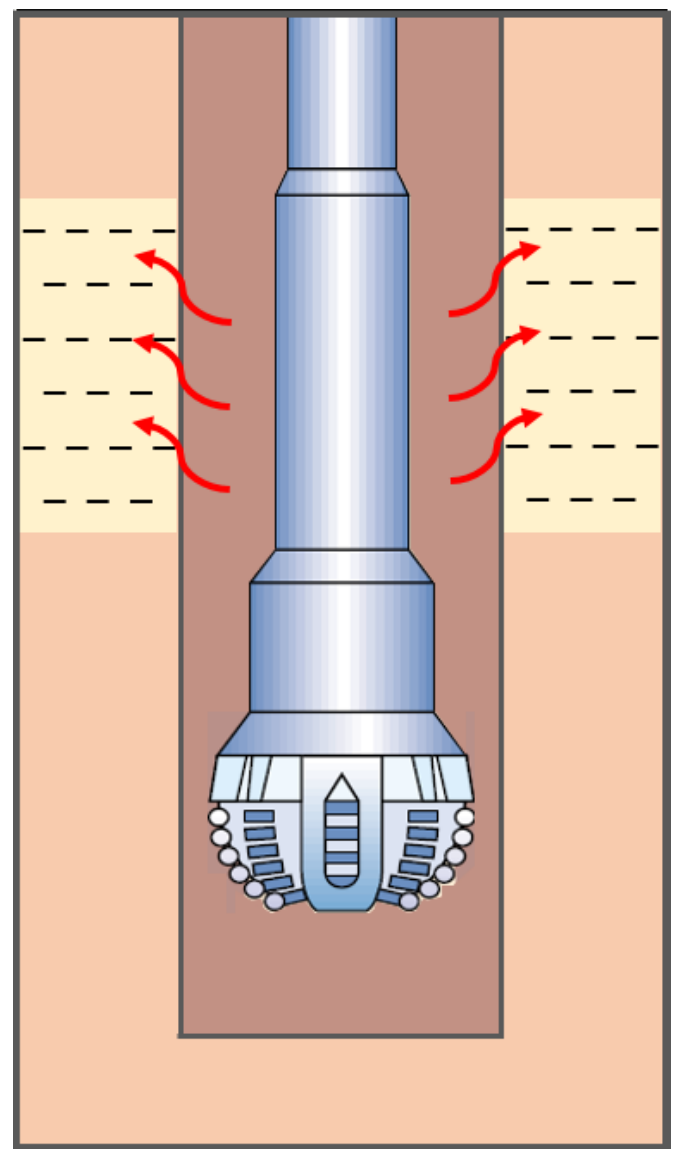

Figura 6 - Ilustração: Perda de circulação. (adaptado de Oilfield Review, 1999)

Javeri et al. (2011) mencionam que o custo médio anual estimado para o tratamento desse tipo de evento à indústria de perfuração supera um bilhão de dólares, dividido entre custos de aluguel da sonda e outros materiais e recursos.

\subsection{2.}

\section{Prisão diferencial}

A prisão diferencial (Figura 7) se dá quando a coluna de perfuração adere à parede do poço e perde os seus movimentos axiais e radiais devido aos efeitos da diferença de pressão entre fluido de perfuração e pressão de poros da formação (Tavares, 2006; Chipindu, 2010). Esse evento indesejado ocorre em formações permeáveis, onde a pressão de poros é baixa, e o peso de fluido é alto (Rabelo, 2008). 
Os fluidos utilizados para a perfuração em zonas permeáveis formam um tipo de reboco na parede do poço. Neste caso, quando a pressão da formação é inferior a pressão dentro do poço, esta pressão hidrostática pressiona a coluna contra o reboco formado ao passo que sólidos se depositam entre a coluna e parede do poço devido a esse mesmo diferencial de pressão excessivo. Dessa forma, a coluna perde seu poder de movimentação e fica presa, apesar de continuar circulando fluido (Tavares, 2006; Cardoso Junior, 1992).

Outra consequência da prisão diferencial é o aumento do drag (arraste da coluna de perfuração consequente do atrito entre a coluna e a parede do poço) e torque nas manobras. Para evitar a ocorrência desse evento, é importante manter a coluna sempre em movimento vertical e circular, evitar paradas muito longas e agilizar o processo de manobra (Rabelo, 2008).

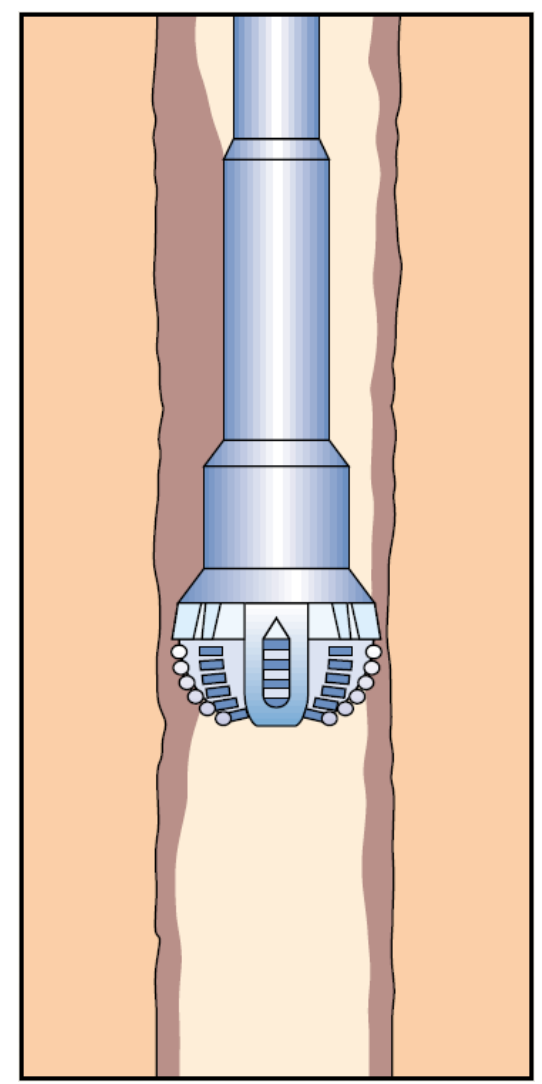

Figura 7 - Ilustração: prisão diferencial. (Oilfield Review, 1999) 


\subsection{3.}

\section{Desmoronamento/Alargamento do poço}

O desmoronamento ou alargamento do poço (Figura 8) é o desprendimento de material rochoso da formação da parede do poço após sua perfuração. Esse evento ocorre predominantemente em formações com baixa resistência de coesão e/ou fraturadas em excesso (Cardoso Junior, 1992; Chieza, 2011; Tavares, 2006; Rabelo, 2008).

Antes de uma camada rochosa ser perfurada, ela está submetida a um regime de tensões de confinamento em equilíbrio. A partir do momento que essa camada é perfurada, a face livre da rocha fica submetida à pressão hidrostática dentro do poço, alterando o regime de tenções da formação. Ou seja, ao passo que a pressão de fluido não pode ser muito alta a ponto de fraturar a formação, ela também não deve ser tão baixa a ponto de não proporcionar a sustentação mecânica necessária à parede do poço (Tavares, 2006).
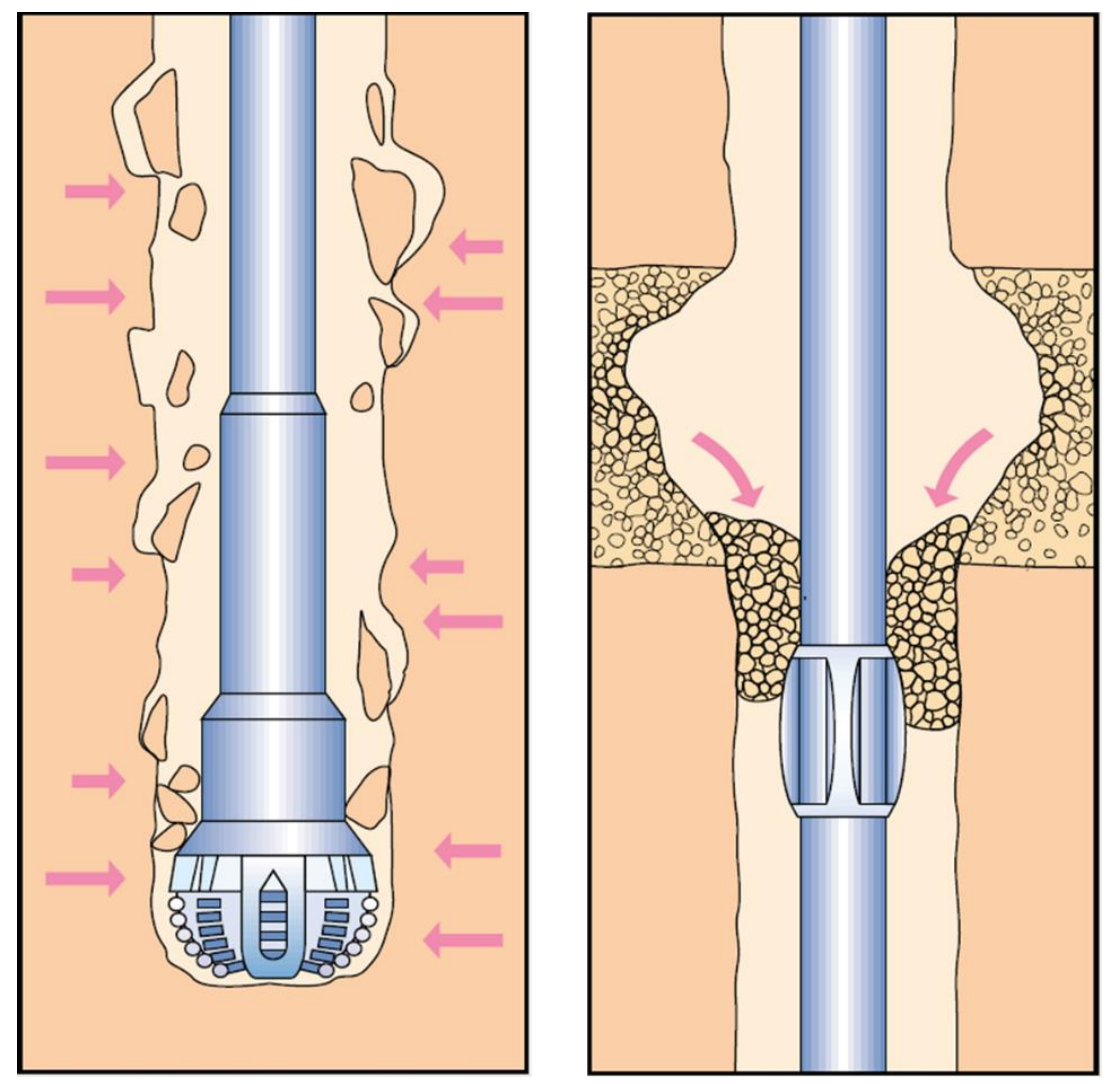

Figura 8 - Ilustração: desmoronamento/alargamento de poço. (Oilfield Review, 1990) 
A queda do volume rochoso tem por consequência a prisão da coluna, topadas na descida do revestimento, packer hidráulico (pack-off), além do que pode também comprometer a qualidade da cimentação (Rabelo, 2008).

\subsection{4.}

Kick

Kick (Figura 9) é a movimentação indesejada dos fluidos da formação (gás, água ou óleo) para o poço e pode ocorrer principalmente em zonas anormalmente pressurizadas. Poços exploratórios são suscetíveis a esse problema, uma vez que as características das formações ainda são escassas (Rabelo, 2008; Chieza, 2011).

Quando a pressão hidrostática do poço não é alta o suficiente para manter os fluidos da formação confinados, esses fluidos escapam para dentro do poço. Ou seja, o kick ocorre quando o ECD é inferior à pressão de poros da formação (Tavares, 2006).

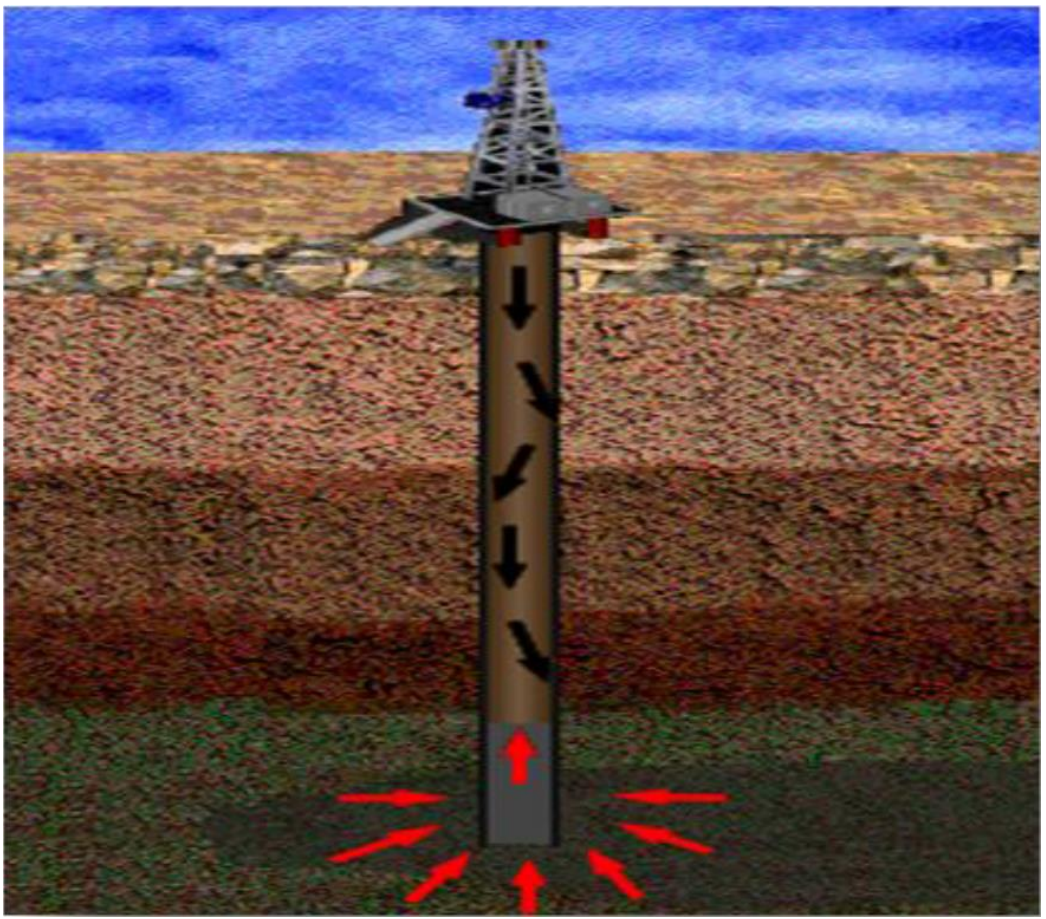

Figura 9 - Ilustração: kick. (Guimarães, 2010) 
Este fenômeno pode provocar o faturamento da formação e desmoronamentos. Se este influxo de fluidos para o poço for descontrolado e chegar a atingir a superfície, ocorre o blowout (Figura 10), que é o maior problema que pode ocorrer durante a perfuração. Isso porque as consequências podem significar perda de vidas humanas, destruição dos equipamentos ou até da própria sonda, danos irreversíveis ao reservatório e ao meio ambiente também (Chipindu, 2010).
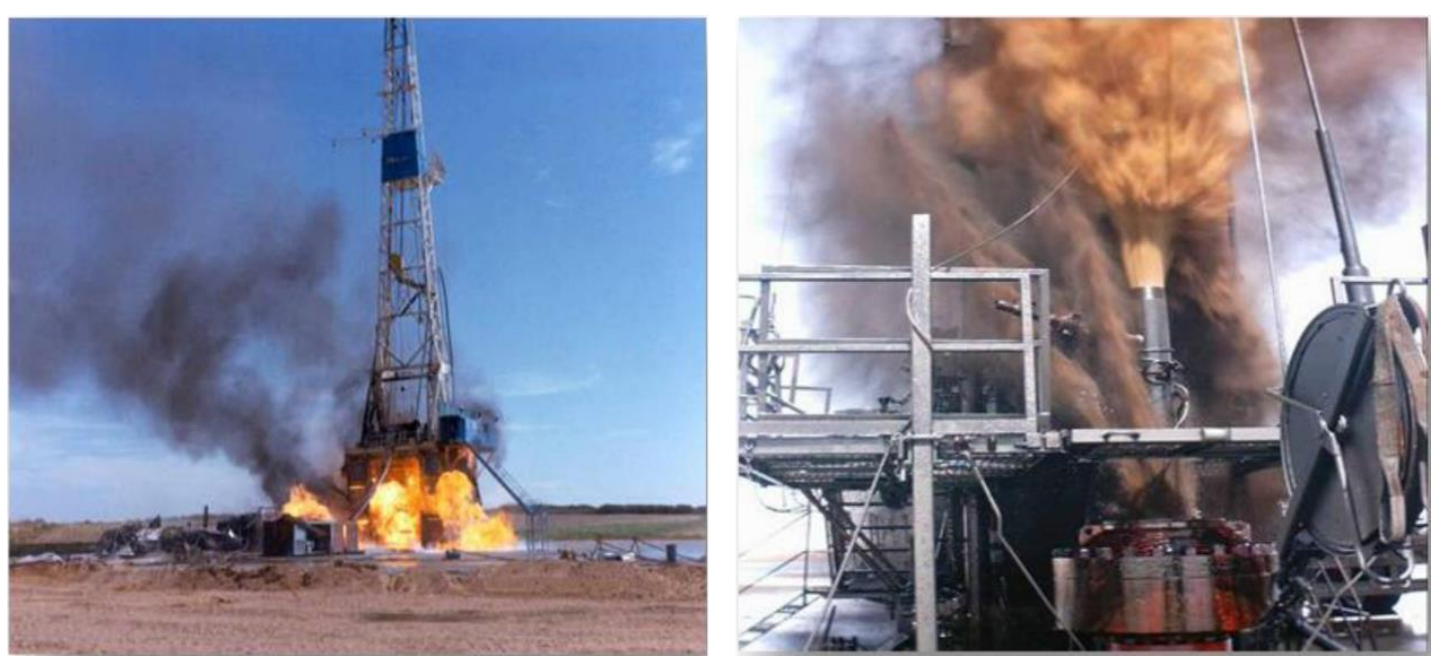

Figura 10 - Poços em Blowout. (Guimarães, 2010)

\subsection{5. \\ Fechamento do poço}

Fechamento do poço (Figura 11) é o bloqueio completo ou estreitamento parcial da seção transversal do poço. Este problema pode ocorrer em formações argilosas, devido ao inchamento por hidratação dos minerais que compõem essa formação quando utiliza-se fluido de perfuração a base água. Pode ocorrer também devido ao desgaste da broca quando perfurando formações abrasivas, e ainda por espessamento do reboco, quando em formações permeáveis. Outro cenário onde pode-se observar esse problema é quando se perfura camadas de sal e a pressão hidrostática não é suficiente para evitar a fluência natural da formação salina (Cardoso Junior, 1992; Rabelo, 2008; Tavares, 2006). 
As consequências do fechamento do poço são prisão da coluna, dificuldade de manobra (drags excessivos), além de complicações na descida do revestimento (Rabelo, 2008).
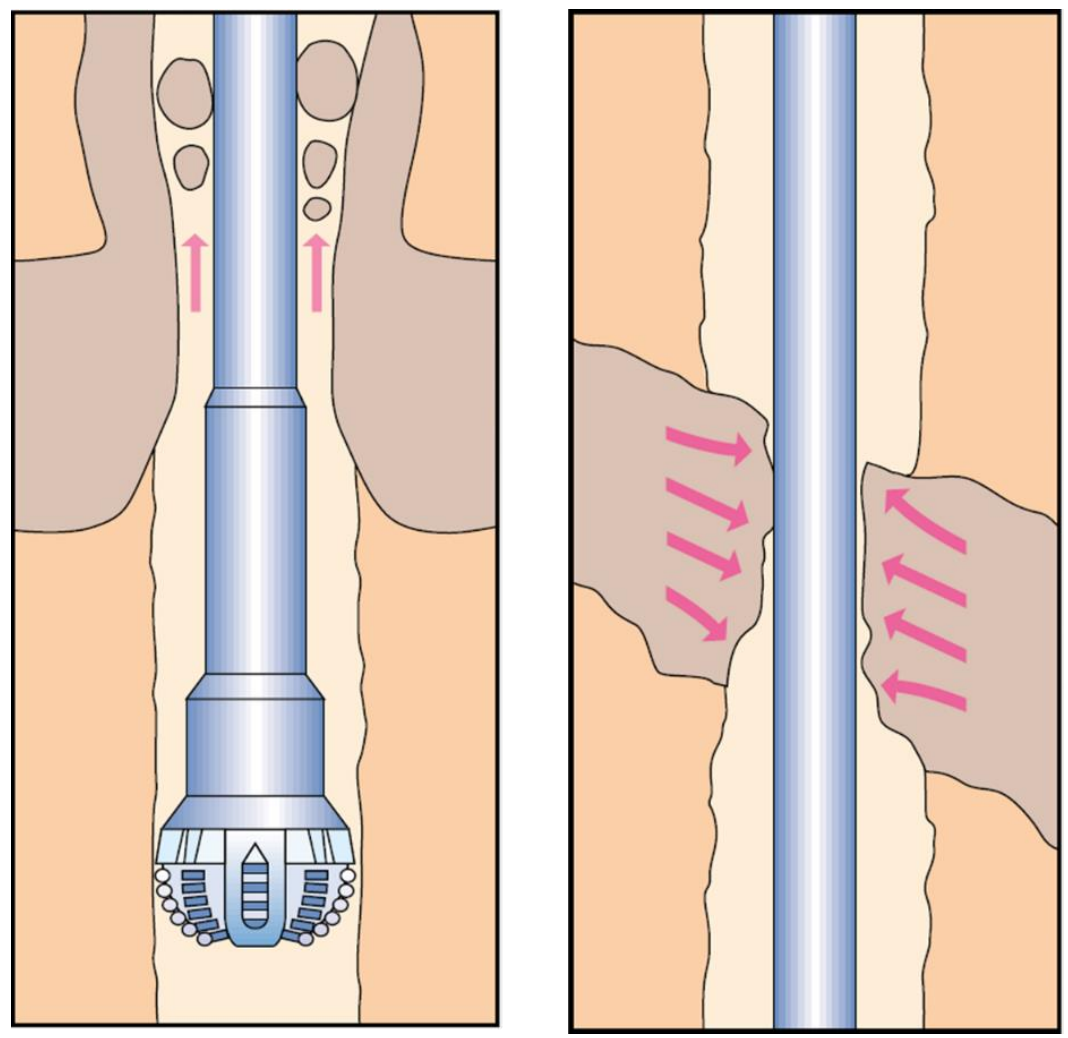

Figura 11 - Ilustração: fechamento do poço. (Oilfield Review, 1999)

\section{4.}

Tempo não produtivo e custos associados

Todos os problemas de perfuração descritos nos tópicos 2.3.1 a 2.3.5 devem ser resolvidos durante a operação de perfuração, o que ocasiona o tempo não produtivo (traduzido do inglês "non-productive time", NPT). Reid et al. (2006) definem NPT como o tempo durante a perfuração do poço em que a taxa de penetração é muito baixa ou quase inexistente. $O$ efeito do NPT pode aumentar consideravelmente os custos de uma operação de perfuração. Isso porque o equipamento de sonda utilizado é alugado e tem um custo diário muito elevado. 
Uma das principais finalidades de uma análise de risco para o processo de perfuração de um poço, é analisar os potenciais riscos, suas probabilidades de ocorrência e o custo associado à sua ocorrência. Dessa forma, o grupo de profissionais encarregado dessa tarefa pode tomar decisões baseadas em análises quantitativas e prevenir a ocorrência de um evento não desejado, o NTP e, consequentemente, os custos extras associados.

Reid et al. (2006) apresentam um estudo sobre os custos relacionados aos poços de gás no Golfo do México e detalham o impacto do NPT causado por eventos de perfuração indesejados nas despesas totais. A Figura 12 mostra que para esses poços estudados, em média $24 \%$ do tempo total de perfuração é considerado tempo não produtivo.

No estudo de Reid et al. (2006) foi verificada a ocorrência de variados eventos indesejados. A Figura 13 apresenta esses eventos e a distribuição de tempo, em porcentagem, demandada por cada um em relação ao tempo total não produtivo. A Figura 14 apresenta uma relação dos custos associados aos tempos produtivo e não produtivo ao longo da perfuração. A partir desse gráfico (Figura 14), é possível concluir que a porcentagem de ocorrência de problemas de perfuração devidos a baixos e altos valores de densidade do fluido utilizado são de $12 \%$ e $22 \%$, respectivamente, o que demanda um total de $8.2 \%$ dos gastos durante a perfuração.

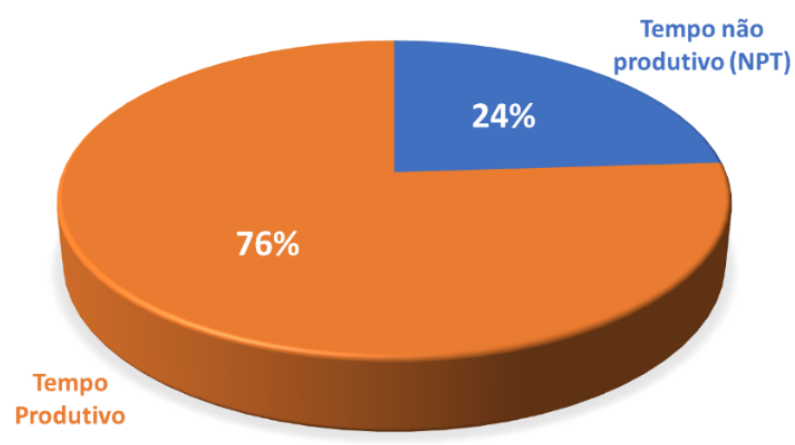

Figura 12. Comparação entre tempo não produtivo associado aos eventos de perfuração e tempo produtivo (adaptado de Reid et al., 2006). 


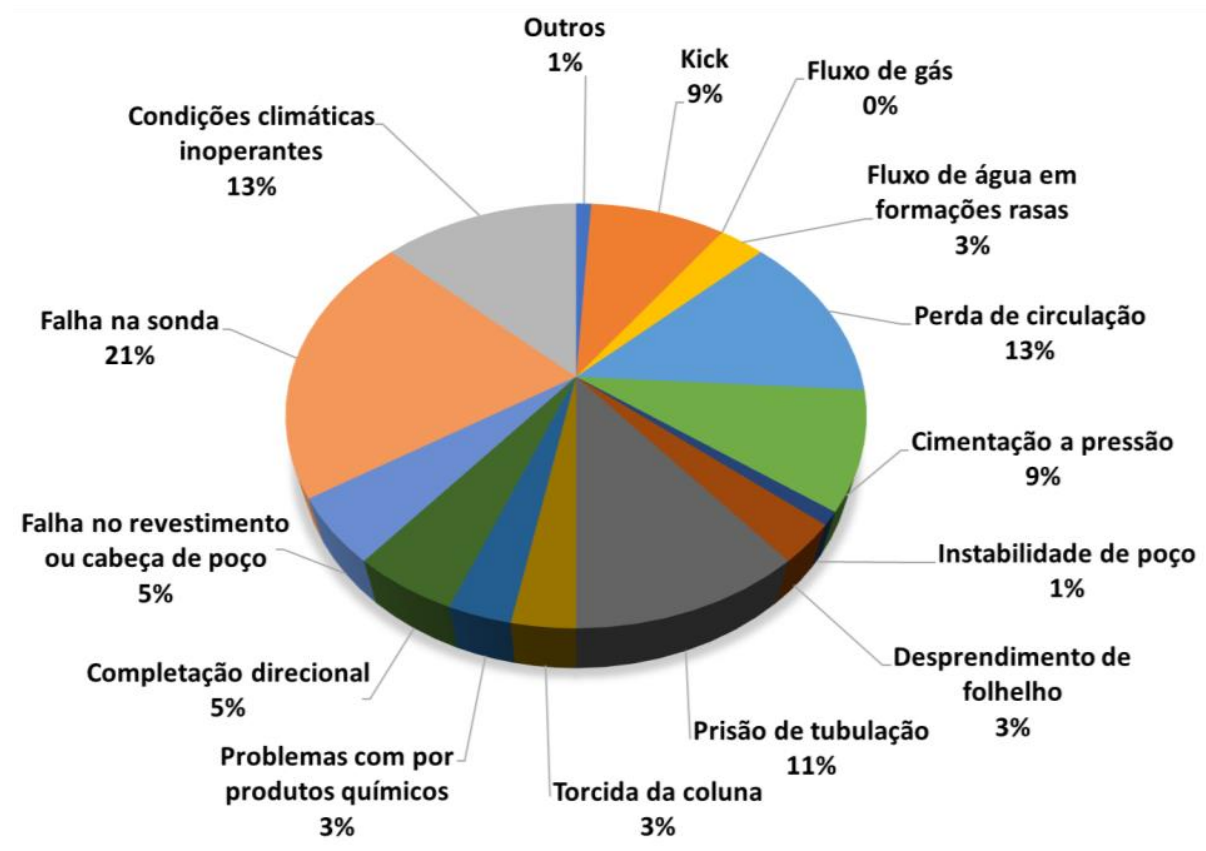

Figura 13. Porcentagem de tempo não produtivo relacionado a cada evento de perfuração. (Adaptado de Reid et al., 2006).

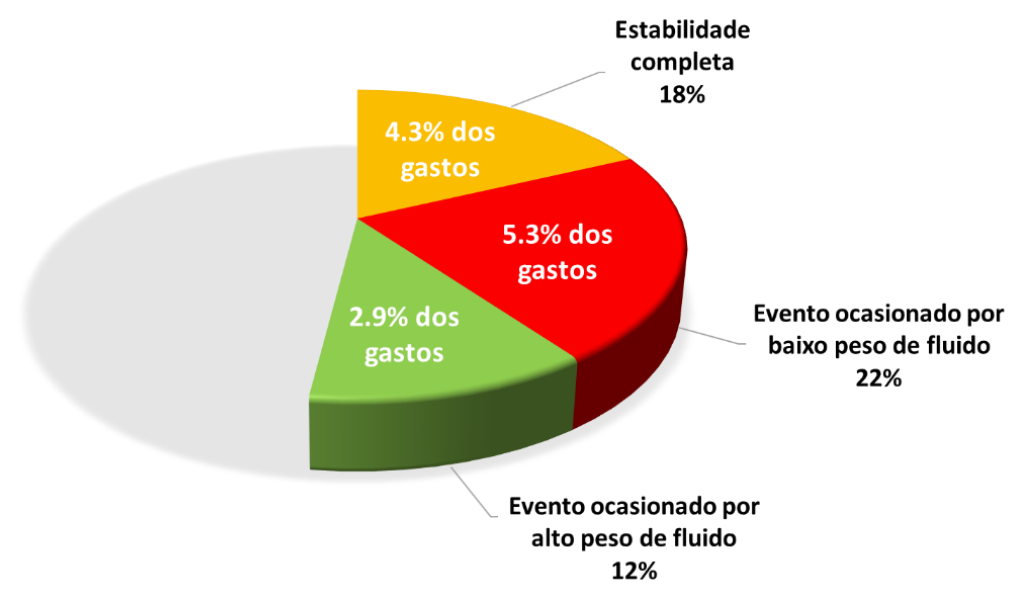

Figura 14. Comparação entre custos relacionados ao tempo produtivo e não produtivo.

(Adaptado de Reid et al., 2006).

Uma das principais razões pelas quais o tempo não produtivo tem influência no aumento dos custos das operações de perfuração é devido aos custos associados à sonda. Freitas (2018) estudou a influência de cada parâmetro no custo final de uma 
perfuração de poço e observou que, para este caso, mais de 39\% do custo total é destinado ao aluguel da sonda. Para ilustrar tais valores, Condol \& Corrêa (2012) compilaram em tabela comparativa os preços médios diários de diferentes tipos de sonda (Tabela 2).

Tabela 2. Média de preços do aluguel diário de diferentes sondas (adaptado de Condol \& Corrêa, 2012).

\begin{tabular}{|l|c|c|}
\hline \multicolumn{1}{|c|}{ Tipo de sonda } & Custo diário & $\begin{array}{c}\text { Lâmina d'água } \\
\text { suportada }\end{array}$ \\
\hline Navio Sonda & $\$ 247,000$ & LDA $<4000 \mathrm{ft}$ \\
\hline Navio Sonda & $\$ 453,000$ & LDA $>4000 \mathrm{ft}$ \\
\hline Semissubmersível & $\$ 233,000$ & LDA $<1500 \mathrm{ft}$ \\
\hline Semissubmersível & $\$ 405,000$ & LDA $>4000 \mathrm{ft}$ \\
\hline Jaqueta & $\$ 36,000$ & LDA $<200 \mathrm{ft}$ \\
\hline Jaqueta & $\$ 74,000$ & LDA $<250 \mathrm{ft}$ \\
\hline Jaqueta & $\$ 75,000$ & LDA $<300 \mathrm{ft}$ \\
\hline Jaqueta & $\$ 78,000$ & LDA $>300 \mathrm{ft}$ \\
\hline
\end{tabular}




\section{3. Metodologia}

O uso de metodologias de análise de risco é importante para a tomada de decisões ao longo de todo o processo petrolífero, desde o projeto para a perfuração do poço até o destino final do fluido produzido. A análise de risco pode ser aplicada em diversos cenários da indústria do petróleo, como mostrado nos itens 2.2 e 2.3. A sua importância para a análise de estabilidade está associada principalmente à prevenção de eventos de perfuração, auxílio em tomadas de decisão e, consequentemente, a redução de custos extras oriundos do NPT.

A análise de risco aplicada à análise de estabilidade de poços de petróleo tem como uma das etapas principais a utilização de métodos probabilísticos. Nesta dissertação, serão apresentados dois modelos de análise probabilística de estabilidade de poços. O passo a passo para esta análise probabilística consiste em:

(i) Cálculo determinístico dos gradientes de fratura e colapsos de projeto;

(ii) Análise estatística e caracterização das incertezas associadas aos parâmetros de entrada para os cálculos dos gradientes;

(iii) Aplicação do método probabilístico adotado e obtenção das janelas operacionais probabilísticas.

\section{1.}

\section{Análise Determinística de Estabilidade de Poços}

A análise de estabilidade de poços consiste na avaliação integrada entre o estado de tensões e geopressões da formação, seus parâmetros de resistência e a adoção de um critério de ruptura adequado. A partir dessas três arestas principais, estima-se o comportamento geomecânico esperado ao longo da trajetória do poço, assim como os gradientes de fratura e colapso. De maneira simplificada, pode-se 
dizer que a análise de estabilidade de um poço segue os passos gerais apresentados no fluxograma da Figura 15.

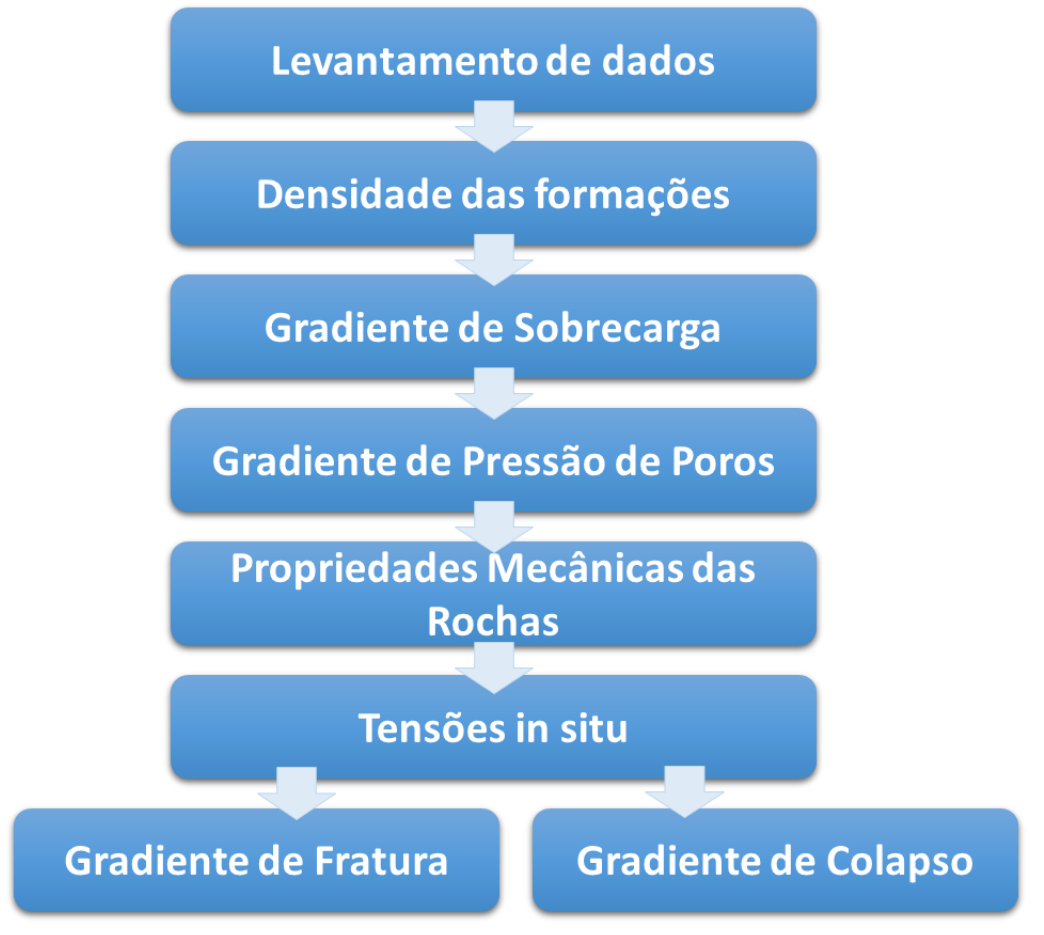

Figura 15 - Fluxo de cálculos para análise de estabilidade.

A estimativa determinística dos parâmetros e gradientes é amplamente adotada, por conseguinte, a calibração e o embasamento teórico e prático das correlações utilizadas nesse tipo de estimativa são importantes para a obtenção de um modelo geomecânico consistente. Neste tópico, serão apresentadas as correlações utilizadas para a estimativa determinística de cada parâmetro assim como o critério de ruptura adotado e o método de obtenção dos gradientes de fratura superior, colapso superior e colapso inferior.

Os dados de entrada utilizados para os cálculos são azimute da tensão horizontal menor, tensão vertical, tensão horizontal maior, tensão horizontal menor, pressão de poros, coeficiente de Biot, coeficiente de Poisson, ângulo de atrito interno, resistência à tração e resistência à compressão simples. Nos tópicos 3.1 .1 e $3.1 .2 \mathrm{a}$ seguir serão apresentados os cálculos para obtenção destes parâmetros de entrada e para obtenção os gradientes de fratura e colapso, respectivamente. 
3.1.1.

Parâmetros de entrada para o cálculo da Janela Operacional

Os valores médios dos parâmetros de entrada foram estimados a partir de equações e correlações da literatura. A seguir, estão listados todos os parâmetros de entrada e o meio de obtenção de cada um.

\section{Coeficiente de Biot $(\alpha)$}

Para este estudo, foi considerado o modelo elástico, portanto o coeficiente de Biot adotado foi:

$\alpha=1$

\section{Coeficiente de Poisson (v)}

A coeficiente de Poisson é calculada a partir da seguinte equação (Zoback, 2007):

$v=0.5\left(\frac{\left(\Delta \mathrm{t}_{\mathrm{s}} / \Delta \mathrm{t}_{\mathrm{c}}\right)^{2}-2}{\left(\Delta \mathrm{t}_{\mathrm{s}} / \Delta \mathrm{t}_{\mathrm{c}}\right)^{2}-1}\right)$

Onde $\Delta \mathrm{t}_{\mathrm{s}}$ é o tempo de trânsito da onda cisalhante em $\mu \mathrm{s} /$ pé e $\Delta \mathrm{t}_{\mathrm{c}}$ é o tempo de trânsito da onda compressional em $\mu$ s/pé.

\section{Resistência à Compressão Simples (UCS)}

A resistência à compressão simples foi estimada a partir de correlações específicas para cada tipo de rocha prevista no projeto ao longo da trajetória.

\section{Carbonatos do pré-sal}

Para esse tipo de rocha, foi adotada a correlação apresentada por Militzer \& Stoll (1973) para carbonatos mais profundos em geral. 
$\mathrm{UCS}=\left(\frac{7682}{\Delta \mathrm{t}_{\mathrm{c}}}\right)^{1.82}$

Onde $\Delta t_{c}$ é o tempo de trânsito da onda compressional em $\mu$ s/pé.

\section{Rochas Ígneas}

Para as rochas ígneas, foi utilizada a correlação proposta por Teikoku (2007) para rochas ígneas fragilizadas.

$\mathrm{UCS}=167185 * \mathrm{e}^{\left(-0.037 * \Delta \mathrm{t}_{\mathrm{c}}\right) * 0.17}$

Onde $\Delta \mathrm{t}_{\mathrm{c}}$ é o tempo de trânsito da onda compressional em $\mu \mathrm{s} /$ pé.

\section{Demais tipos de rochas exceto rochas salinas}

Para os demais tipos de rochas, foi utilizada a correlação a partir da envoltória de Mohr-Coulomb (Zoback, 2007), que relaciona a resistência à compressão simples com a coesão e com o ângulo de atrito interno da formação.

$\mathrm{UCS}=2 * \mathrm{C} * \tan \left(\frac{\pi}{4}+\frac{\phi}{2}\right)$

Onde C é coesão em psi e $\phi$ é o ângulo de atrito interno em graus.

Coesão

Assim como a resistência à compressão simples, a coesão também foi estimada a partir de correlações específicas para cada tipo de rocha prevista no projeto ao longo da trajetória.

\section{Carbonatos do pré-sal e rochas ígneas}

Para esse grupo de formações, utilizou-se a correlação a partir da envoltória de Mohr-Coulomb (Zoback, 2007), que relaciona a coesão com a resistência à compressão simples e ângulo de atrito interno da formação. 
$\mathrm{C}=\frac{\mathrm{UCS}}{2 * \tan \left(\frac{\pi}{4}+\frac{\phi}{2}\right)}$

Onde UCS é a resistência à compressão simples em psi e ф é o ângulo de atrito interno em graus.

\section{Demais tipos de rochas exceto rochas salinas}

Para as demais formações, adotou-se a correlação de MECPRO (1985).

$\mathrm{C}=0.025 * \frac{0.0045 * \mathrm{E} *(1-\mathrm{VCL})+0.008 * \mathrm{E} * \mathrm{VCL}}{10^{6} * \mathrm{C}_{\mathrm{b}}}$

Onde E é o módulo de Young em psi, VCL é o fator volume de argila, e $\mathrm{C}_{\mathrm{b}}$ é um parâmetro definido como indicado na equação 8.

$\mathrm{C}_{\mathrm{b}}=\left(13.4 * \rho_{\mathrm{b}} *\left(\frac{1}{\Delta \mathrm{t}_{\mathrm{c}}{ }^{2}}-\frac{4}{3 * \Delta \mathrm{t}_{\mathrm{s}}{ }^{2}}\right)\right)^{-1}$

Onde $\rho_{\mathrm{b}}$ é a densidade da formação em $\mathrm{g} / \mathrm{cm}^{3}, \Delta \mathrm{t}_{\mathrm{c}}{ }^{2}$ é o tempo de trânsito da onda compressional em $\mu \mathrm{s} /$ pé e $\Delta \mathrm{t}_{\mathrm{s}}$ é o tempo de trânsito da onda cisalhante em $\mu \mathrm{s} /$ pé.

\section{Ângulo de atrito interno ( $\phi)$}

O ângulo de atrito interno é definido a partir das correlações utilizadas para a estimativa da resistência à compressão simples. Neste estudo, todas as correlações usadas para cálculo de UCS estão associadas a um valor de ângulo de atrito interno igual a $30^{\circ}$.

\section{Resistência à Tração ( $\left.T_{0}\right)$}

Ensaios experimentais mostram que a resistência à tração pode ser estimada em âmbito geral a partir da equação 9. No estudo de caso utilizado neste trabalho, essa correlação foi utilizada.

$\mathrm{T}_{0}=\frac{\mathrm{UCS}}{12}$

Onde UCS é a resistência à compressão simples em psi. 


\section{Pressão de Poros (PP)}

Em 1975, Eaton propôs uma metodologia para a estimativa da pressão de poros em formações argilosas a partir do tempo de transido da onda compressional da formação:

$\mathrm{P}_{\mathrm{P}}=\sigma_{\mathrm{v}}-\left(\sigma_{\mathrm{v}}-\mathrm{P}_{\mathrm{h}}\right) \cdot\left(\frac{\Delta \mathrm{t}_{\mathrm{c}_{\text {normal }}}}{\Delta \mathrm{t}_{\mathrm{c}_{\mathrm{obs}}}}\right)^{\text {EXP }}$

Onde $\sigma_{\mathrm{v}}$ é a tensão vertical em psi, $\mathrm{P}_{\mathrm{h}}$ é a pressão de poros normal em psi, $\Delta \mathrm{t}_{\mathrm{c}_{\text {normal }}}$ é o tempo de trânsito da onda compressional para o trend de compactação normal em $\mu \mathrm{s} /$ pé, $\Delta \mathrm{t}_{\mathrm{c}_{\mathrm{obs}}}$ é o tempo de trânsito da onda compressional da formação em $\mu \mathrm{s} /$ pé e EXP é o expoente de Eaton, cujo valor padrão definido para o Golfo do México é 3.

Para as camadas de carbonatos do pre-sal, a pressão de poros é calibrada utilizando-se dados de registros de pressão de poros. O gradiente de pressão de poros é calculado a partir da normalização da pressão de poros em relação a profundidade vertical do poço.

\section{Tensão Vertical $\left(\sigma_{\mathrm{v}}\right)$}

A tensão vertical é calculada para uma profundidade específica a partir da integral da densidade de cada camada sobrejacente a essa profundidade (Zoback, 2007). Para o presente estudo, deve-se considerar também a influência da lâmina d'água, portanto, a tensão vertical é estimada como:

$\sigma_{\mathrm{v}}=\rho_{\mathrm{w}} \mathrm{gd}_{\mathrm{w}}+\int_{\mathrm{d}_{\mathrm{w}}}^{\mathrm{z}} \rho_{\mathrm{i}} \mathrm{gdx_{ \textrm {i } }}$

Onde $\rho_{\mathrm{w}}$ é a densidade da água do mar em $\mathrm{g} / \mathrm{cm} 3, \mathrm{~g}$ é a aceleração da gravidade em $\mathrm{m} / \mathrm{s}^{2}, \mathrm{~d}_{\mathrm{w}}$ é a espessura da lâmina d'água em $\mathrm{m}, \rho_{\mathrm{x}}$ é a densidade da formação da camada de índice $i$ em $\mathrm{g} / \mathrm{cm} 3, x_{\mathrm{i}}$ é a espessura da camada de índice $i$ e $z$ é a profundidade de interesse em $\mathrm{m}$.

O gradiente de sobrecarga é calculado a partir da normalização da tensão vertical em relação a profundidade vertical do poço.

\section{Regime de tensões}




\section{Tensão horizontal menor $\left(\sigma_{\mathrm{h}}\right)$}

A estimativa da tensão horizontal menor pode ser calculada a partir de uma metodologia baseada na normalização pela pressão de poros. Essa metodologia consiste em utilizar dados de teste de absorção ou minifrac do próprio poço ou de poços de correlação e remover a influência da pressão de poros.

De maneira geral, a metodologia segue o seguinte passo a passo (manual teórico SEST TR 2.0C):

- Plotar em um gráfico as seguintes coordenadas:

- Eixo y: resultados do teste de absorção ou minifrac sem a influência da pressão de poros;

- Eixo x: profundidade de soterramento em que foram feitos os testes profundidade vertical de sedimentos.

- Traçar a reta que melhor se ajusta aos pontos plotados, passando pela origem do plano cartesiano;

- A lei que rege a reta que melhor se ajusta será do tipo:

$\mathrm{LOT}-\mathrm{P}_{\mathrm{P}, \mathrm{LOT}}=\mathrm{m} . \mathrm{PS}_{\mathrm{LOT}}$

Onde LOT é o valor obtido no do teste de absorsão em psi (ou resultado do minifrac), $\mathrm{P}_{\mathrm{P}, \mathrm{LOT}}$ é a pressão de poros na profundidade em que foi obtido o resultado do LOT em psi, m é o coeficiente de normalização do método em psi/m e $\mathrm{PS}_{\mathrm{LOT}}$ é a profundidade de soterramento em $\mathrm{m}$.

- Uma vez calculado o coeficiente de normalização, a tensão horizontal menor é estimada a partir da equação 13.

$\sigma_{\mathrm{h}}=\mathrm{m} . \mathrm{PS}+\mathrm{P}_{\mathrm{P}}$

Onde $\sigma_{\mathrm{h}}$ é a tensão horizontal menor em psi, m é o coeficiente de normalização calculado anteriormente em $\mathrm{psi} / \mathrm{m}$, PS é a profundidade de soterramento em $\mathrm{m}$ e $\mathrm{P}_{\mathrm{P}}$ é a pressão de poros naquela profundidade de soterramento em psi. 
Caso os testes de absorsão ou minifrac sejam do próprio poço, $\mathrm{P}_{\mathrm{P}, \mathrm{LOT}}=\mathrm{P}_{\mathrm{P}} \mathrm{e}$ $\mathrm{PS}_{\mathrm{LOT}}=\mathrm{PS}_{\mathrm{LOT}}$.

Outra maneira de se estimar a tensão horizontal menor é a partir do método de utilização de $\mathrm{K}_{0}$. Essa metodologia consiste em utilizar dados de teste de absorção ou minifrac do próprio poço ou de poços de correlação, pressão de poros e tensão vertical para o cálculo do parâmetro $\mathrm{K}_{0}$ conforme a equação 14 .

$\mathrm{K}_{0}=\frac{\text { LOT }-\mathrm{P}_{\mathrm{P}}}{\sigma_{\mathrm{v}}-\mathrm{P}_{\mathrm{P}}}$

Onde LOT é o valor obtido no do teste de absorsão em psi (ou resultado do minifrac) em psi, $P_{\mathrm{P}}$ é a pressão de poros em psi e $\sigma_{\mathrm{v}}$ é a tensão vertical em psi.

Uma vez calculado o parâmetro $\mathrm{K}_{0}$, este valor é considerado para as demais profundidades. Portanto a tensão horizontal menor pode ser calculada da seguinte maneira:

$\sigma_{\mathrm{h}}=\mathrm{K}_{0}\left(\sigma_{\mathrm{v}}-\mathrm{P}_{\mathrm{P}}\right)+\mathrm{P}_{\mathrm{P}}$

\section{Tensão horizontal maior $\left(\sigma_{\mathrm{H}}\right)$}

A tensão horizontal maior pode ser estimada utilizando-se dados de breakouts. A partir de perfis de imagem (Figura 16) é possível observar os intervalos onde ocorreram breakouts e o seu ângulo de abertura. 


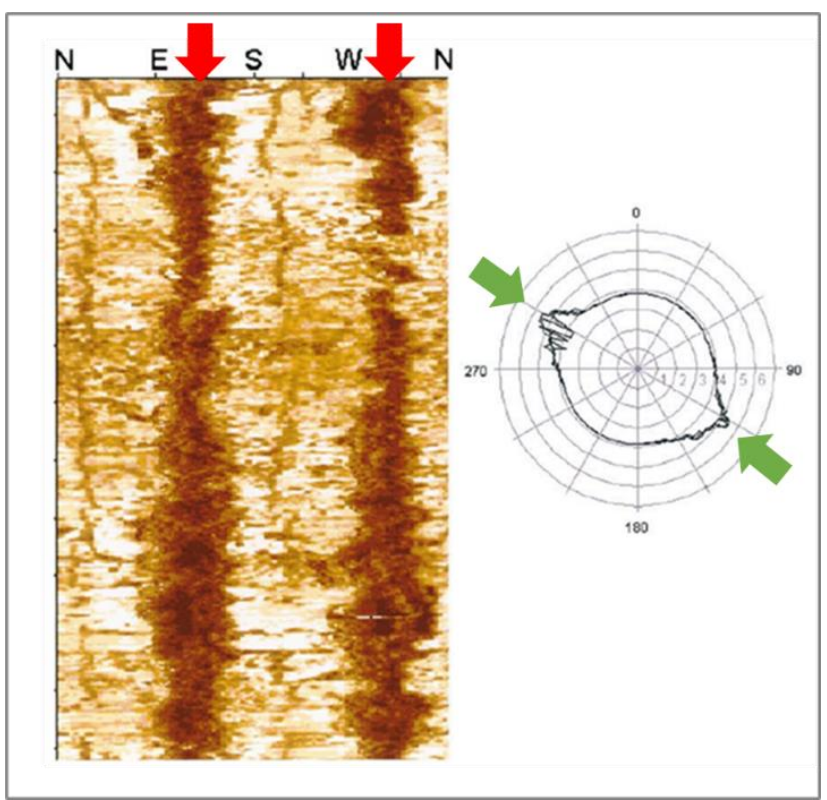

Figura 16 - Exemplo de perfil de imagem corrido para a observação de ocorrência de breakouts. As setas vermelhas indicam onde é possível verificar a ocorrência de breakouts no perfil de imagem e as setas verdes indicam a representação desses breakouts na sessão transversal do poço. (Modificado de Zoback, 2003)

Para poços de trajetória vertical, a estimativa da tensão horizontal maior pode ser feita a partir da equação 16.

$\sigma_{\mathrm{H}}=\frac{\mathrm{UCS}+\left(\mathrm{P}_{\mathrm{w}}-\mathrm{P}_{\mathrm{p}}\right) \frac{1+\operatorname{sen} \emptyset}{1-\operatorname{sen} \phi}-\sigma_{\mathrm{h}}(1+2 \cos 2 \theta)+\left(\mathrm{P}_{\mathrm{w}}+\mathrm{P}_{\mathrm{p}}\right)}{1-2 \cos 2 \theta}$

Onde $\sigma_{\mathrm{H}}$ é a tensão horizontal maior em psi, UCS é a resistência à compressão simples, $\mathrm{P}_{\mathrm{w}}$ é o peso de fluido de perfuração em psi, $\mathrm{P}_{\mathrm{p}}$ é a pressão de poros em psi, $\varnothing$ é o ângulo de atrito em graus, $\sigma_{\mathrm{h}}$ é a tensão horizontal menor em psi e $\theta$ é o ângulo ao redor do poço em graus.

Os gradientes de tensão horizontal maior e menor são calculados a partir da normalização das tensões horizontais maior e menor, respectivamente, em relação a profundidade vertical do poço. 


\subsection{2.}

\section{Cálculo dos gradientes em estabilidade de poços}

Uma vez que os valores médios dos parâmetros de entrada são definidos, é possível estimar os valores médios dos gradientes de fratura e colapsos superior e inferior. Para o cálculo destes gradientes, são consideradas as seguintes hipóteses:

- Considera-se o material rochoso como sendo contínuo e com comportamento elástico, homogêneo e isotrópico;

- Considera-se o poço cilíndrico;

- Uma das tensões principais na crosta terrestre é considerada atuando na direção vertical;

- Existe uma pressão de fluido na formação; e

- É válido o princípio das tensões efetivas como enunciado por Terzaghi (1936).

Considerando que as tensões principais atuantes na formação são as tensões vertical, horizontal maior e horizontal menor, é apropriado calcular a partir destas, as tensões ao redor do poço, em coordenadas cilíndricas.

Dessa forma, as tensões em um ponto da formação nas coordenadas cilíndricas $\mathrm{r}, \theta$ e z são definidas como $\sigma_{\mathrm{r}}, \sigma_{\theta}, \sigma_{\mathrm{z}}$. Entretanto, para que as tensões ao redor do poço sejam calculadas, é necessário definir as tensões atuantes em um sistema de eixos ainda perpendiculares entre si, porém com as seguintes características: este novo sistema de eixos em coordenadas $x, y$ e $z$ terá o eixo $z$ apontando na direção axial do poço, o eixo y pertencerá ao plano horizontal e será perpendicular a $z$, e o eixo x obedecerá a regra de ortogonalidade. Estas tensões nos eixos x, y e z podem ser calculadas a partir das seguintes equações matriciais (Fjaer, 2008): 


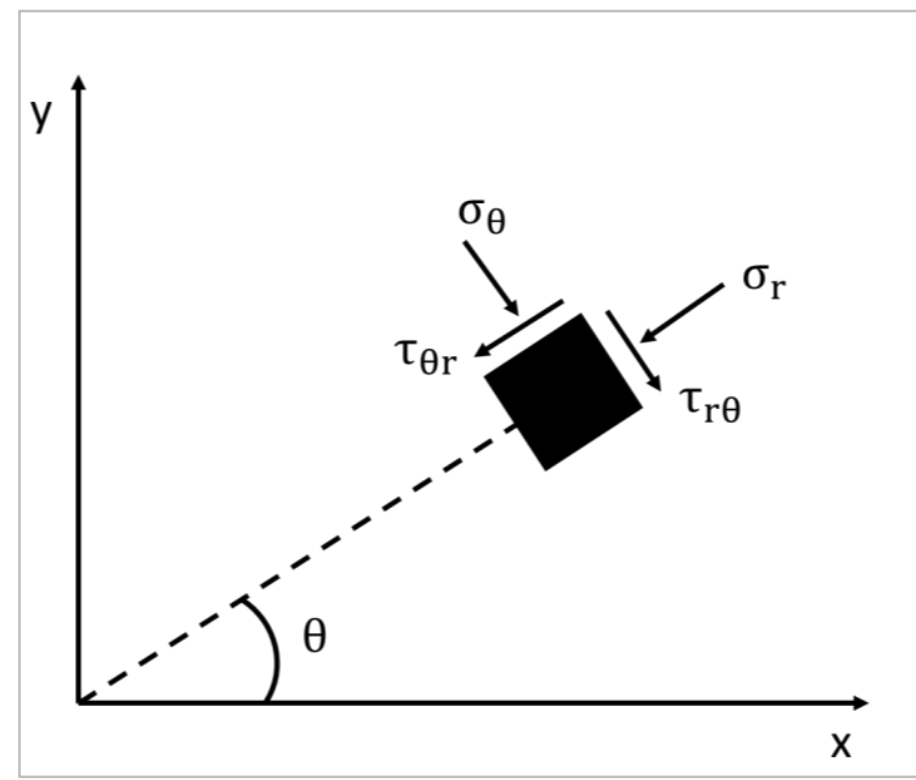

Figura 17 - Distribuição de tensões em coordenadas cilíndricas. (Fjaer, 2008)

$$
\begin{aligned}
& {\left[\begin{array}{lll}
\sigma_{\mathrm{x}} & \tau_{\mathrm{yx}} & \tau_{\mathrm{zx}} \\
\tau_{\mathrm{xy}} & \sigma_{\mathrm{y}} & \tau_{\mathrm{zy}} \\
\tau_{\mathrm{xz}} & \tau_{\mathrm{yz}} & \sigma_{\mathrm{z}}
\end{array}\right]=[\mathrm{A}]\left[\begin{array}{ccc}
\sigma_{\mathrm{H}} & 0 & 0 \\
0 & \sigma_{\mathrm{h}} & 0 \\
0 & 0 & \sigma_{\mathrm{v}}
\end{array}\right][\mathrm{A}]^{\mathrm{T}}} \\
& {[\mathrm{A}]=\left[\begin{array}{ccc}
\cos \psi \cos \mathrm{i} & \sin \psi \cos \mathrm{i} & -\sin \mathrm{i} \\
-\sin \psi & \cos \psi & 0 \\
\cos \psi \sin \mathrm{i} & \sin \psi \sin \mathrm{i} & \cos \mathrm{i}
\end{array}\right]}
\end{aligned}
$$

$\psi=90+\mathrm{Az}\left(\sigma_{\mathrm{h}}\right)-\mathrm{Az}$

Onde $\tau_{\mathrm{yx}}, \tau_{\mathrm{zx}}, \tau_{\mathrm{xy}}, \tau_{\mathrm{zy}}, \tau_{\mathrm{xz}}, \tau_{\mathrm{yz}}$ são tensões cisalhantes em psi atuantes nos planos definidos pelos seus índices, i é a inclinação do poço em graus, Az é o azimute do poço.

As tensões ao redor do poço são calculadas a partir das equações (Fjaer, 2008):

$$
\begin{aligned}
& \sigma_{\mathrm{r}}=\left(\frac{\sigma_{\mathrm{x}}+\sigma_{\mathrm{y}}}{2}\right)\left(1-\frac{\mathrm{a}^{2}}{\mathrm{r}^{2}}\right)+\left(\frac{\sigma_{\mathrm{x}}-\sigma_{\mathrm{y}}}{2}\right)\left(1+\frac{3 \mathrm{a}^{4}}{\mathrm{r}^{4}}-\frac{4 \mathrm{a}^{2}}{\mathrm{r}^{2}}\right) \cos (2 \theta)+\tau_{\mathrm{xy}}\left(1+\frac{3 \mathrm{a}^{4}}{\mathrm{r}^{4}}-\frac{4 \mathrm{a}^{2}}{\mathrm{r}^{2}}\right) \sin (2 \theta)+ \\
& \mathrm{P}_{\mathrm{f}} \frac{\mathrm{a}^{2}}{\mathrm{r}^{2}} \\
& \sigma_{\theta}=\left(\frac{\sigma_{\mathrm{x}}+\sigma_{\mathrm{y}}}{2}\right)\left(1+\frac{\mathrm{a}^{2}}{\mathrm{r}^{2}}\right)-\left(\frac{\sigma_{\mathrm{x}}-\sigma_{\mathrm{y}}}{2}\right)\left(1+\frac{3 \mathrm{a}^{4}}{\mathrm{r}^{4}}\right) \cos (2 \theta)-\tau_{\mathrm{xy}}\left(1+\frac{3 \mathrm{a}^{4}}{\mathrm{r}^{4}}\right) \sin (2 \theta)-\mathrm{P}_{\mathrm{f}} \frac{\mathrm{a}^{2}}{\mathrm{r}^{2}}
\end{aligned}
$$




$$
\begin{aligned}
& \sigma_{\mathrm{a}}=\sigma_{\mathrm{z}}-v\left(2\left(\sigma_{\mathrm{x}}-\sigma_{\mathrm{y}}\right) \frac{\mathrm{a}^{2}}{\mathrm{r}^{2}} \cos (2 \theta)+4 \tau_{\mathrm{xy}} \frac{\mathrm{a}^{2}}{\mathrm{r}^{2}} \sin (2 \theta)\right) \\
& \tau_{\mathrm{r} \theta}=\left(\frac{\sigma_{\mathrm{x}}-\sigma_{\mathrm{y}}}{2}\right)\left(1-\frac{3 \mathrm{a}^{4}}{\mathrm{r}^{4}}+\frac{2 \mathrm{a}^{2}}{\mathrm{r}^{2}}\right) \sin (2 \theta)+\tau_{\mathrm{xy}}\left(1-\frac{3 \mathrm{a}^{4}}{\mathrm{r}^{4}}+\frac{2 \mathrm{a}^{2}}{\mathrm{r}^{2}}\right) \cos (2 \theta) \\
& \tau_{\theta \mathrm{a}}=\left(-\tau_{\mathrm{xz}} \sin \theta+\tau_{\mathrm{yz}} \cos \theta\right)\left(1+\frac{\mathrm{a}^{2}}{\mathrm{r}^{2}}\right) \\
& \tau_{\mathrm{ra}}=\left(\tau_{\mathrm{xz}} \cos \theta+\tau_{\mathrm{yz}} \sin \theta\right)\left(1-\frac{\mathrm{a}^{2}}{\mathrm{r}^{2}}\right)
\end{aligned}
$$

Onde $\tau_{\mathrm{r} \theta}, \tau_{\theta \mathrm{a}}, \tau_{\mathrm{ra}}$ são tensões cisalhantes em psi atuantes nos planos definidos pelos seus índices, $\mathrm{P}_{\mathrm{f}}$ é a pressão interna do poço em psi, $\theta$ é o ângulo ao redor do poço, a é o raio do poço em m e r é a distância em entre o ponto de interesse e o eixo axial do poço em $\mathrm{m}$.

Neste estudo serão considerados os pontos na parede do poço, portanto a razão $\frac{a}{r}$ presente nas equações 20 a 25 assumirá valor 1 .

\section{Gradiente de Fratura}

O gradiente de fratura é a normalização da pressão de fratura com a profundidade. Define-se a pressão de fratura como o limite de pressão em que ocorre a falha da rocha por tração. A ruptura da formação por tração pode ocorrer de duas maneiras: devido ao alto peso de fluido de perfuração - pressão de fratura superior e devido ao baixo peso de fluido de perfuração - pressão de fratura inferior.

Os gradientes de fratura delimitam a faixa de densidade que o fluido de perfuração pode assumir para que não haja a falha da formação por tração. $O$ limitante inferior de fratura, em geral, assume valores muito abaixo do limite inferior de colapso (gradiente de colapso), dessa forma, o gradiente de fratura inferior pode ser desprezado.

A pressão de fratura superior, no entanto, não pode ser desprezada. Nas condições de perfuração de um poço com fluido não penetrante, estima-se que o limite de pressão para que não haja ruptura por tração da formação na parede do poço ocorre quando a tensão tangencial no poço e a resistência à tração da rocha 
estão em equilíbrio, como indicado na equação 26 e posteriormente expressado a partir da equação 27.

$\sigma_{\theta}^{\prime}+\mathrm{T}_{0}=0$

$\sigma_{\mathrm{x}}+\sigma_{\mathrm{y}}-4 \cdot\left(\sigma_{\mathrm{x}}-\sigma_{\mathrm{y}}\right) \cos (2 \theta)-4 \cdot \tau_{\mathrm{xy}} \sin (2 \theta)-\mathrm{P}_{\mathrm{f}}-\mathrm{P}_{\mathrm{P}}+\mathrm{T}_{0}=0$

Onde $\sigma_{\theta}^{\prime}$ é a tensão tangencial efetiva em psi

Dessa forma, a pressão de fratura superior pode ser determinada de maneira direta a partir da equação 28.

$\mathrm{P}_{\mathrm{f}}=\sigma_{\mathrm{x}}+\sigma_{\mathrm{y}}-4 \cdot\left(\sigma_{\mathrm{x}}-\sigma_{\mathrm{y}}\right) \cos (2 \theta)-4 \cdot \tau_{\mathrm{xy}} \sin (2 \theta)-\mathrm{P}_{\mathrm{P}}+\mathrm{T}_{0}$

Onde $\mathrm{P}_{\mathrm{f}}$ é a pressão interna do poço em psi, $\sigma_{\mathrm{x}}$ e $\sigma_{\mathrm{y}}$, são as tensões normais aos planos x e y, respectivamente, em psi, $\tau_{x y}$ é a tensão cisalhante ao plano xy em psi, $\theta$ é o ângulo ao redor do poço medido em graus, $\mathrm{P}_{\mathrm{P}}$ é a pressão de poros em psi e $\mathrm{T}_{0}$ é a resistência à tração em psi.

Uma vez que a janela operacional é apresentada em termos de gradiente, calcula-se o gradiente de fratura (GFRAT) em lb/gal a partir do fator de conversão:

GFRAT $=\frac{P_{f}}{z} \cdot 5.8674$

Onde $\mathrm{P}_{\mathrm{f}}$ é a pressão interna do poço em psi e $\mathrm{z}$ é a profundidade vertical em $\mathrm{m}$.

\section{Gradiente de Colapso}

O gradiente de fratura é a normalização da pressão de fratura com a profundidade. Define-se a pressão de colapso como o limite de pressão em que ocorre a falha da rocha por cisalhamento. A ruptura da formação por cisalhamento, assim como a fratura, pode ocorrer de duas maneiras: devido ao alto peso de fluido de perfuração - pressão de colapso superior - e devido ao baixo peso de fluido de perfuração - pressão de colapso inferior.

Os gradientes de colapso delimitam o intervalo de valores que a densidade do fluido de perfuração pode assumir para que não haja a ruptura da formação por tensões compressivas. Para o cálculo das pressões de colapso, é necessário a adoção de um critério de ruptura e, nesse trabalho, será empregada a técnica de 
múltiplas iterações, que foi desenvolvida no simulador SEST TR 2.0@ utilizado neste trabalho.

Uma vez calculadas as tensões ao redor do poço, para a estimativa dos gradientes de colapso é necessário determinar primeiro as tensões principais ao redor do poço $\sigma_{1}, \sigma_{2}$ e $\sigma_{3}$ que são definidas como tensão principal maior, intermediária e menor, respectivamente. Para isso, calcula-se $S_{a}, S_{b}$ e $S_{c}$.

$\mathrm{S}_{\mathrm{a}}=\sigma_{\mathrm{r}}$

$\mathrm{S}_{\mathrm{b}}=\frac{\sigma_{\mathrm{z}}+\sigma_{\theta}}{2}+\sqrt{\left(\frac{\sigma_{\mathrm{z}}-\sigma_{\theta}}{2}\right)^{2}+\tau^{2}{ }_{\theta \mathrm{z}}}$

$\mathrm{S}_{\mathrm{c}}=\frac{\sigma_{\mathrm{z}}+\sigma_{\theta}}{2}-\sqrt{\left(\frac{\sigma_{\mathrm{z}}-\sigma_{\theta}}{2}\right)^{2}+\tau^{2}{ }_{\theta \mathrm{z}}}$

Posteriormente, associa-se a maior, intermediária e menor tensão entre $S_{a}, S_{b}$ e $S_{c}$ a $\sigma_{1}, \sigma_{2}$ e $\sigma_{3}$ respectivamente.

Este estudo terá o critério de Mohr-Coulomb como base para o cálculo dos colapsos. Apesar deste modelo apresentar resultados conservativos - devido ao fato de não considerar a influência que a tensão principal intermediária exerce -este critério é amplamente utilizado na indústria, não só devido a sua simplicidade, mas principalmente por conferir um cenário de resultados mais seguro. O critério de MohrCoulomb é expresso pela equação 33.

$\sigma_{1}^{\prime}=\frac{2 C \cos \phi}{1-\sin \phi}+\sigma_{3}^{\prime} \frac{1+\sin \phi}{1-\sin \phi}$

Onde $\sigma_{1}^{\prime}$ é a tensão principal maior efetiva em psi, $\sigma_{3}^{\prime}$ é a tensão principal efetiva menor em psi e C é a coesão em psi.

Uma vez calculada a tensão principal maior - e consequentemente a tensão principal maior efetiva - e determinado o critério a ser utilizado, o próximo passo é definir o fator de plastificação. O fator de plastificação consiste na razão entre a tensão principal maior efetiva de campo e a tensão principal maior efetiva teórica (equação 34). Esta será considerada aquela calculada a partir do critério de MohrCoulomb, já aquela será sempre a maior entre $\mathrm{S}_{\mathrm{a}}, \mathrm{S}_{\mathrm{b}}$ e $\mathrm{S}_{\mathrm{c}}$ calculados anteriormente.

$\mathrm{fp}=\frac{\sigma_{1}^{\prime}}{\sigma_{1(\mathrm{MC})}^{\prime}}$ 
Onde $\sigma_{1(\mathrm{MC})}^{\prime}$ é a tensão principal maior efetiva determinada pelo critério de MohrCoulomb.

\section{Colapso Inferior}

O cálculo dos colapsos ocorre de maneira iterativa. Para o colapso inferior, adota-se uma pressão interna de magnitude muito baixa. Calcula-se a tensão principal maior em todos os pontos ao redor do poço e posteriormente o fator de plastificação (fp). Espera-se que o fp em algum ponto ao redor de todo o poço seja maior que 1. Neste caso, significa que a pressão de colapso inferior é maior que zero, logo a pressão interna do poço sofre um incremento e os cálculos são refeitos até encontrar o novo fator de plastificação. Este processo se repete até que o fator de plastificação máximo ao redor do poço seja 1. Neste ponto, se dará a pressão de colapso inferior. (SEST TR 2.0C)

\section{Colapso Superior}

Para o colapso superior, inicialmente adota-se uma pressão interna de magnitude muito alta. Calcula-se a tensão principal maior em todos os pontos ao redor do poço e posteriormente o fator de plastificação. Espera-se que o fp em algum ponto ao redor de todo o poço seja menor que 1. Neste caso, significa que a pressão de colapso superior é menor do que o peso de fluido inicial, logo a pressão interna do poço sofre um incremento negativo e os cálculos são refeitos até encontrar o novo fator de plastificação. Este processo se repete até que o fator de plastificação mínimo ao redor do poço seja 1. Neste ponto, se dará a pressão de colapso superior. (SEST TR 2.0())

Os gradientes de colapso superior e inferior são calculados de maneira análoga ao gradiente de fratura (equação 29).

\section{2.}

\section{Análise Estatística dos Parâmetros de Entrada}

A fim de estimar os gradientes da janela operacional a partir de métodos probabilísticos, se faz necessária a análise estatística dos parâmetros de entrada. Os 
métodos probabilísticos contabilizam os diferentes cenários possíveis e suas probabilidades de ocorrência a partir do grau de variação de cada parâmetro de entrada. Dessa forma, é necessário fazer a análise individual de cada parâmetro e determinar que tipo de padrão de distribuição se adequa melhor e os seus parâmetros estatísticos associados.

Neste estudo, assume-se como hipótese simplificadora que todos os parâmetros de entrada seguem um mesmo padrão de variação. Dessa forma, os métodos probabilísticos serão aplicados em dois casos diferentes para fins de comparação:

i. Aplicação para o caso em que todos os parâmetros de entrada seguem o padrão de distribuição normal;

ii. Aplicação para o caso em que todos os parâmetros de entrada seguem uma distribuição uniforme.

A seguir, nos tópicos 3.2.1 e 3.2.2, será detalhado como esses padrões de distribuição serão abordados.

\subsection{1. \\ Distribuição Normal}

Neste tipo de variação, é considerada uma distribuição normal para os parâmetros de entrada. A distribuição normal é caracterizada como aquela onde o valor médio, a moda e a mediana coincidem (Pinheiro et al., 2012). Um parâmetro que segue um padrão de distribuição normal pode ser descrito por uma função de densidade regida pelo valor médio e desvio padrão associados a ele, como mostrado na equação 35 (Pinheiro et al., 2012).

$\mathrm{f}(\mathrm{x})=\frac{1}{\sqrt{2 \pi * \sigma^{2}}} * \mathrm{e}^{-\left(\frac{1}{2} *\left(\frac{\mathrm{x}-\mu}{\sigma}\right)^{2}\right)}$

Onde x é o parâmetro cuja distribuição é normal, $\sigma$ é o seu desvio padrão e $\mu$ a sua média. 
A Figura 18 mostra um exemplo de distribuição normal de dados de um perfil de raios gama ao longo da trajetória de um poço. Já a Figura 19 apresenta o modelo teórico de uma distribuição normal.

Neste estudo, para a aplicação do método probabilístico, será necessário definir uma variação para cada parâmetro de entrada. Para o caso em que os parâmetros de entrada que terão, por hipótese simplificadora, distribuição normal, será aplicada uma variação de um desvio padrão. Dessa forma, será abrangido aproximadamente $68.26 \%$ da amostragem da distribuição. Outra hipótese simplificadora é que o desvio padrão associado a cada parâmetro de entrada será de 10\% do seu valor médio.

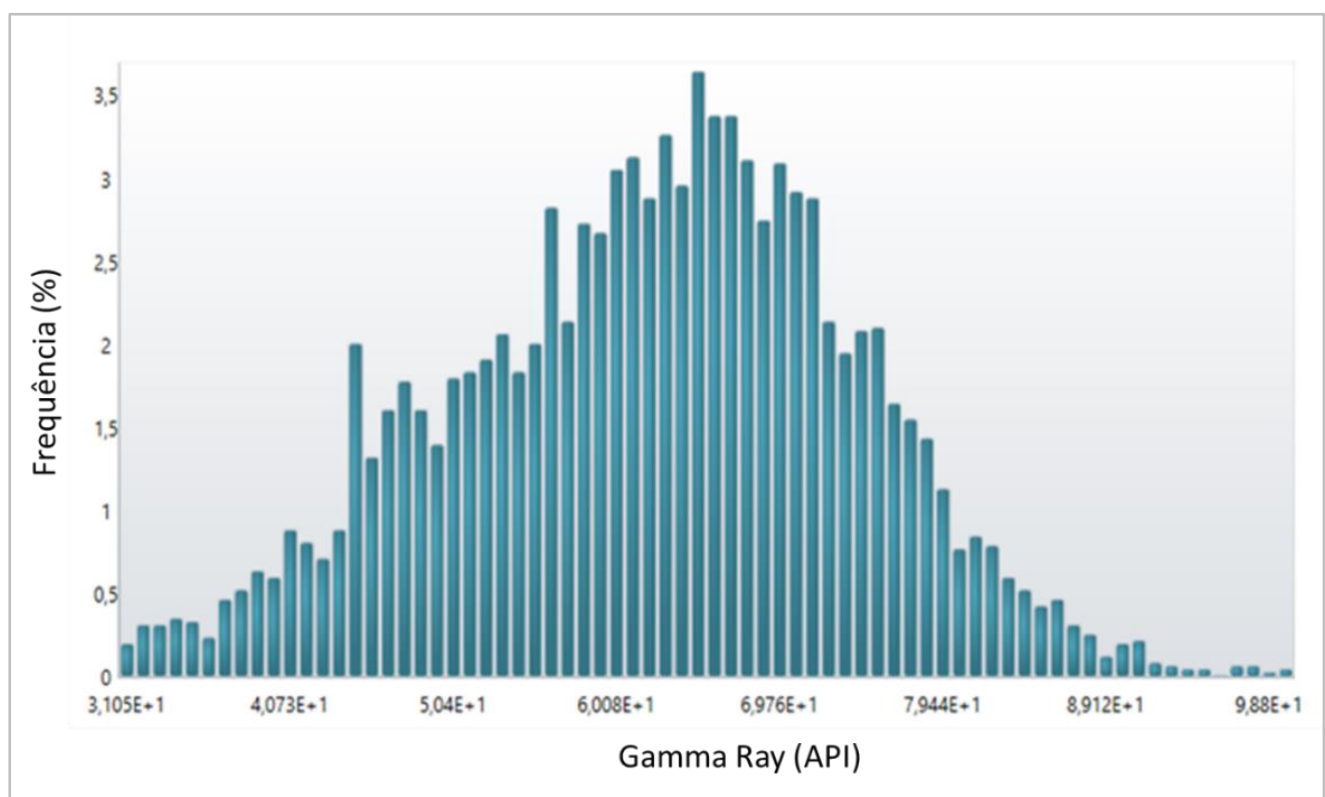

Figura 18. Histograma apresentando uma distribuição normal de frequência de um perfil raios gama ${ }^{[4]}$. (SESTC)

[4] O perfil de raios gama mede a radioatividade das formações. Este perfil auxilia na identificação de formações argilosas devido à alta concentração de elementos radioativos presentes nos minerais constituintes desse tipo de formação. 


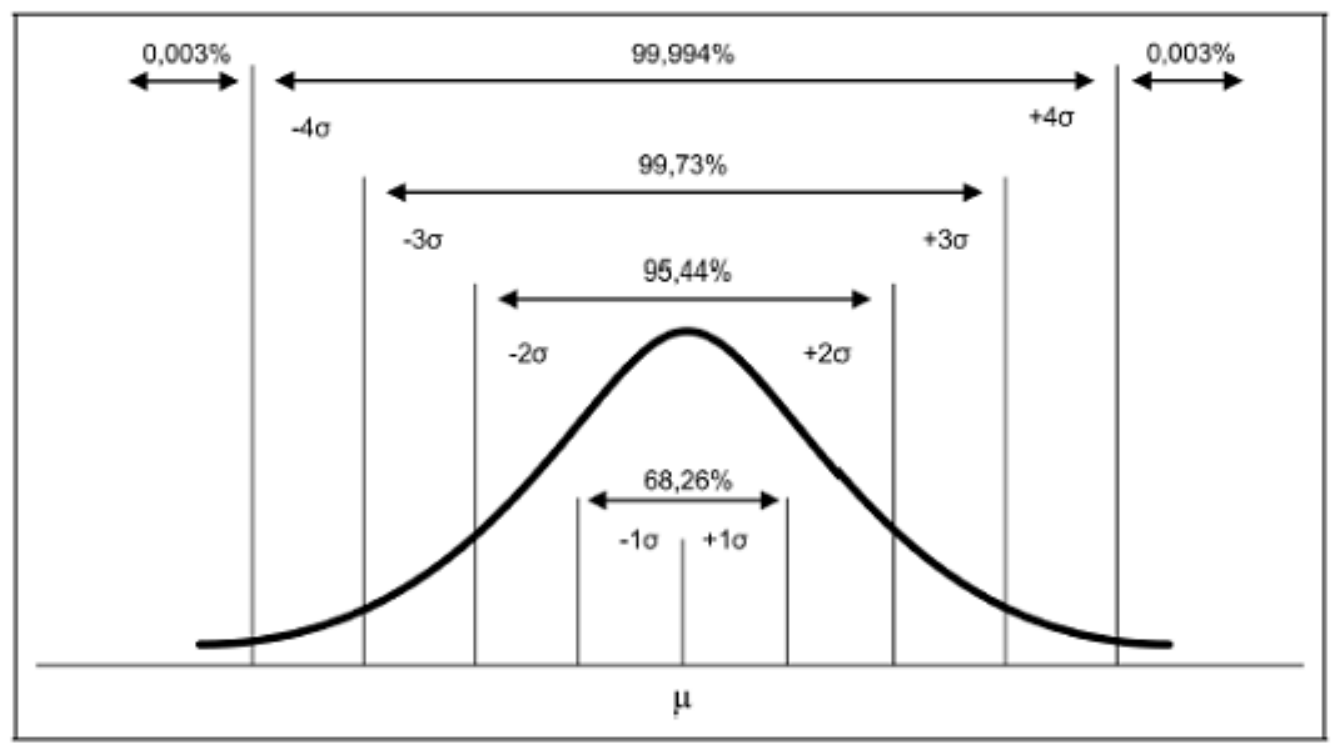

Figura 19 - Distribuição de amostragem ao longo da função de densidade de um distribuição normal. (Portal Action, acesso em 20/09/2020)

\subsection{2. Distribuição Uniforme}

A distribuição uniforme é caracterizada por apresentar probabilidades iguais de ocorrência de qualquer classe dentro do intervalo entre um limite inferior e superior, ou seja, a probabilidade de ocorrência de uma variável em um subintervalo dentro dos limites inferior e superior da distribuição uniforme é igual a probabilidade de ocorrência dessa variável em qualquer outro subintervalo de mesmo comprimento (Pinheiro et al., 2012).

Um parâmetro que segue um padrão de distribuição uniforme pode ser descrito por uma função de densidade regida pelos limites superior e inferior de amostragem, como mostrado na equação 36 (Pinheiro et al., 2012).

$f(x)=\frac{1}{b-a}$

Onde a é o limite inferior de amostragem e b é o limite superior de amostragem. A probabilidade de ocorrência da variável x para qualquer intervalo fora dos limites de amostragem é zero. 
Além dos principais parâmetros associados a uma distribuição uniforme, a e b, são definidos também os parâmetros (Pinheiro et al., 2012):

$\mu=\frac{a+b}{2}$

$\sigma=\frac{\mathrm{b}-\mathrm{a}}{\sqrt{12}}$

Onde $\mu$ é o valor médio do parâmetro, $\sigma$ é o desvio padrão desse parâmetro.

A Figura 20 apresenta um exemplo de distribuição uniforme de dados de pressão de poros ao longo da trajetória de um poço. Já a Figura 21 apresenta o modelo teórico de uma distribuição uniforme.

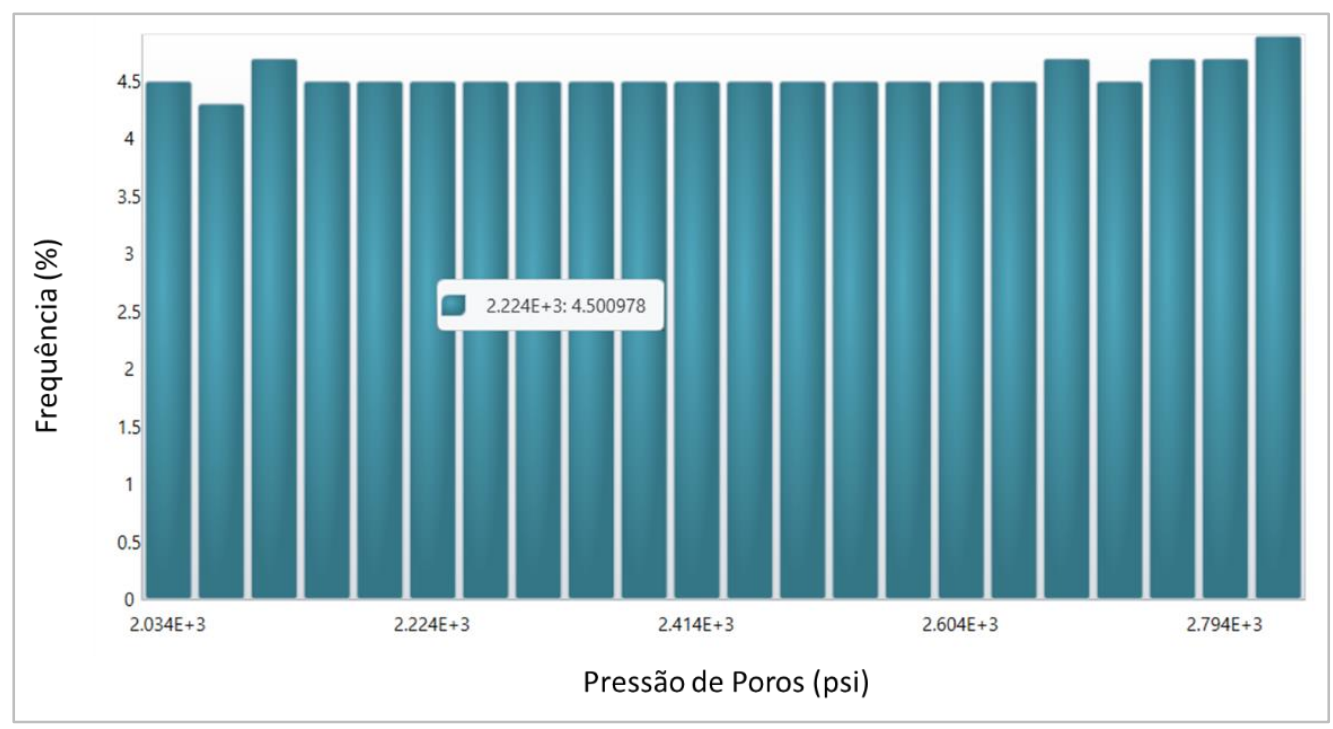

Figura 20. Histograma apresentando uma distribuição uniforme de frequência de dados de pressão de poros. (SESTC) 


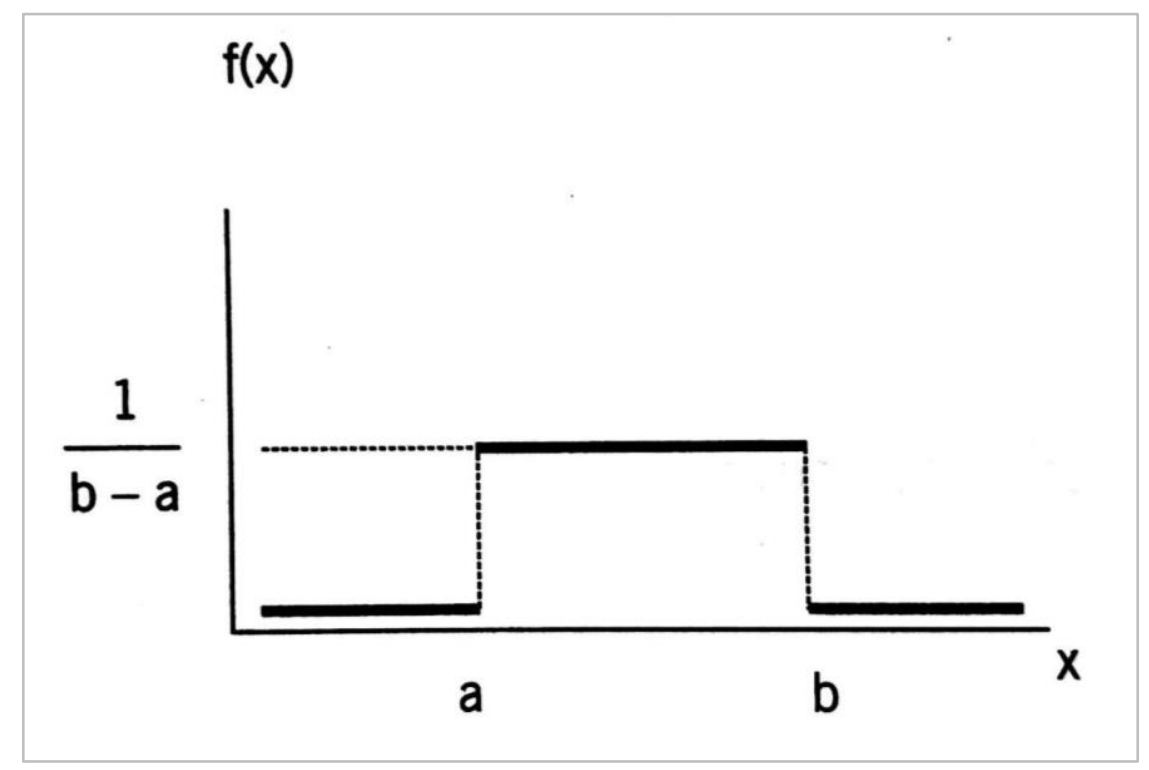

Figura 21 - Função densidade de uma distribuição uniforme. (Pinheiro et al., 2012)

Neste estudo, para a aplicação do método probabilístico, será necessário definir uma variação para cada parâmetro de entrada e em cada profundidade. Para o caso em que os parâmetros de entrada terão, por hipótese simplificadora, uma distribuição uniforme, será aplicada uma variação selecionada aleatoriamente para cada parâmetro de entrada e para cada profundidade dentro de um intervalo definido. Esse intervalo deve corresponder à mesma porcentagem amostral daquela apresentada para o caso da distribuição normal, ou seja, será abrangido, igualmente, aproximadamente $68.26 \%$ da amostragem da distribuição.

\section{3.}

\section{Análise Probabilística de Estabilidade de Poços}

Para que se possa fazer uma análise de estabilidade baseada em uma janela operacional obtida probabilisticamente é necessário definir inicialmente o método probabilístico a ser utilizado e quais os parâmetros de entrada com suas incertezas associadas a se considerar. $O$ método de estimativa dos gradientes que limitam a janela operacional é o mesmo utilizado no cálculo determinístico, entretanto, para a estimativa a partir de metodologias probabilísticas, serão aplicadas variações nos parâmetros de entrada e a estimativa será feita considerando essas variações. 
Neste estudo, será considerado que, para a estimativa probabilística, os mesmos parâmetros de entrada previamente apresentados para os cálculos da janela operacional determinística possuem incertezas associadas:

- Tensão vertical;

- Tensão horizontal maior;

- Tensão horizontal menor;

- Azimute da tensão horizontal menor;

- Pressão de poros;

- Coeficiente de Biot;

- Coeficiente de Poisson;

- Ângulo de atrito interno;

- Resistência à tração;

- Resistência à compressão simples;

- Coesão.

A análise probabilística de estabilidade se dará com base na metodologia apresentada para o cálculo determinístico, porém associando as incertezas dos dados de entrada conforme dois dos três métodos probabilísticos apresentados por Fontoura et al. (2002): SEAM e FOSM. As duas metodologias foram implementadas em código desenvolvido no MATLAB@ para contemplar a análise probabilística em toda a extensão do poço.

A aplicação dos métodos probabilísticos se dará da seguinte maneira: uma vez que os valores médios dos parâmetros de entrada e dos gradientes de fratura e colapso já foram calculados, e as incertezas associadas aos parâmetros de entrada já foram definidas, observa-se a variação obtida nos gradientes a partir do incremento (positivo e negativo) de cada parâmetro individualmente. Nesse momento, os métodos probabilísticos são aplicados, contabilizando essas variações observadas e associando-as a uma probabilidade de falha a partir de uma função de distribuição 
acumulada. Os métodos probabilísticos abordados nesse estudo serão detalhados nos tópicos 3.3.1 e 3.3.2.

\subsection{1.}

Método de Análise Estatística de Erro (Statistical Error Analysis Method, SEAM)

O Método de Análise Estatística de Erro (Fontoura et al., 2002) baseia-se na função normal padrão, que traz a necessidade de definir o índice de confiabilidade padrão normal Z.

Primeiramente, para o caso da análise de estabilidade de poços, a pressão de ruptura pode ser calculada usando os valores médios dos parâmetros de entrada, como na equação 39.

$\overline{\mathrm{P}}=\mathrm{P}\left(\overline{\mathrm{X}_{1}}, \overline{\mathrm{X}_{2}}, \overline{\mathrm{X}_{3}}, \ldots, \overline{\mathrm{X}_{\mathrm{n}}}\right)$

Essa pressão pode ser assumida como pressão de colapso superior, colapso inferior ou de fratura e $\mathrm{X}_{\mathrm{i}}$ denota o valor médio do parâmetro de entrada i. Neste estudo, será assumido que os parâmetros de entrada são independentes e suas incertezas apresentam um comportamento normal ou uniforme, com desvio padrão $\sigma\left(\mathrm{X}_{\mathrm{i}}\right)$. É possível correlacionar o desvio padrão da pressão de falha calculada, $\sigma(\mathrm{P})$, com $\sigma\left(\mathrm{X}_{\mathrm{i}}\right)$, conforme mostrado na equação 40.

$\sigma(\mathrm{P})=\sqrt{\sum_{\mathrm{i}=1}^{\mathrm{n}}\left(\frac{\partial \mathrm{P}}{\partial \mathrm{X}_{\mathrm{i}}} * \sigma\left(\mathrm{X}_{\mathrm{i}}\right)\right)^{2}}$

As derivadas parciais apresentadas na equação 40 podem ser aproximadas individualmente para cada parâmetro de entrada da seguinte maneira:

- Calcula-se a magnitude da variação na pressão de ruptura ocasionado por um pequeno incremento positivo no parâmetro de entrada;

- Divide-se essa variação pelo incremento imposto ao parâmetro de entrada;

- Repete-se esse procedimento para um pequeno incremento negativo;

- Faz-se a média entre os dois valores encontrados. 
Nesse ponto, os incrementos serão definidos de maneiras diferentes para cada tipo de distribuição. Para este estudo, utilizou-se incremento igual ao desvio padrão em distribuições normais. Já para as distribuições uniformes, o incremento foi estipulado de maneira randômica dentro de um intervalo limitado por zero e o desvio padrão do parâmetro de entrada. Nos dois casos, as derivadas parciais podem ser representadas pela equação 41 .

$\left|\frac{\partial \mathrm{P}}{\partial \mathrm{X}_{\mathrm{i}}}\right|=\frac{\left|\mathrm{P}_{\mathrm{i}}^{+}-\overline{\mathrm{P}}\right|+\left|\mathrm{P}_{\mathrm{i}}^{-}-\overline{\mathrm{P}}\right|}{2 * \delta\left(\mathrm{X}_{\mathrm{i}}\right)}$

Com $\delta\left(\mathrm{X}_{\mathrm{i}}\right)=\sigma\left(\mathrm{X}_{\mathrm{i}}\right)$ para o caso de distribuições normais e $\left.\delta\left(\mathrm{X}_{\mathrm{i}}\right) \epsilon\right] 0, \sigma\left(\mathrm{X}_{\mathrm{i}}\right)$ ] selecionado aleatóriamente para o caso de distribuições uniformes.

Onde $\mathrm{P}_{\mathrm{i}}^{+}$é o resultado para a pressão de ruptura quando há o incremento positivo do parâmetro de entrada, $\mathrm{P}_{\mathrm{i}}^{-}$é o resultado para a pressão de ruptura quando há o incremento negativo do parâmetro de entrada, $\overline{\mathrm{P}}$ é o valor obtido com valores médios dos parâmetros e $\delta\left(X_{i}\right)$ é o incremento definido de acordo com cada distribuição.

Uma vez calculado o desvio padrão e o valor médio da pressão de falha, é possível definir o índice de confiabilidade padrão normal Z, como mostrado na equação 42.

$\mathrm{Z}=\frac{\mathrm{P}_{\mathrm{w}}-\overline{\mathrm{P}}}{\sigma(\mathrm{P})}$

Onde $\mathrm{P}_{\mathrm{w}}$ é a pressão de falha que se quer calcular probabilisticamente.

Uma vez calculado o índice Z, a pressão de falha pode ser obtida para qualquer probabilidade de falha a partir da função normal padrão acumulada, conforme indicado nas equações 43 e 44.

$\mathrm{PR}=\phi(\mathrm{Z})$

$\phi(Z)=\int_{-\infty}^{Z} \frac{1}{\sqrt{2 \pi}} * e^{-\frac{t^{2}}{2}} d t$

Onde PR é a probabilidade de falha e $\phi(Z)$ é a função normal padrão acumulada.

É importante mencionar que ao utilizar a função normal padrão acumulada para o cálculo dos gradientes em função de uma probabilidade de falha, este método assume que os resultados probabilísticos dos gradientes apresentam uma 
distribuição normal. Este tipo de distribuição é caracterizado por apresentar resultados para probabilidade de falha de $50 \%$ (P50) igual ao valor médio. Portanto, nesta metodologia, tem-se que $\mathrm{P} 50=\overline{\mathrm{P}}$.

\subsection{2.}

\section{Método do Segundo Momento de Primeira Ordem (First Order Second Moment Method, FOSM)}

O Método do Segundo Momento de Primeira Ordem (Fontoura et al., 2002) aborda os primeiros termos da expansão da série de Taylor para calcular os valores médios e o desvio padrão relacionados à função de desempenho. Para este estudo, a função desempenho depende do fator de segurança, que pode ser definido como mostrado nas equações 45 e 46.

$\overline{\mathrm{FS}}_{\mathrm{LS}}=\frac{\overline{\mathrm{P}}}{\mathrm{P}_{\mathrm{w}}}$

$\overline{\mathrm{FS}}_{\mathrm{LI}}=\frac{\mathrm{P}_{\mathrm{w}}}{\overline{\mathrm{P}}}$

Onde $\mathrm{P}_{\mathrm{w}}$ é a pressão interna do poço e $\overline{\mathrm{P}}$ pode representar as pressões médias de fratura e colapso superior na equação 45 e pressão média de colapso inferior na equação 46.

A pressão de falha $(\overline{\mathrm{P}})$ relacionada a um determinado modo de ruptura (fratura, colapso superior ou colapso inferior) pode ser calculada com os valores médios dos parâmetros da mesma forma que no método SEAM (equação 39). Entretanto, no método FOSM, utiliza-se o índice de confiabilidade de segunda ordem $\beta$ (equação 47) para estimar a probabilidade de falha.

$\beta=\frac{\overline{\mathrm{FS}}-1}{\sigma(\mathrm{FS})}$

Onde $\overline{\mathrm{FS}}$ é o fator de segurança calculado com valores médios dos parâmetros de entrada e $\sigma(\mathrm{FS})$ é o desvio padrão do fator de segurança.

Neste estudo, será assumido que os parâmetros de entrada são independentes e suas incertezas apresentam um comportamento normal ou uniforme, com desvio padrão $\sigma\left(\mathrm{X}_{\mathrm{i}}\right)$. Portanto, é possível correlacionar o desvio padrão do fator de segurança, $\sigma(\mathrm{FS})$, com $\sigma\left(\mathrm{X}_{\mathrm{i}}\right)$, como mostrado na equação 48 . 
$\sigma(\mathrm{FS})^{2}=\sum_{\mathrm{i}=1}^{\mathrm{n}}\left(\frac{\partial \mathrm{FS}}{\partial \mathrm{X}_{\mathrm{i}}}\right)^{2} * \sigma\left(\mathrm{X}_{\mathrm{i}}\right)^{2}$

As derivadas parciais apresentadas na equação 48 podem ser aproximadas individualmente para cada parâmetro de entrada da seguinte maneira:

- Calcula-se a magnitude da variação do fator de segurança ocasionado por um pequeno incremento positivo no parâmetro de entrada;

- Divide-se essa variação pelo incremento imposto ao parâmetro de entrada;

- Repete-se esse procedimento para um pequeno incremento negativo;

- Faz-se a média entre os dois valores encontrados.

Assim como no método SEAM, os incrementos serão definidos de maneiras diferentes para cada tipo de distribuição no método FOSM também. Para a hipótese de distribuição normal dos dados de entrada, utiliza-se incremento igual ao desvio padrão do parâmetro de entrada. Já para a hipótese de distribuições uniformes, o incremento foi estipulado de maneira randômica dentro de um intervalo limitado por zero e o desvio padrão do parâmetro de entrada. A aproximação da derivada parcial para estes casos é representada na equação 49.

$\left|\frac{\partial \mathrm{FS}}{\partial \mathrm{X}_{\mathrm{i}}}\right|=\frac{\left|\mathrm{FS}_{\mathrm{i}}^{+}-\overline{\mathrm{FS}}\right|+\left|\mathrm{FS}_{\mathrm{i}}^{-}-\overline{\mathrm{FS}}\right|}{2 * \delta\left(\mathrm{X}_{\mathrm{i}}\right)}$

Com $\delta\left(X_{i}\right)=\sigma\left(X_{i}\right)$ para o caso de distribuição normal e $\left.\delta\left(X_{i}\right) \epsilon\right] 0, \delta\left(X_{i}\right)$ ] selecionado aleatoriamente para o caso de distribuição uniforme dos parâmetros iniciais.

Onde $\delta \mathrm{X}_{\mathrm{i}}$ é o incremento estipulado para cada tipo de distribuição, $\mathrm{FS}_{\mathrm{i}}^{+}$é o fator de segurança obtido com incremento positivo do parâmetro de entrada, $\mathrm{FS}_{\mathrm{i}}^{-}$o fator de segurança obtido com incremento negativo do parâmetro de entrada.

Uma vez definida uma equação para o índice de confiabilidade $\beta$ em função de $\mathrm{P}_{\mathrm{w}}$, a probabilidade de falha pode ser escrita conforme mostrado nas equações $50 \mathrm{e}$ 51.

$\mathrm{PR}=1-\phi(\beta)$

$\phi(\beta)=\int_{-\infty}^{\beta} \frac{1}{\sqrt{2 \pi *}} * \mathrm{e}^{-\frac{\mathrm{t}^{2}}{2}} \mathrm{dt}$ 
Onde PR é a probabilidade de falha e $\phi(\beta)$ é a função normal padrão acumulada.

É importante mencionar que ao utilizar a função normal padrão acumulada para o cálculo dos gradientes em função de uma probabilidade de falha, este método assume que os resultados probabilísticos dos gradientes apresentam uma distribuição normal. Este tipo de distribuição é caracterizado por apresentar resultados para probabilidade de falha de 50\% (P50) igual ao valor médio. Portanto, nesta metodologia, também tem-se que $\mathrm{P} 50=\overline{\mathrm{P}}$. 


\section{4. Estudo de Caso}

A aplicação da metodologia de análise probabilística será feita em um poço vertical designado com o nome fictício Poço PUC, a fim de preservar a confidencialidade de dados. Para esse estudo será abordada uma visão ampla do cenário em que o poço PUC foi perfurado. Neste capítulo serão apresentados:

- Poço de correlação: poço já perfurado próximo à área onde se planeja perfurar o poço PUC. Ao selecionar um poço de correlação, assume-se que este apresentará um comportamento geomecânico semelhante àquele que se quer perfurar. Portanto, os dados de poço de correlação são utilizados para estimar o comportamento esperado para o poço se projeto (a ser perfurado);

- Poço de projeto: projeto de estabilidade do poço que se quer perfurar. Com base em informações de campo e de poços de correlação, estima-se o cenário geomecânico esperado para a perfuração do poço. A partir dessas estimativas, obtém-se a janela operacional que será utilizada para o dimensionamento da densidade de fluido de perfuração durante a perfuração;

- Poço de retroanálise: análise de estabilidade do poço após a sua perfuração. Uma vez que o poço foi perfurado, utiliza-se dados reais do poço para calcular o estado de tensões in sito, as propriedades mecânicas e por fim a janela operacional. A análise é feita com base nesses resultados em conjunto com os eventos de perfuração observados e a densidade do fluido de perfuração utilizada.

O Poço PUC apresenta uma camada constituída de formações salinas ao longo da sua trajetória, dessa forma, serão apresentados nesse trabalho os resultados para as camadas pré-sal e pós-sal. O modelo geomecânico adotado para o Poço PUC se dá conforme modelo apresentado no tópico 3.1, fornecendo um cenário calibrado e consistente para diferentes tipos de formações, com exceção da sequência salina. Assim como o Poço PUC, o poço correlato também apresenta uma camada salina ao 
longo de sua trajetória perfurada, sendo assim, as análises apresentadas aqui também serão referentes as camadas pré-sal e pós-sal.

\section{1.}

Poço de Correlação

Para a elaboração de um projeto de poço é necessário seguir etapas importantes. Cada etapa do fluxo de trabalho é abrangida por diferentes segmentos da engenharia de poços e o primeiro passo para um projeto consiste no estudo da área onde se planeja perfurar o poço. É nesse momento que se faz a caracterização do cenário geológico da área a ser perfurada e análise histórica dos poços já perfurados para a seleção do poço de correlação. Este item apresenta as características do poço de correlação utilizado para o estudo de caso e os resultados e conclusões obtidas a partir da sua retroanálise de estabilidade.

Para esse estudo de caso, o poço de correlação utilizado para o projeto possui trajetória vertical e apresenta configuração de perfis iniciais como apresentada na Figura 22. Na camada pós-sal, os perfis e litologia utilizados para a retroanálise desse poço de foram adaptados a partir dos dados obtidos na fase de investigação do poço. Já nas camadas pré-sal, foram utilizados os perfis corridos do próprio poço. A faixa cinza denota a camada de sal para a qual os modelos propostos neste trabalho não se aplicam. Para esta análise, o material rochoso foi considerado contínuo, elástico, homogêneo e isotrópico. Inicialmente, foi observado o cenário apresentado pelo poço de correlação. 


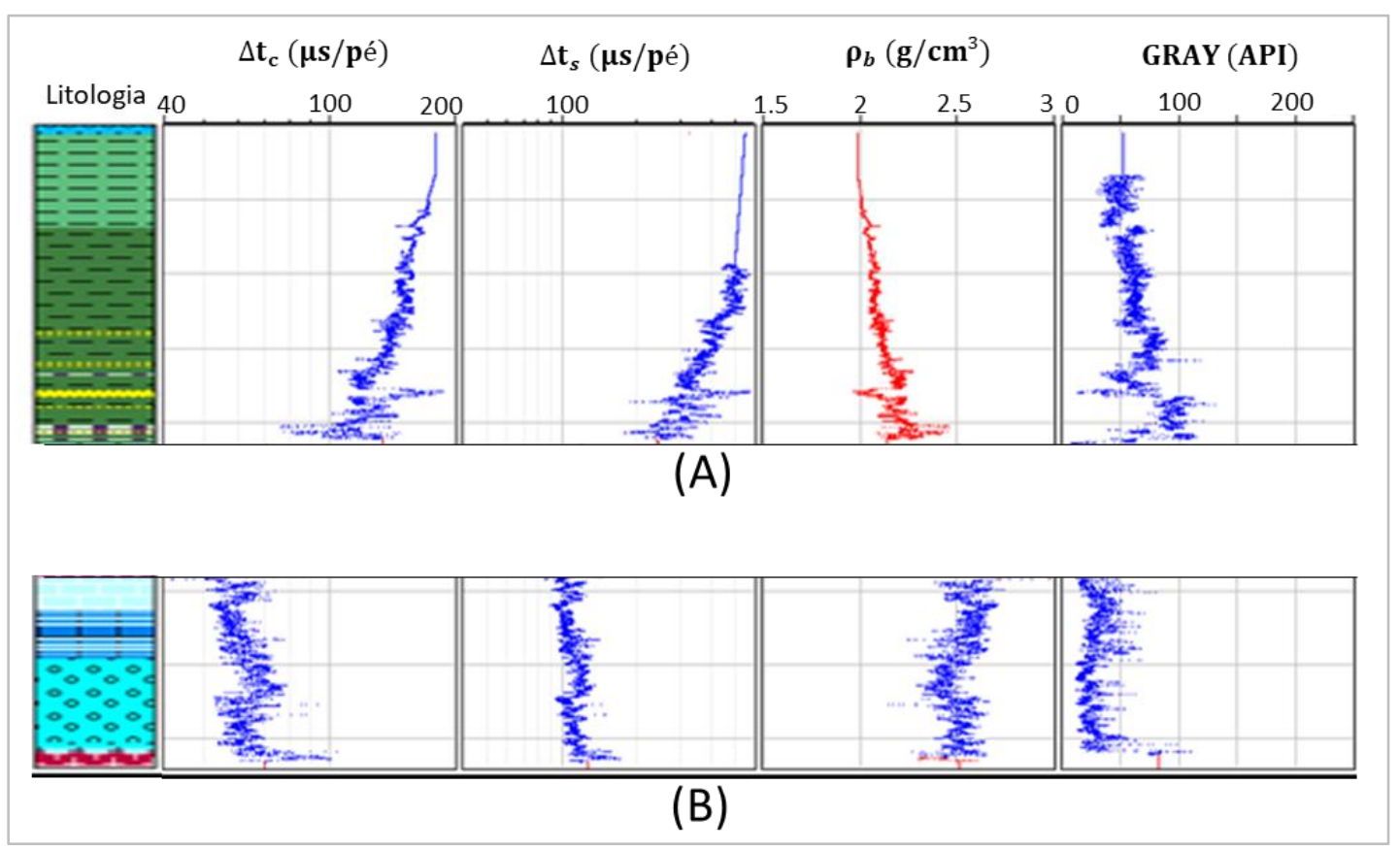

Figura 22 - Perfis iniciais utilizados para a retroanálise do poço de correlação para o estudo de caso. $\Delta t_{c}$ é o tempo de trânsito compressional da onda, $\Delta t_{s}$ é o tempo de trânsito cisalhante, $\rho_{b}$ é a densidade da formação e GRAY é o perfil de raios gama para as camadas (A) pós sal e (B) pré-sal. (SESTC)

A partir dos perfis iniciais apresentados na Figura 22, foram estimadas as propriedades elásticas e mecânicas das formações com base em correlações da literatura apresentadas no item 3.1.1. Os resultados obtidos estão apresentados nas Figura 23 e Figura 24, respectivamente. 


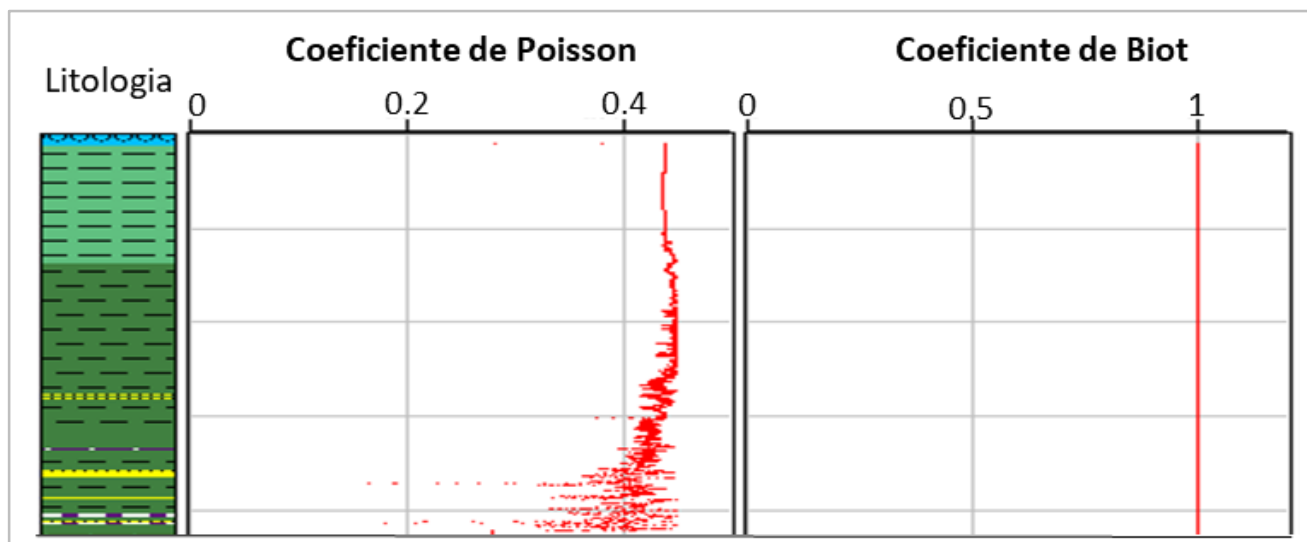

(A)

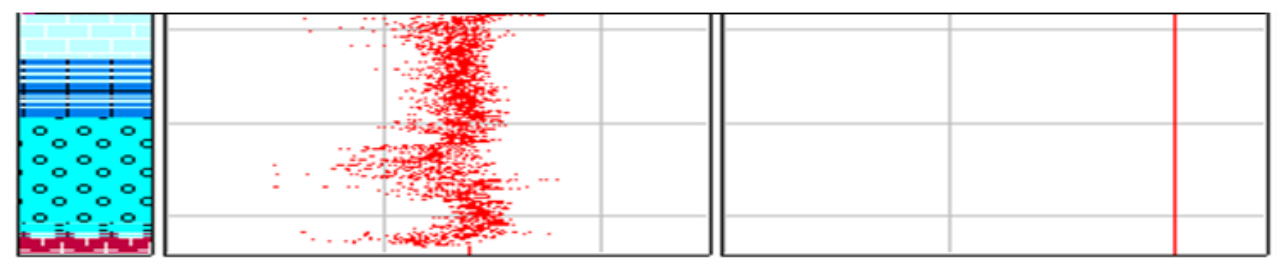

(B)

Figura 23 - Propriedades mecânicas estimadas nas camadas (A) pós sal e (B) pré-sal para o poço de correlação para o estudo de caso. (SESTC)

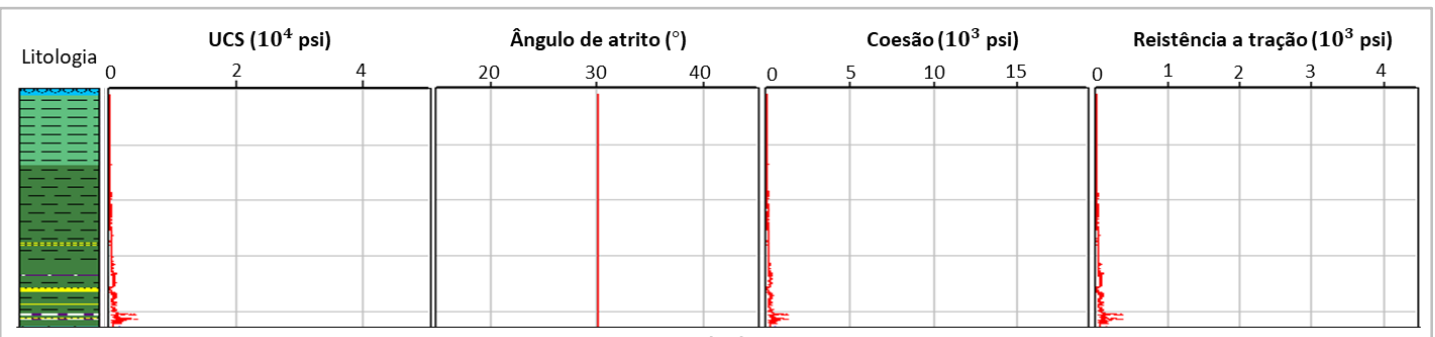

(A)

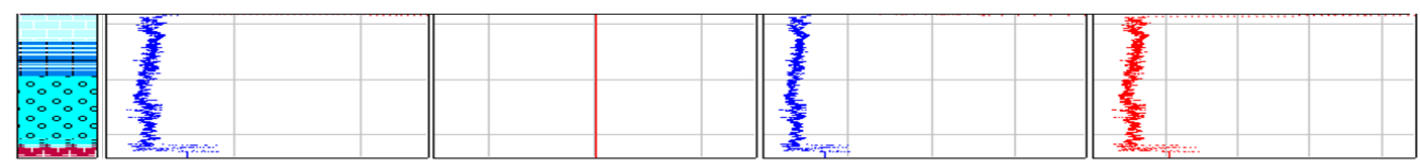

(B)

Figura 24 - Propriedades mecânicas estimadas nas camadas (A) pós sal e (B) pré-sal para o poço de correlação para o estudo de caso. (SESTC) 
Com base nos parâmetros estimados para o poço de correlação, foi possível estimar também a janela operacional com base na metodologia apresentada para cálculo determinístico (tópico 3.1.1).

- A pressão de poros foi estimada a partir da equação 10 proposta por Eaton e calibrada com dados de registro de pressão de poros nas camadas pré-sal.

- A tensão vertical foi calculada a partir da equação 11 e a partir da sua normalização em relação a profundidade, obtém-se o gradiente de sobrecarga.

- A tensão horizontal menor foi estimada a partir das equações 12 e 13 e os coeficientes de normalização encontrados foram:

- Camada pós-sal: $\mathrm{m}=1.1142 \mathrm{psi} / \mathrm{m}$

- Camada pré-sal: $\mathrm{m}=1.006 \mathrm{psi} / \mathrm{m}$

- A tensão horizontal maior foi calculada a partir da equação 14 (tópico 3.1.1) para as camadas pré-sal. Após corrido o perfil de imagem nessa camada, observou-se os dados de breakout apresentados na Figura 25.

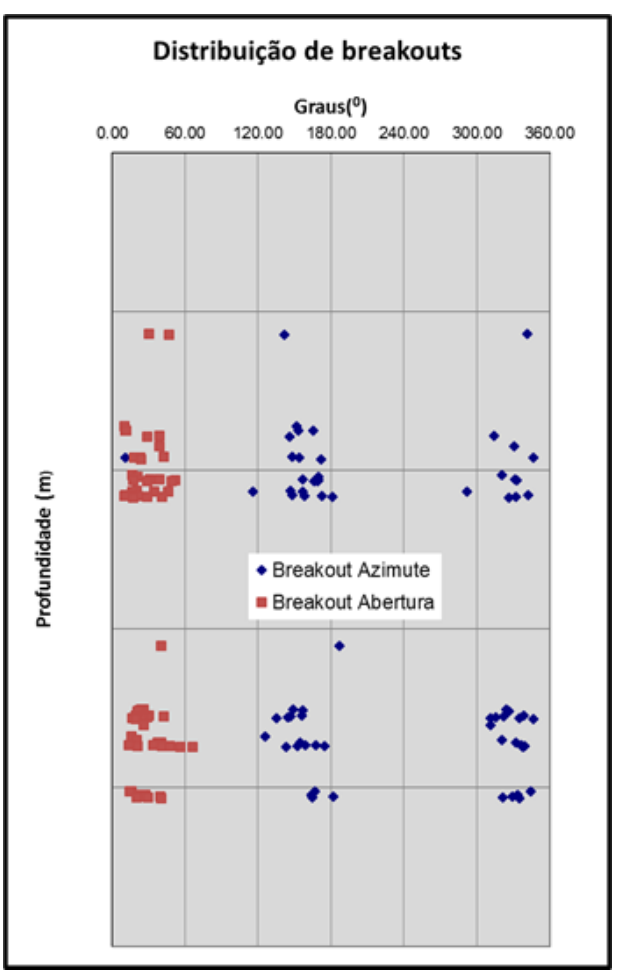

Figura 25 - Dados de breakout observados na camada pré-sal do poço de correlação utilizados para a estimativa da tensão horizontal maior. (GTEP, 2016) 
Nas camadas pós-sal, foi assumido que as tensões horizontais são iguais, ou seja, para esse caso utilizou-se $\sigma_{\mathrm{H}}=\sigma_{\mathrm{h}}$. As tensões horizontais foram estimadas em psi e posteriormente normalizadas com relação a profundidade e convertidas em gradientes (lb/gal).

- Os gradientes de colapsos inferior e superior e de fratura superior foram calculados segundo a metodologia apresentada no tópico 3.1.2.

A Figura 26 apresenta as curvas de gradientes de pressão de poros, sobrecarga, tensão horizontal maior, tensão horizontal menor, colapsos superior e inferior e fratura superior estimadas a partir da retroanálise do poço de correlação, assim como a densidade do fluido de perfuração (dado em lb/gal) e a densidade de equivalente de circulação no fundo do poço (dado em lb/gal).

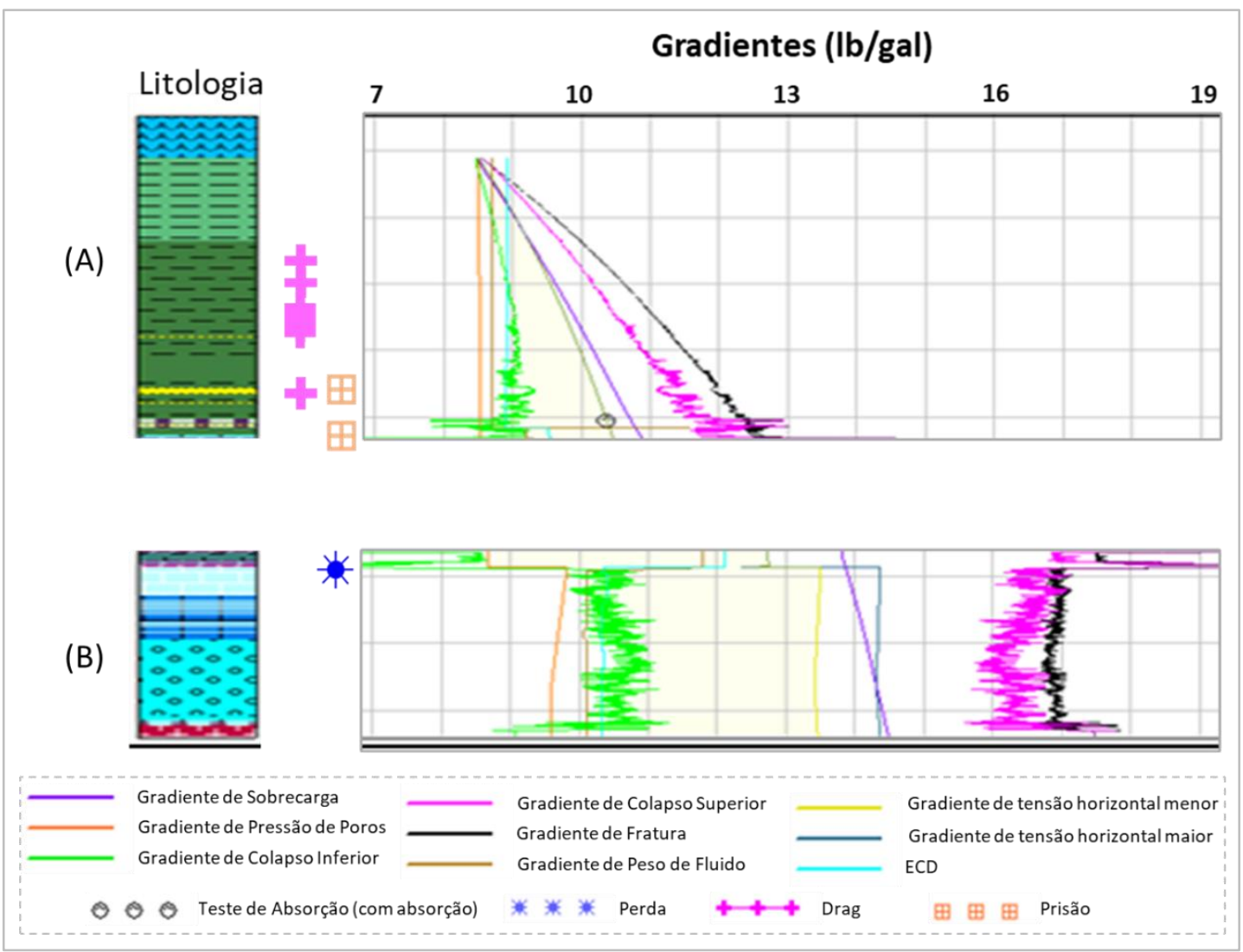

Figura 26 - Janela Operacional obtida a partir da retroanálise do poço de correlação nas camadas (A) pós sal e (B) pré-sal para o estudo de caso. (SEST@) 
Nessa figura também estão apresentadas as informações de resultado de teste de absorção realizado no referido poço e utilizado para a calibração da curva de tensão horizontal menor, assim como eventos que ocorreram durante a perfuração.

Os eventos de perfuração ocorridos (drag e prisão) são indicativos de instabilidade geomecânica da parede do poço. No momento da perfuração do poço, ao serem observados os referidos eventos, conclui-se que a densidade de fluido de perfuração utilizada não foi corretamente dimensionada e está fora da faixa de densidade que garante a estabilidade do poço. Isso pode ser ratificado ao final da aplicação do modelo geomecânico para a estimativas de gradientes em uma retroanálise.

Os perfis iniciais utilizados para a retroanálise deste poço de correlação - nas camadas pós-sal - foram adaptados a partir dos dados obtidos na fase de investigação do poço, o que torna os resultados para as profundidades iniciais menos confiáveis. Ainda assim, é possível verificar a partir da janela operacional estimada (Figura 26) que na fase pós-sal, a densidade de fluido de perfuração é inferior à curva de colapso inferior estimada na maior parte desse trecho, o que indica que a ocorrência de eventos como drag e prisão da coluna ocorreram devido à instabilidade da formação nessas camadas.

Já na camada pré-sal, apesar do colapso inferior estimado estar acima do peso de fluido aplicado durante a perfuração em toda a extensão dessa camada, de acordo com o relatório de análise de estabilidade para este poço, foram observados breakouts somente nas formações iniciais do pré-sal e não houve registro de problemas significativos nestas profundidades. Dessa forma, é possível concluir que pode haver incertezas associadas aos parâmetros de entrada e consequente necessidade de análise probabilística para melhor previsão da janela operacional.

\section{2. Poço de Projeto - Montagem}

Uma vez feita a análise de estabilidade do poço já perfurado, este foi utilizado como correlação para o projeto do Poço PUC, ou seja, o comportamento geomecânico observado nas formações do poço de correlação serão observados 
também no poço a ser perfurado. Dessa forma, os perfis iniciais e litologia utilizados para a modelagem geomecânica do poço de projeto foram adaptados do poço de correlação.

A correlação é feita com base no histórico geológico da formação presente ao longo da trajetória prevista. Dessa forma a litologia prevista, que é obtida a partir do quadro de previsão geológica, é comparada com a litologia interpretada dos poços correlatos a fim de definir as camadas que se correlacionam, como em uma seção geológica estratigráfica entre perfis de sondagem. A partir da definição dos trechos de correlação litológica, são montados também os perfis iniciais.

Para que essa correlação seja feita, podem ser utilizados um ou mais poços de correlação. O procedimento de correlação pode ocasionar o efeito "estica e encolhe". Este efeito é observado quando um trecho de dados do poço de correlação é correlacionado a um trecho mais largo (estica) ou mais fino (encolhe) do poço de projeto. A Figura 27 (A) e (B) apresenta de forma ilustrada o procedimento de correlação entre os dados de litologia e perfis iniciais.

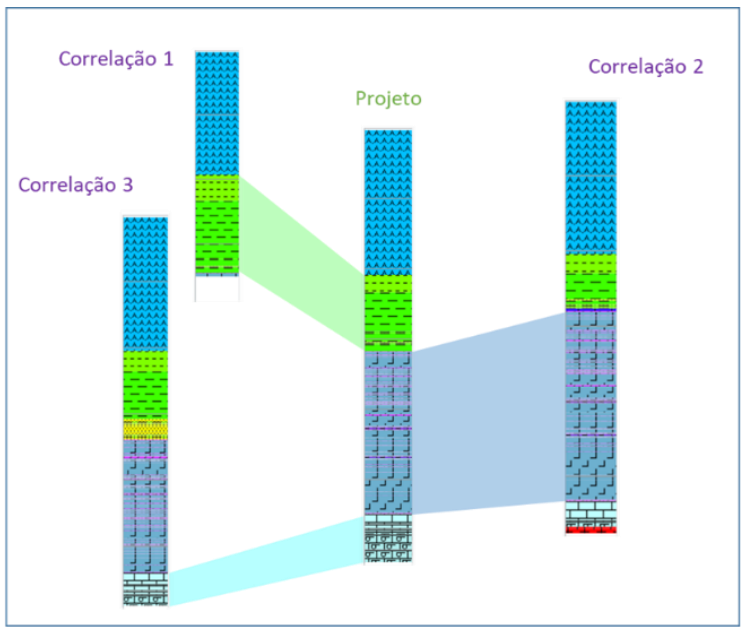

(A)

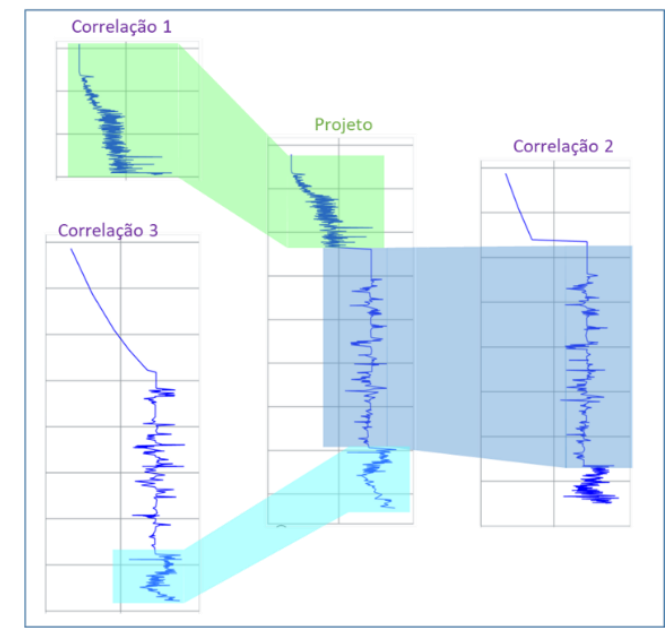

(B)

Figura 27 - Ilustração do processo de correlação entre um poço correlato e um poço de projeto. (A) correlação entre litologias interpretadas de poços de correlação e litologia prevista para o projeto a partir do quadro de previsão geológico; (B) correlação entre os perfis iniciais de poços de correlação para a criação dos perfis adaptados para o projeto. 
Uma vez definidos os trechos de correlação entre os dois poços, os seguintes perfis e litologia são utilizados como base para os cálculos subsequentes (Figura 28):

- Litologia Adaptada

- Tempo de trânsito compressional $\left(\Delta \mathrm{t}_{\mathrm{c}}\right)$

- Densidade da formação $\left(\rho_{\mathrm{b}}\right)$

- Tempo de trânsito cisalhante $\left(\Delta \mathrm{t}_{\mathrm{s}}\right)$

- Raios Gama (GR)

A Figura 28 apresenta os dados de litologia prevista para o projeto a partir do quadro de previsão geológico e a litologia interpretada do poço de correlação (adaptada) utilizadas para a definição dos trechos de correlação e os perfis iniciais adaptados do poço de correlação para o poço de projeto.
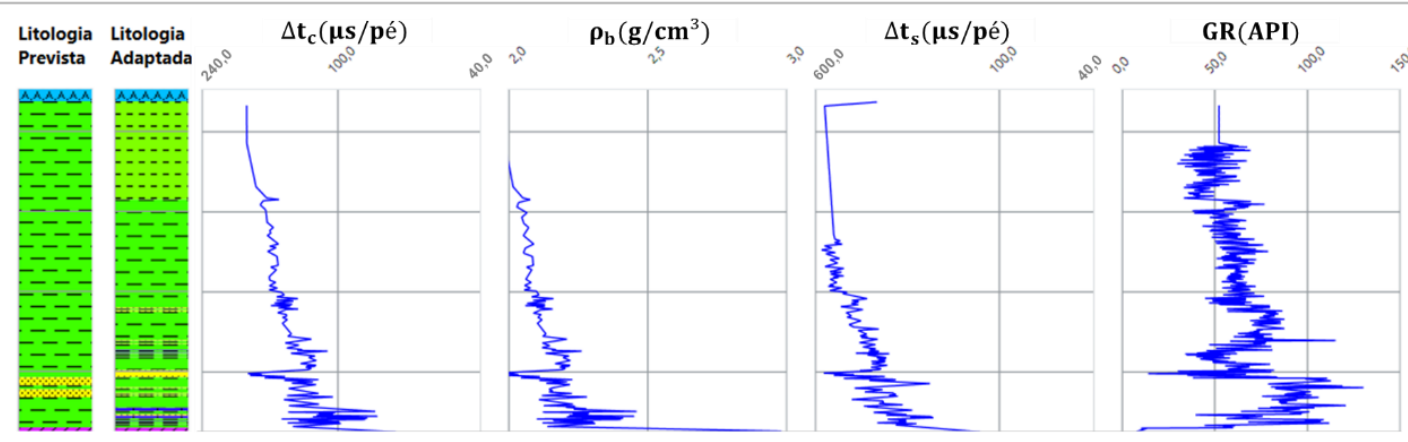

(A)
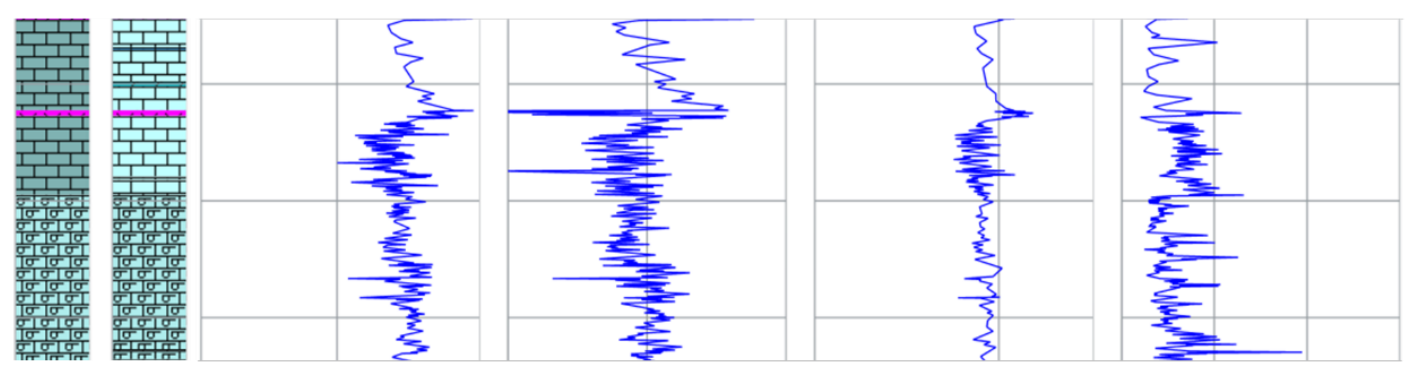

(B)

Figura 28 - Perfis iniciais para o projeto do Poço PUC obtidos nas camadas (A) pós sal e (B) pré-sal a partir do poço de correlação. (SEST TR 2.0@) 
A partir dos perfis iniciais e litologia adaptada, com base na metodologia indicada no item 3.1, é possível fazer o cálculo determinístico da sobrecarga, dos parâmetros elásticos e mecânicos, prever o estado de tensões in situ e pressão de poros e posteriormente, estimar também os valores de gradientes de colapso superior, inferior e fratura superior.

\section{3. \\ Poço Retroanalisado}

Após a perfuração de um poço, com os dados reais deste, faz-se uma retroanálise de estabilidade desse poço. A retroanálise de estabilidade de um poço tem por finalidade a estimativa de vários parâmetros como o estado de tensões, propriedades mecânicas e os gradientes da janela operacional. Durante a retroanálise é verificado o comportamento geomecânico real das formações, com base em perfis iniciais corridos no poço após sua perfuração.

A partir da retroanálise, é possível comparar os resultados baseados em dados reais com aqueles obtidos no projeto e verificar os parâmetros que foram mal calibrados, concluir as causas de eventos ocorridos e, por fim, é possível estabelecer um cenário que seja útil para correlação de perfurações futuras. Uma vez feito o projeto para o poço PUC, este foi perfurado e posteriormente, sua retroanálise de estabilidade foi feita. A Figura 29 apresenta os perfis iniciais corridos no poço PUC. 


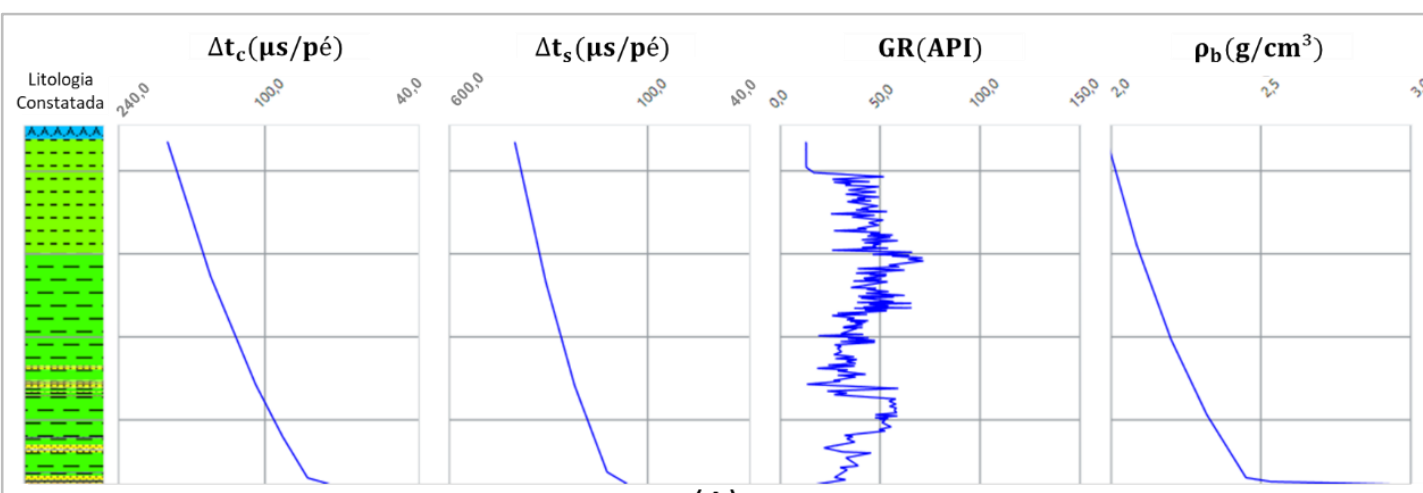

(A)

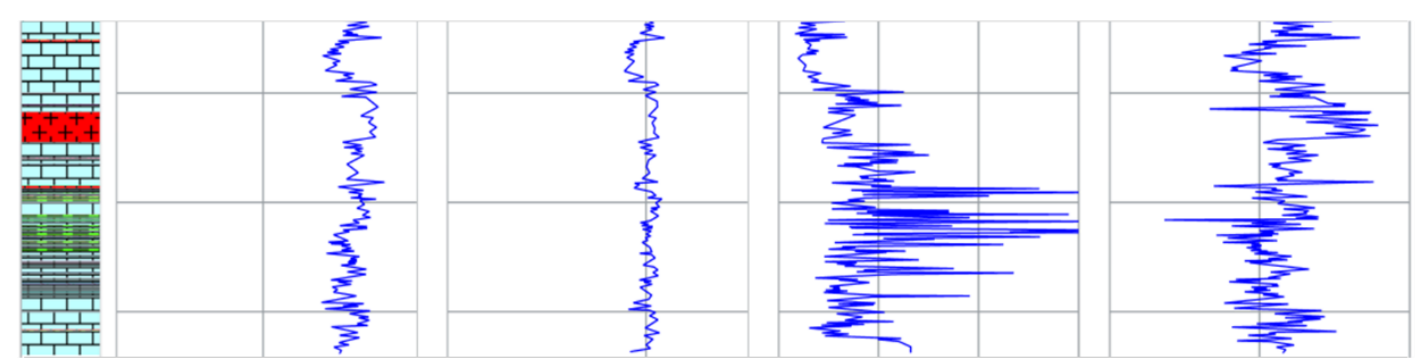

(B)

Figura 29 - Perfis iniciais corridos nas camadas (A) pós sal e (B) pré-sal do Poço PUC.

(SEST TR 2.0C)

Por falta de dados, os perfis de tempo de trânsito compressional $\left(\Delta \mathrm{t}_{\mathrm{c}}\right)$, tempo de trânsito cisalhante $\left(\Delta t_{s}\right)$ e densidade da formação $\left(\rho_{b}\right)$ foram estimados na camada pós-sal. Essa estimativa foi feita a partir de um ajuste de regressão potencial. A partir dos perfis iniciais, foi possível calcular os parâmetros elásticos (Figura 30) e propriedades mecânicas (Figura 31). 


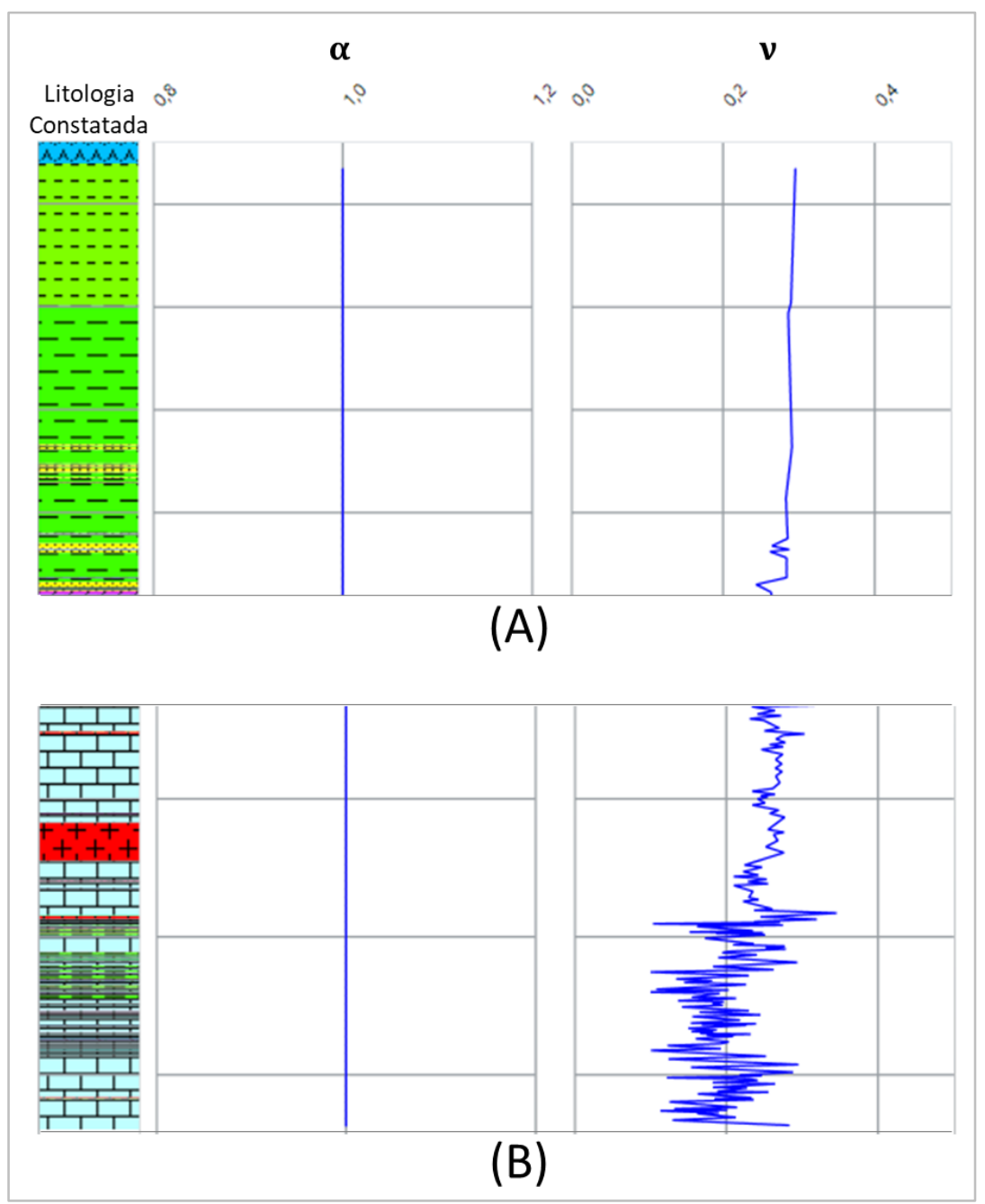

Figura 30 - Estimativa dos parâmetros elásticos durante a retroanálise do Poço PUC, nas camadas (A) pós sal e (B) pré-sal. (SEST TR 2.0@) 


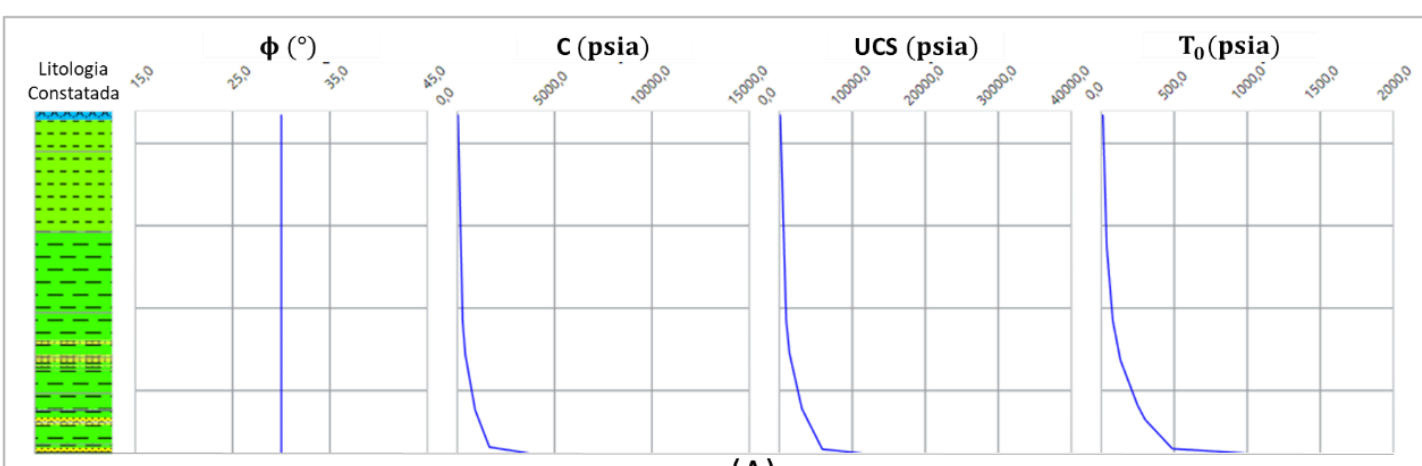

(A)

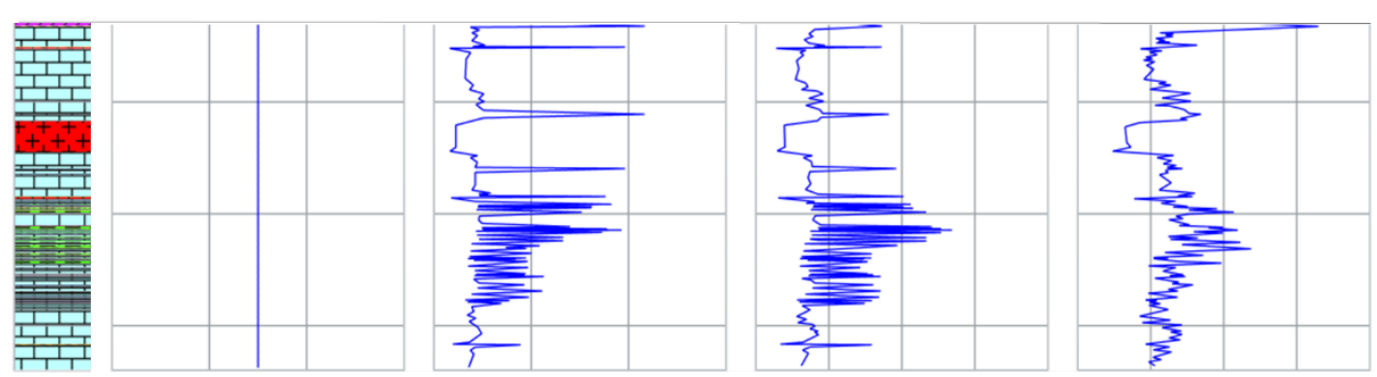

(B)

Figura 31 - Estimativa das propriedades mecânicas durante a retroanálise do Poço PUC, nas camadas (A) pós sal e (B) pré-sal. (SEST TR 2.0@)

A partir do cenário de propriedades elásticas e mecânicas estimadas com base em perfis iniciais reais do Poço PUC, foi possível estimar o gradiente de pressão de poros e estado de tensões in situ:

- A pressão de poros foi estimada a partir da equação 10 proposta por Eaton e calibrada com dados de registro de pressão de poros nas camadas pré-sal. A partir da sua normalização em relação a profundidade, obtém-se o gradiente de pressão de poros.

- A tensão vertical foi calculada a partir da equação 11 e a partir da sua normalização em relação a profundidade, obtém-se o gradiente de sobrecarga.

- A tensão horizontal menor foi estimada a partir da equação 14 para as camadas pré-sal a partir de um dado de LOT. O valor encontrado para $\mathrm{K}_{0}$ foi de 0.47 e esse valor foi utilizado para a estimativa da tensão horizontal menor em toda a camada pré-sal. Já na camada pós-sal, devido a ausência de dados para a calibração da curva, optou-se por manter a curva de projeto. 
- A tensão horizontal maior foi estimada, nas camadas de pré-sal, a partir da equação 15 para as profundidades onde observou-se a ocorrência de breakouts. Posteriormente, verificou-se a curva que melhor se ajusta a esses resultados e observou-se para esse trecho a relação $\sigma_{\mathrm{h}}^{\prime}=0.52 * \sigma_{\mathrm{H}}^{\prime}$. Onde $\sigma_{\mathrm{H}}$ é a tensão horizontal maior efetiva e $\sigma_{\mathrm{h}}$ é a tensão horizontal menor efetiva. Para as camadas pós-sal, assumiu-se $\sigma_{\mathrm{H}}^{\prime}=\sigma_{\mathrm{h}}^{\prime}$

A Figura 32 mostra as curvas de gradientes obtidas na retroanálise de estabilidade do Poço PUC, assim como os eventos observados ao longo de sua perfuração. Com base nessa figura observa-se que nas camadas pós-sal ocorreram eventos de perfuração como drag, perda e prisão. Como os perfis iniciais nesses trechos não foram corridos, mas sim estimados, não é possível concluir se esses eventos ocorreram devido ao mau dimensionamento do fluido de perfuração.

Nas camadas de pré-sal, entretanto, foi possível estimar os gradientes a partir de dados originais do poço perfurado. Nesses trechos, observa-se também a ocorrência de vários eventos de perfuração. Como a densidade do fluido de perfuração utilizado nessas camadas do poço possui valor inferior ou igual ao colapso inferior, constatou-se no relatório de retroanálise, que as perdas observadas foram ocasionadas por fraturas já abertas ou semi-abertas. 


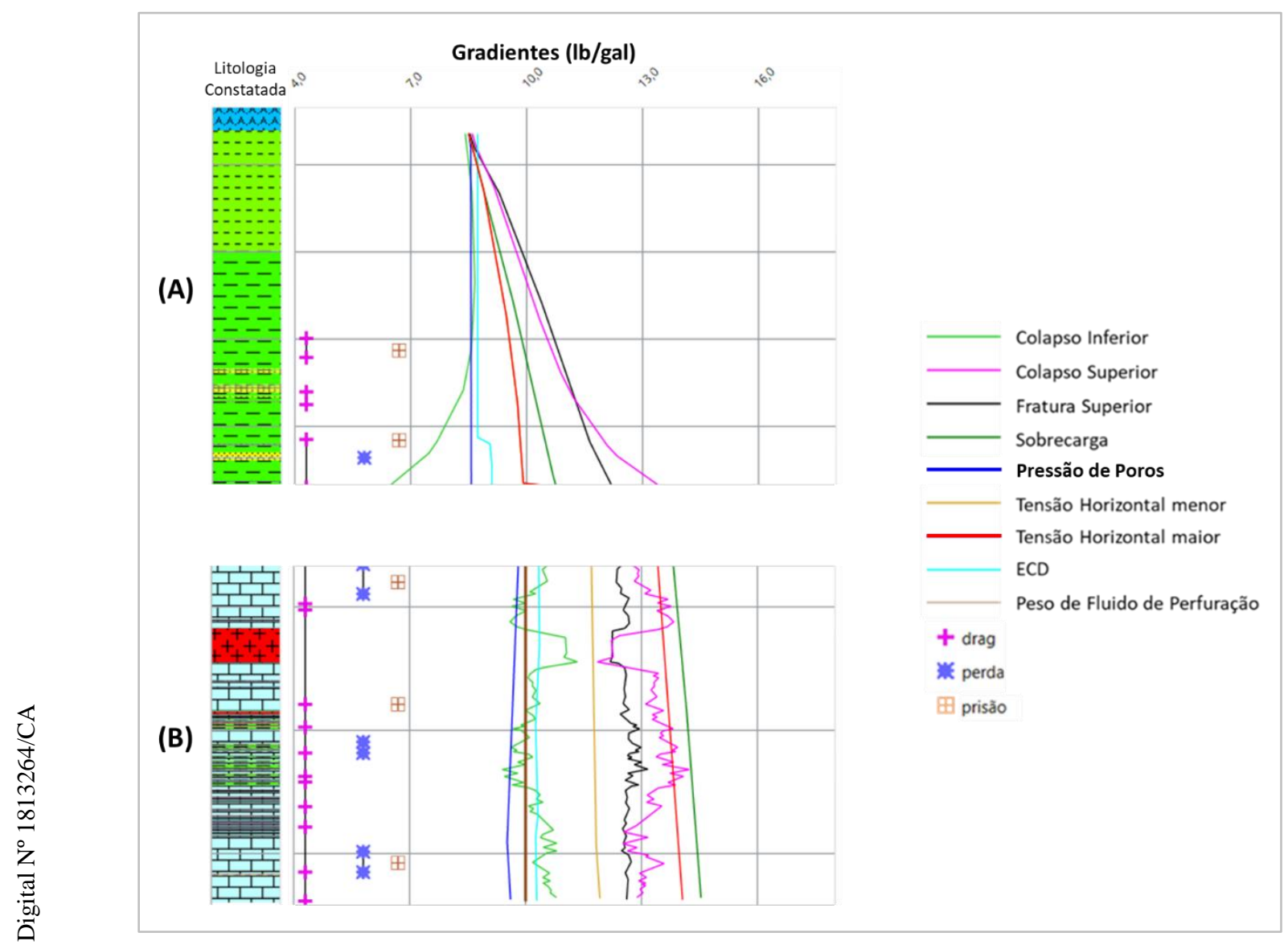

Figura 32 - Janela operacional estimada nas camadas (A) pós sal e (B) pré-sal a partir da retroanálise do Poço PUC. (SEST TR 2.0@) 
5. Resultados e Discussões

\section{1.} Análise Determinística de Estabilidade de Poços para o Projeto

A análise determinística de estabilidade utilizou a integração de três fatores principais a fim de estimar os gradientes de fratura e colapsos: estimativa do estado de tensões e geopressões, das propriedades mecânicas e adoção de um critério de ruptura.

A partir da metodologia apresentada no tópico 3.1, foram obtidos os resultados para a propriedades elásticas - coeficiente de Biot $(\alpha)$ e coeficiente de Poisson $(v)$ como mostrado na Figura 33:

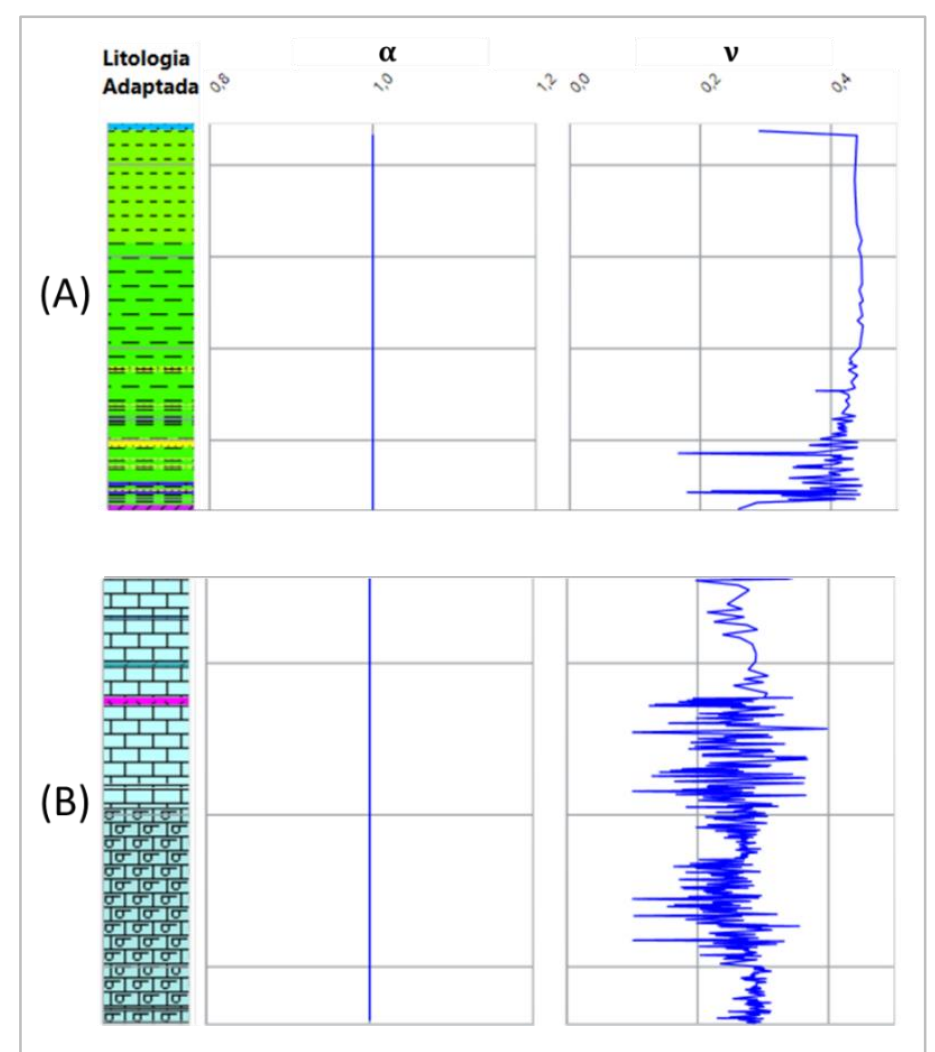

Figura 33 - Propriedades elásticas estimadas deterministicamente nas camadas $(A)$ pós sal e (B) pré-sal. (SEST TR 2.0@) 
Uma vez estimadas as propriedades elásticas, foi possível avaliar as propriedades mecânicas - ângulo de atrito interno $(\phi)$, coesão $(C)$, resistência à compressão simples (UCS) e resistência à tração $\left(T_{0}\right)$ :

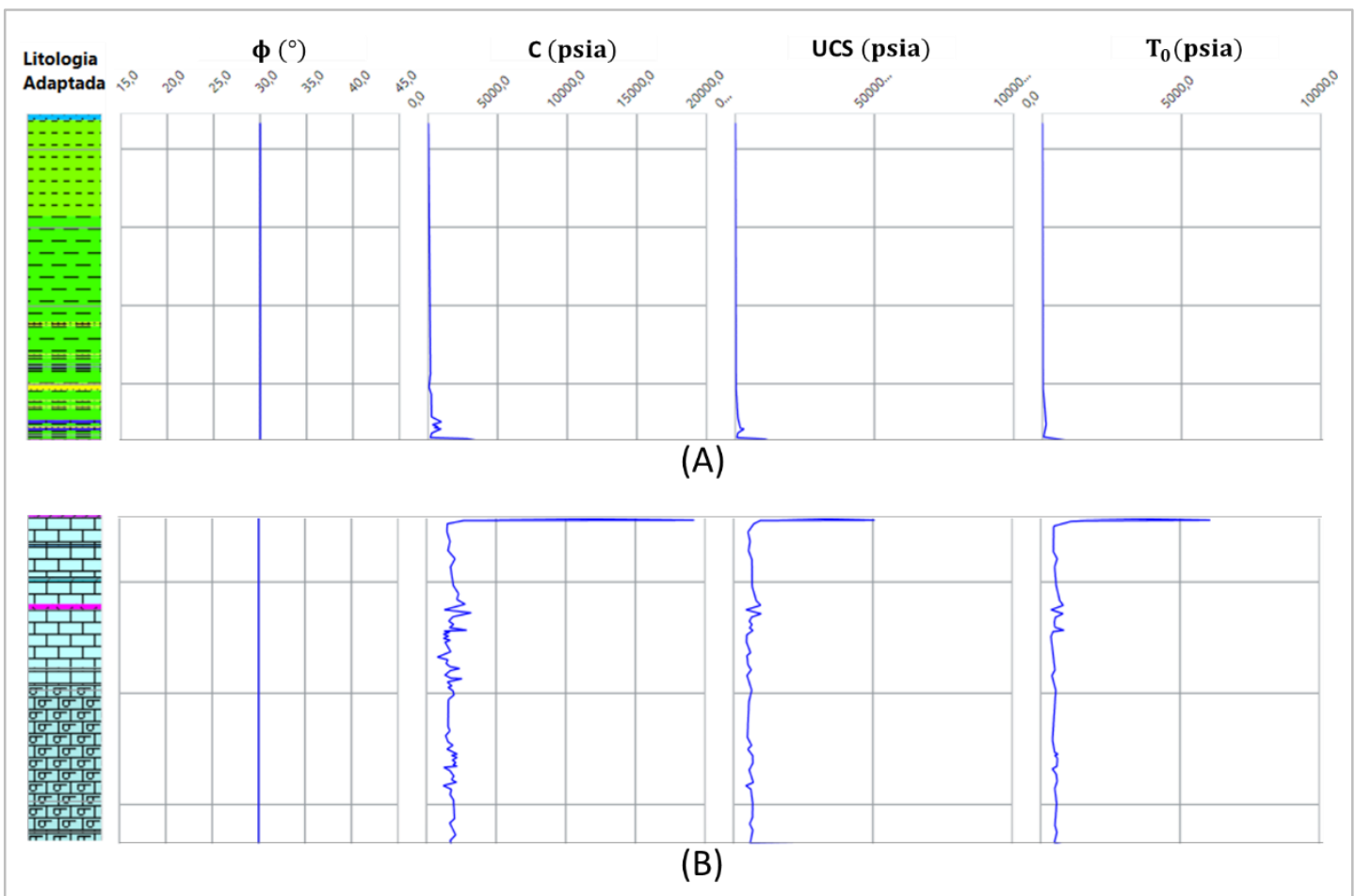

Figura 34 - Propriedade mecânicas estimadas deterministicamente nas camadas (A) pós sal e (B) pré-sal. (SEST TR 2.0 (C)

As tensões in situ foram estimadas com base na localização do poço de estudo e no poço de correlação utilizado. Para a modelagem geomecânica do projeto de poço, estimou-se o seguinte regime de tensões:

\section{Formações pré-sal}

$\sigma_{\mathrm{h}}^{\prime}=0.70 * \sigma_{\mathrm{v}}^{\prime}$

$\sigma_{\mathrm{H}}^{\prime}=1.13 * \sigma_{\mathrm{h}}^{\prime}$

\section{Formações pós-sal}

$\sigma_{\mathrm{h}}^{\prime}=0.65 * \sigma_{\mathrm{v}}^{\prime}$ 
$\sigma_{\mathrm{H}}^{\prime}=0.95 * \sigma_{\mathrm{v}}^{\prime}$

Onde $\sigma_{\mathrm{h}}^{\prime}$ é a tensão horizontal menor efetiva em psi, $\sigma_{\mathrm{H}}^{\prime}$ é a tensão horizontal maior efetiva em psi e $\sigma_{\mathrm{v}}^{\prime}$ é a tensão vertical efetiva em psi.

\section{Azimute da tensão Horizontal menor $\left(\operatorname{Az}\left(\sigma_{h}\right)\right)$}

Com base no relatório de interpretação do perfil imagem feito a partir do poço de correlação utilizado para o projeto, concluiu-se que a direção da tensão horizontal menor é N26W. Entretanto, este dado não apresenta relevância para este estudo, uma vez que o poço estudado é vertical.

A pressão de poros foi estimada como indicado a partir da metodologia de Eaton, equação 10, (item 3.1.1) para rochas argilosas. Nas camadas pré-sal, foi feita uma calibração com base nos registros de pressão de poros do poço de correlação. O comportamento observado para estes parâmetros - tensão vertical $\left(\sigma_{\mathrm{v}}\right)$, tensão horizontal menor $\left(\sigma_{\mathrm{h}}\right)$, tensão horizontal maior $\left(\sigma_{\mathrm{H}}\right)$ e pressão de poros $\left(\mathrm{P}_{\mathrm{P}}\right)$ - está apresentado na Figura 35.

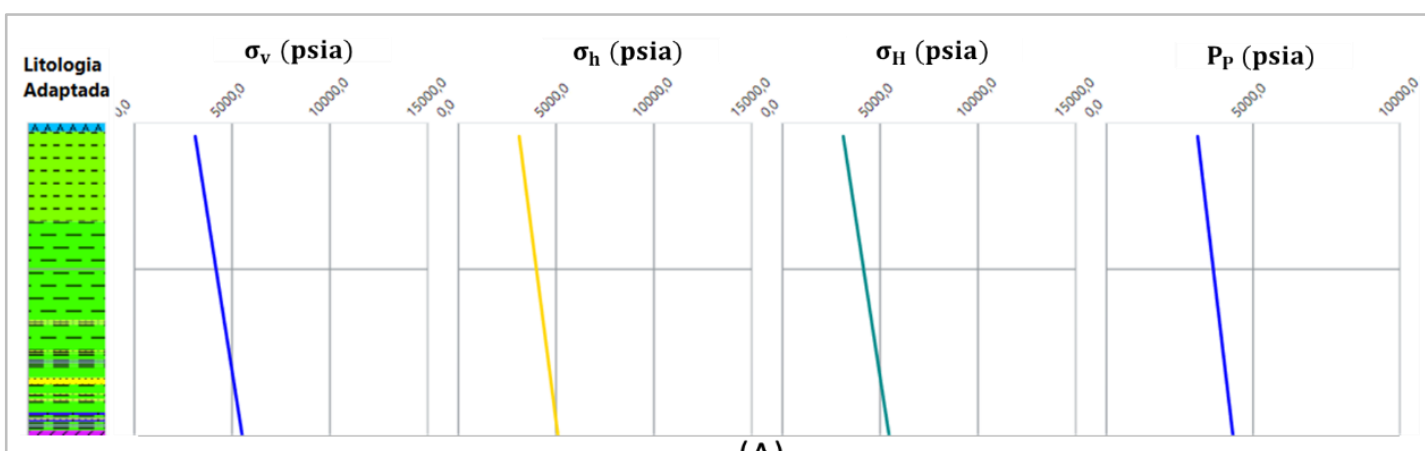

(A)

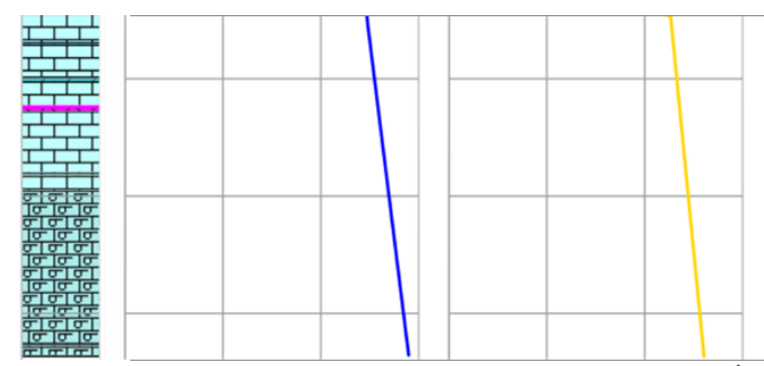

(B)

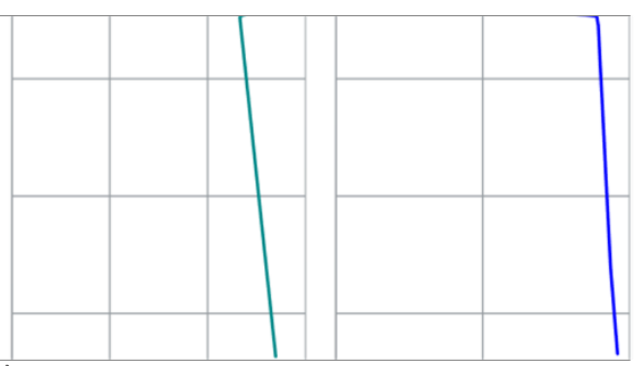

Figura 35 - Estado de tensões estimado deterministicamente nas camadas (A) pós sal e (B) pré-sal. (SEST TR 2.0 (C) 
Por fim, é possível estimar a janela operacional. O critério de ruptura proposto por Mohr-Coulomb foi adotado para a estimativa dos gradientes de colapso e a partir da equação de Kirsch (1898) para obtenção das tensões ao redor do poço associada a definição de ruptura por tração (item 3.1.2), foi possível estimar o gradiente de fratura. Os resultados obtidos para esses gradientes podem ser vistos na Figura 36.

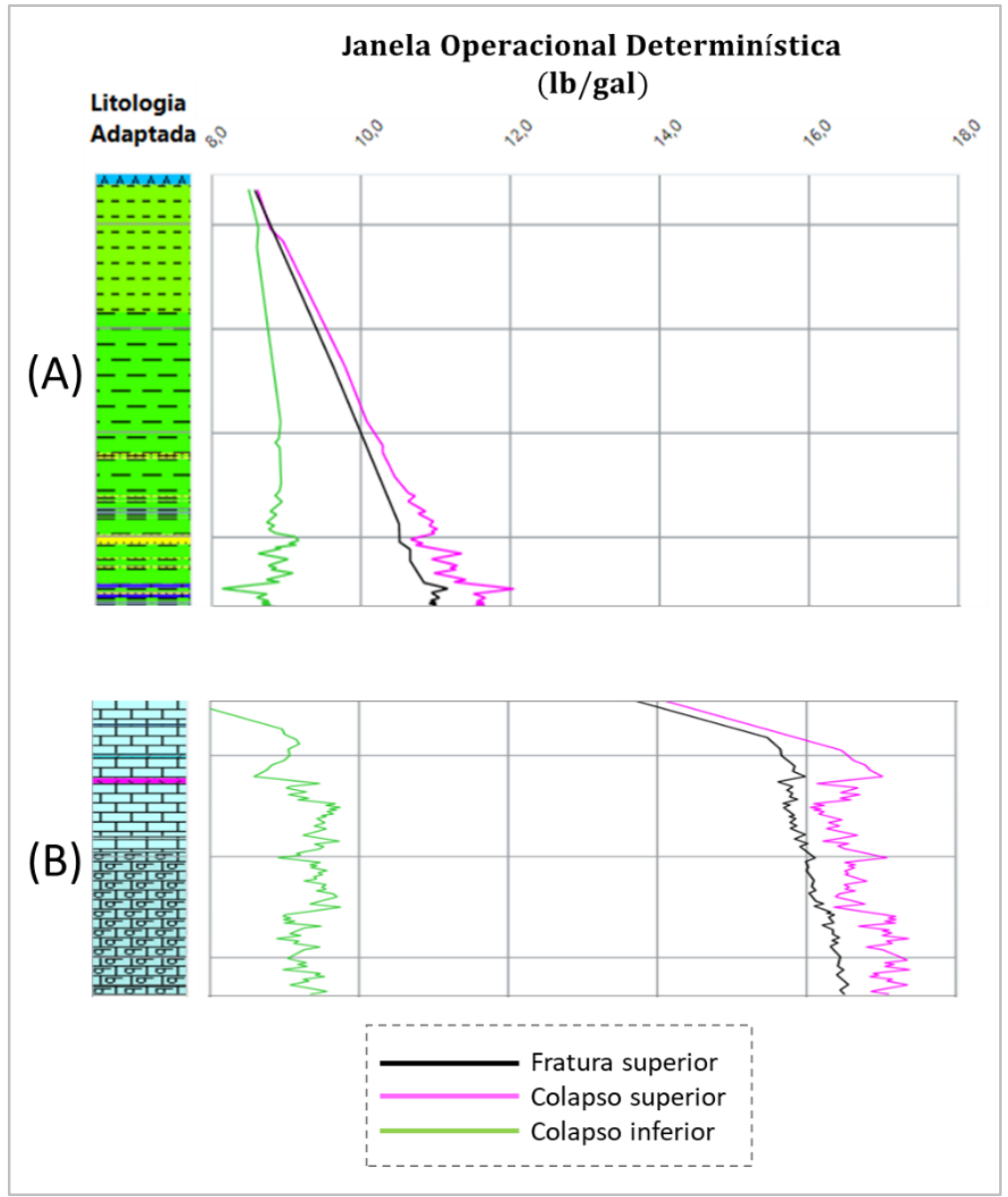

Figura 36 - Gradientes de fratura superior e colapsos superior e inferior estimados deterministicamente nas camadas (A) pós sal e (B) pré-sal. (SEST TR 2.0 (C) 


\section{2. Análise Estatística dos Parâmetros de Entrada}

A análise estatística dos parâmetros de entrada foi necessária para definir as entradas para as metodologias probabilísticas. Posto que o principal foco dessa pesquisa é a aplicação dos métodos probabilísticos para a análise de estabilidade de poços, partiu-se das seguintes hipóteses simplificadoras:

- Todos os parâmetros de entrada apresentam o mesmo perfil de distribuição estatística;

- Para esta pesquisa, foram adotados dois tipos de distribuição estatística de dados: normal e uniforme. Dessa forma, serão apresentados dois resultados de análise probabilística: quando todos os parâmetros de entrada possuem distribuição normal e posteriormente, para o cenário em que todos os parâmetros de entrada possuem distribuição uniforme;

- A variação positiva e negativa imposta aos parâmetros de entrada adotada para a distribuição normal foi de um desvio padrão $( \pm 10 \%$ do valor médio do parâmetro), o que abrange aproximadamente 68.26\% da amostragem da distribuição. A variação para os parâmetros de entrada associados a distribuição uniforme que equivale a mesma porcentagem de amostragem é de $\pm 11.8 \%$ do valor médio do parâmetro;

- Algumas medidas foram adotadas para evitar resultados inconsistentes. Dado que os métodos probabilísticos consistem em resultados baseados na variação positiva e negativa dos parâmetros iniciais, os seguintes limites foram impostos:

- Tensão horizontal menor é sempre menor ou igual a tensão horizontal maior;

○ Coeficiente de Biot não ultrapassa o valor 1;

- $\quad$ Coeficiente de Poisson não ultrapassa o valor 0.5 .

- Para que os dois cenários de distribuição apresentassem a mesma porcentagem amostral assumiu-se: 
- Desvio padrão de $10 \%$ do valor médio dos parâmetros de entrada (obtido deterministicamente) para a distribuição normal;

- Parâmetro a e b iguais a aproximadamente 0.83 e 1.17 do valor médio dos parâmetros de entrada (obtido deterministicamente) para a distribuição uniforme.

\section{3.}

\section{Análise Probabilística de Estabilidade de Poços para o Projeto}

A estimativas probabilísticas dos gradientes de fratura superior e colapsos superior e inferior foram feitas a partir dos métodos FOSM e SEAM, como detalhado nos itens 3.3.1 e 3.3.2 respectivamente.

Para a aplicação dessas metodologias, foi necessária a integração entre dois softwares. Inicialmente, as estimativas determinísticas e os resultados para incrementos positivos $\left(\mathrm{P}_{i}^{+}\right.$e $\mathrm{FS}_{\mathrm{i}}^{+}$dos métodos SEAM e FOSM respectivamente) e negativos $\left(\mathrm{P}_{\mathrm{i}}^{-} e \mathrm{FS}_{\mathrm{i}}^{-}\right.$dos métodos SEAM e FOSM respectivamente) de cada parâmetro individual foi feito no Sistema de Estabilidade em Tempo Real (SEST TR 2.0() e posteriormente, os resultados foram utilizados em um código desenvolvido nesse trabalho na plataforma MATLAB@ (apêndice A) para a aplicação das metodologias probabilísticas.

O código implementado em MATLABC foi validado comparando-se os resultados obtidos a partir dele com os resultados apresentados no artigo utilizado como referência para esta dissertação, Fontoura et al. (2002). Essa validação está detalhada no tópico seguinte (5.3.1). Após a validação do código, este será aplicado em um estudo de caso no qual será feita a análise ao longo de toda a trajetória do poço. Os resultados obtidos para os dois métodos para o estudo de caso serão apresentados e comparados no tópico 5.3.2. 


\subsection{1. \\ Validação dos Métodos Probabilísticas Implementadas no MATLABC}

Para a aplicação das metodologias probabilísticas ao longo de toda a extensão de um poço, foi implementado um código desenvolvido em MATLABC. A validação das metodologias implementadas foi feita com base nos resultados obtidos no estudo de Fontoura et al. (2002) - artigo utilizado como base para este trabalho.

No referido artigo, os autores fazem a análise de estabilidade probabilística a partir dos métodos FOSM e SEAM para uma profundidade específica. Para esta profundidade, são analisados os resultados para 9 probabilidades de falha diferentes para os gradientes de fratura e colapso superiores e 7 probabilidades de falha diferentes para o gradiente de colapso inferior. A magnitude dos parâmetros de entrada utilizados está apresentada na Tabela 3.

Tabela 3 - Valores médios dos parâmetros de entrada utilizados no estudo de Fontoura et al. para a aplicação dos métodos probabilísticos. (Modificado de Fontoura et al., 2002)

\begin{tabular}{|l|c|c|}
\hline \multicolumn{1}{|c|}{ Parâmetro } & $\begin{array}{c}\text { Valor } \\
\text { médio }\end{array}$ & $\begin{array}{c}\text { Desvio } \\
\text { padrão }\end{array}$ \\
\hline Profundidade vertical (m) & 2000.0 & - \\
\hline Inclinação $\left(^{\circ}\right.$ ) & 0.0 & - \\
\hline Azimute $\left(^{\circ}\right.$ ) & 0.0 & - \\
\hline Azimute de Sh ( ${ }^{\circ}$ ) & 90.0 & 9.0 \\
\hline Tensão vertical (MPa) & 50.0 & 5.0 \\
\hline Tensão horizontal maior (MPa) & 40.0 & 4.0 \\
\hline Tensão horizontal menor (MPa) & 35.2 & 3.52 \\
\hline Pressão de poros (MPa) & 20.0 & 2.0 \\
\hline Coeficiente de Biot & 0.8 & 0.08 \\
\hline Coeficiente de Poisson & 0.2 & 0.02 \\
\hline Ângulo de atrito ( ${ }^{\circ}$ ) & 25.0 & 2.5 \\
\hline Resistência a tração (MPa) & 3.0 & 0.3 \\
\hline Coesão (MPa) & 15.9 & 1.59 \\
\hline
\end{tabular}


O código desenvolvido em MATLAB@ para este trabalho foi aplicado para o cenário apresentados na Tabela 3 e os gradientes de fratura e colapso obtidos foram comparados com aqueles apresentado por Fontoura et al. (2002), conforme apresentado nas Tabela 4, Tabela 5 e Tabela 6.

Tabela 4 - Comparação entre os resultados obtidos em Fontoura et al. (2002) e o código desenvolvido para esta dissertação a partir da aplicação dos métodos FOSM e SEAM para a estimativa do gradiente de fratura.

\section{Gradiente de Fratura Superior}

\begin{tabular}{|c|c|c|c|}
\hline \multicolumn{4}{|c|}{ Resultados obtidos Para método FOSM } \\
\hline Prob. Falha & $\begin{array}{c}\text { Fontoura et } \\
\text { al. (2002) } \\
\text { (MPa) }\end{array}$ & $\begin{array}{c}\text { Código } \\
\text { desenvolvido } \\
\text { (MPa) }\end{array}$ & $\begin{array}{c}\text { Diferença } \\
\text { associada }\end{array}$ \\
\hline $\mathbf{7 3 . 9 6 \%}$ & 60 & 59.99 & $0 \%$ \\
\hline $\mathbf{5 8 . 2 5 \%}$ & 55 & 55.00 & $0 \%$ \\
\hline $\mathbf{5 1 . 3 8 \%}$ & 53 & 53.00 & $0 \%$ \\
\hline $\mathbf{5 0 . 0 0 \%}$ & 52.6 & 52.60 & $0 \%$ \\
\hline $\mathbf{3 1 . 3 5 \%}$ & 47 & 47.00 & $0 \%$ \\
\hline $\mathbf{2 5 . 4 8 \%}$ & 45 & 45.00 & $0 \%$ \\
\hline $\mathbf{2 0 . 2 4 \%}$ & 43 & 43.00 & $0 \%$ \\
\hline $\mathbf{1 7 . 8 8 \%}$ & 42 & 42.00 & $0 \%$ \\
\hline $\mathbf{1 3 . 7 1 \%}$ & 40 & 40.00 & $0 \%$ \\
\hline
\end{tabular}

\begin{tabular}{|c|c|c|c|}
\hline \multicolumn{4}{|c|}{ Resultados obtidos Para método SEAM } \\
\hline Prob. Falha & $\begin{array}{c}\text { Fontoura et } \\
\text { al. (2002) } \\
\text { (MPa) }\end{array}$ & $\begin{array}{c}\text { Código } \\
\text { desenvolvido } \\
\text { (MPa) }\end{array}$ & $\begin{array}{c}\text { Diferença } \\
\text { associada }\end{array}$ \\
\hline $75.15 \%$ & 60 & 60.42 & $1 \%$ \\
\hline $58.71 \%$ & 55 & 55.13 & $0 \%$ \\
\hline $51.60 \%$ & 53 & 53.06 & $0 \%$ \\
\hline $50.00 \%$ & 52.6 & 52.60 & $0 \%$ \\
\hline $30.50 \%$ & 47 & 46.72 & $1 \%$ \\
\hline $24.20 \%$ & 45 & 44.53 & $1 \%$ \\
\hline $18.94 \%$ & 43 & 42.46 & $1 \%$ \\
\hline $16.60 \%$ & 42 & 41.42 & $1 \%$ \\
\hline $12.51 \%$ & 40 & 39.35 & $2 \%$ \\
\hline
\end{tabular}

Tabela 5 - Comparação entre os resultados obtidos em Fontoura et al. (2002) e o código desenvolvido para esta dissertação a partir da aplicação dos métodos FOSM e SEAM para a estimativa do gradiente de colapso superior.

\begin{tabular}{|c|c|c|c|c|c|c|c|}
\hline \multicolumn{8}{|c|}{ Gradiente Colapso Superior } \\
\hline \multicolumn{4}{|c|}{ Resultados obtidos Para método FOSM } & \multicolumn{4}{|c|}{ Resultados obtidos Para método SEAM } \\
\hline Prob. Falha & $\begin{array}{l}\text { Fontoura et } \\
\text { al. (2002) } \\
\text { (MPa) }\end{array}$ & $\begin{array}{c}\text { Código } \\
\text { desenvolvido } \\
\text { (MPa) }\end{array}$ & $\begin{array}{l}\text { Diferença } \\
\text { associada }\end{array}$ & Prob. Falha & $\begin{array}{l}\text { Fontoura et } \\
\text { al. (2002) } \\
\text { (MPa) }\end{array}$ & $\begin{array}{c}\text { Código } \\
\text { desenvolvido } \\
\text { (MPa) }\end{array}$ & $\begin{array}{l}\text { Diferença } \\
\text { associada }\end{array}$ \\
\hline $73.96 \%$ & 60 & 59.99 & $0 \%$ & $75.15 \%$ & 60 & 60.01 & $0 \%$ \\
\hline $58.25 \%$ & 55 & 55.00 & $0 \%$ & $58.71 \%$ & 55 & 55.00 & $0 \%$ \\
\hline $51.38 \%$ & 53 & 53.00 & $0 \%$ & $51.60 \%$ & 53 & 53.03 & $0 \%$ \\
\hline $50.00 \%$ & 52.6 & 52.60 & $0 \%$ & $50.00 \%$ & 52.6 & 52.60 & $0 \%$ \\
\hline $31.35 \%$ & 47 & 47.00 & $0 \%$ & $30.50 \%$ & 47 & 47.03 & $0 \%$ \\
\hline $25.48 \%$ & 45 & 45.00 & $0 \%$ & $24.20 \%$ & 45 & 44.96 & $0 \%$ \\
\hline $20.24 \%$ & 43 & 43.00 & $0 \%$ & $18.94 \%$ & 43 & 42.99 & $0 \%$ \\
\hline $17.88 \%$ & 42 & 42.00 & $0 \%$ & $16.60 \%$ & 42 & 42.01 & $0 \%$ \\
\hline $13.71 \%$ & 40 & 40.00 & $0 \%$ & $12.51 \%$ & 40 & 40.05 & $0 \%$ \\
\hline
\end{tabular}


Tabela 6 - Comparação entre os resultados obtidos em Fontoura et al. (2002) e o código desenvolvido para esta dissertação a partir da aplicação dos métodos FOSM e SEAM para a estimativa do gradiente de colapso inferior.

\section{Gradiente Colapso Inferior}

\begin{tabular}{|c|c|c|c|}
\hline \multicolumn{4}{|c|}{ Resultados obtidos Para método FOSM } \\
\hline Prob. Falha & $\begin{array}{c}\text { Fontoura et } \\
\text { al. (2002) } \\
\text { (MPa) }\end{array}$ & $\begin{array}{c}\text { Código } \\
\text { desenvolvido } \\
\text { (MPa) }\end{array}$ & $\begin{array}{c}\text { Diferença } \\
\text { associada }\end{array}$ \\
\hline $\mathbf{8 1 . 8 9 \%}$ & 14 & 13.84 & $1 \%$ \\
\hline $\mathbf{7 0 . 7 9 \%}$ & 15 & 14.90 & $1 \%$ \\
\hline $\mathbf{5 9 . 0 5 \%}$ & 16 & 15.96 & $0 \%$ \\
\hline $\mathbf{5 0 . 0 0 \%}$ & 16.8 & 16.83 & $0 \%$ \\
\hline $\mathbf{2 3 . 3 9 \%}$ & 20 & 20.35 & $\mathbf{2} \%$ \\
\hline $\mathbf{1 4 . 1 6 \%}$ & 22 & 22.60 & $3 \%$ \\
\hline $\mathbf{6 . 8 1 \%}$ & 25 & 26.08 & $4 \%$ \\
\hline
\end{tabular}

\begin{tabular}{|c|c|c|c|}
\hline \multicolumn{4}{|c|}{ Resultados obtidos Para método SEAM } \\
\hline Prob. Falha & $\begin{array}{c}\text { Fontoura et } \\
\text { al. (2002) } \\
\text { (MPa) }\end{array}$ & $\begin{array}{c}\text { Código } \\
\text { desenvolvido } \\
\text { (MPa) }\end{array}$ & $\begin{array}{c}\text { Diferença } \\
\text { associada }\end{array}$ \\
\hline $75.49 \%$ & 14 & 14.07 & $1 \%$ \\
\hline $67.00 \%$ & 15 & 15.07 & $0 \%$ \\
\hline $57.93 \%$ & 16 & 16.03 & $0 \%$ \\
\hline $50.00 \%$ & 16.8 & 16.83 & $0 \%$ \\
\hline $21.77 \%$ & 20 & 19.96 & $0 \%$ \\
\hline $10.20 \%$ & 22 & 21.92 & $0 \%$ \\
\hline $2.22 \%$ & 25 & 24.88 & $0 \%$ \\
\hline
\end{tabular}

Observando os resultados apresentados nas Tabela 4, Tabela 5 e Tabela 6, é possível verificar que as diferenças entre os resultados obtidos no artigo e no código implementado são muito baixas para o cálculo dos limites superiores. O maior percentual de diferença associado é de $2 \%$ para o gradiente de fratura superior obtido pela metodologia SEAM. Foi observado também, que para o gradiente de colapso inferior, o percentual de diferença associado foi maior - chegando a 4\% - porém, ainda dentro de um limite aceitável, visto que nesta dissertação, esse gradiente é calculado a partir de metodologias de iterações, o que pode provocar uma diferença baixa entre esses gradientes calculados na metodologia implementada e no artigo.

\subsection{2.}

\section{Comparação entre Resultados Obtidos por FOSM e SEAM para o Poço de Projeto}

As metodologias probabilísticas foram aplicadas no projeto do poço PUC. Este poço possui 3751 pontos de profundidades em que os gradientes foram estimados. Durante a aplicação das metodologias probabilísticas, observou-se que para o cálculo probabilístico do gradiente de fratura - para probabilidades de falha de $10 \%, 50 \%$ e $90 \%$ - em todas as profundidades do poço, o tempo médio demandado foi de aproximadamente 42 segundos, o que denota uma média de tempo factível e bem mais acessível do que aquele proporcionado a partir das simulações de Monte Carlo. 
A metodologia de Monte Carlo, apesar de ser uma estimativa confiável, é onerosa no que diz respeito ao tempo de processamento necessário para o cálculo de um único ponto de profundidade. Isso se deve a quantidade de simulações feitas ao longo da aplicação dessa metodologia. Por outro lado, o número de iterações necessárias para a aplicação das metodologias FOSM e SEAM para a estimativa de cada gradiente é dado pela expressão $(2 n+1)$, onde n é o número de parâmetros de entrada com incertezas associadas. Neste trabalho, foram considerados 11 parâmetros de entrada com incertezas associadas, portanto, foram feitas 23 iterações para a estimativa probabilística de cada gradiente.

A aplicação dos métodos probabilísticos para o cálculo dos gradientes de colapso demandou um tempo consideravelmente maior do que aquele necessário para a fratura. Aproximadamente 4.5 minutos foram necessários para a estimativa dos gradientes de colapso superior e inferior, ao longo da trajetória, para probabilidades de falha de 10\%, 50\% e 90\%. Essa diferença é justificada pela complexidade associada ao cálculo dos colapsos. Estes gradientes são obtidos a partir de processos iterativos, como descrito no item 3.1.2. Ainda assim, esse tempo de processamento se apresenta mais acessível quando comparado ao Monte Carlo, uma vez que para estas simulações, também é necessário calcular os colapsos a partir de processos iterativos.

Os resultados obtidos para o estudo de caso não serão comparados com aqueles obtidos a partir das simulações de Monte Carlo. Isso porque de acordo com a metodologia apresentada neste trabalho, os métodos FOSM e SEAM irão abranger uma porcentagem amostral dos parâmetros de entrada de aproximadamente $68.26 \%$, ao passo que o método de Monte Carlo abrange uma porcentagem amostral de aproximadamente 100\%. Essa diferença de porcentagem amostral empregada para os métodos gera uma diferença significativa nos resultados, o que inviabiliza a comparação de valores entre eles.

Para a aplicação dos métodos probabilísticos, foram empregados os parâmetros estatísticos de cada parâmetro de entrada, conforme pontuados no item anterior, assim como os valores médios dos parâmetros de entrada estimados no item 5.1. Nos tópicos a) e b) estão dispostos os resultados para os diferentes cenários de distribuição. 


\section{a) Distribuição Normal}

Baseando-se na hipótese simplificadora de que todos os parâmetros de entrada possuem uma distribuição normal e desvio padrão de $10 \%$ do seu valor médio, o código desenvolvido neste trabalho foi aplicado para os dois métodos probabilísticos na análise de estabilidade do poço ao longo da profundidade. Na Figura 37 estão apresentados uma comparação entre os resultados obtidos a partir dos métodos FOSM e SEAM para cada gradiente (fratura superior, colapso superior e colapso inferior), considerando diferentes probabilidades de falha: 10\% (P10), 50\% (P50) e 90\% (P90).

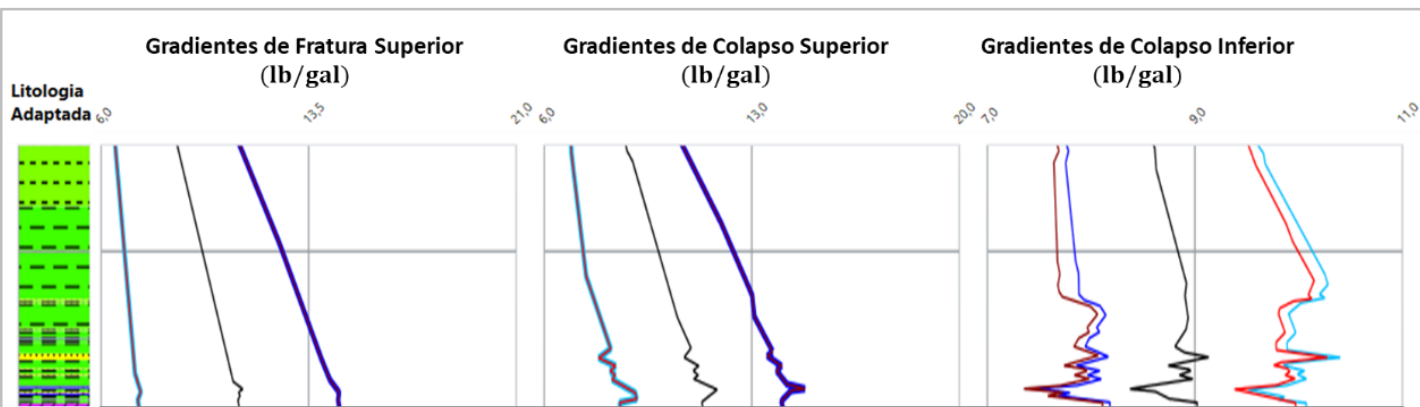

(A)

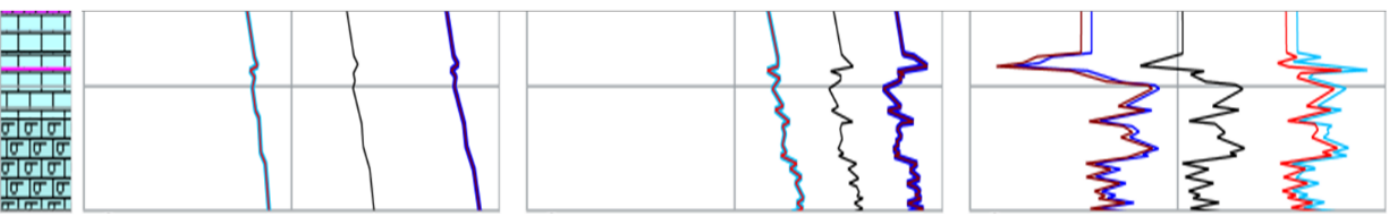

(B)

Figura 37 - Gradientes de fratura e colapso obtidos a partir dos métodos probabilísticos FOSM e SEAM nas camadas $(A)$ pós sal e $(B)$ pré-sal para as probabilidades de falha: $\mathrm{PF}=$ $10 \%, P F=50 \%$ e PF $=90 \%$ - com distribuição normal dos parâmetros de entrada. (SEST TR 
A partir da Figura 37, observa-se que os limites superiores apresentam resultados muito próximos para os dois métodos probabilísticos. Isso se dá devido a metodologia matemática abordada nos dois casos. Os dois métodos se baseiam em uma variável principal diretamente proporcional à pressão interna do poço - o método SEAM baseia-se diretamente em $\mathrm{P}_{\mathrm{i}}$ (pressão interna do poço), enquanto o método FOSM se baseia em $\mathrm{FS}_{\mathrm{i}}$, que é diretamente proporcional a $\mathrm{P}_{\mathrm{i}}$.

Este cenário já é diferente para o limite inferior, uma vez que o método SEAM permanece baseando-se em uma variável principal diretamente proporcional à pressão interna do poço $\left(\mathrm{P}_{\mathrm{i}}\right)$ e o método FOSM se baseia em uma variável principal que, para o colapso inferior, é inversamente proporcional à pressão interna do poço $\left(\mathrm{FS}_{\mathrm{i}}\right)$. Essa diferença matemática em suas formulações ocasiona a leve diferença de resultados entre os dois métodos para o gradiente de colapso inferior.

As Figura 38 e Figura 39 mostram as janelas operacionais referentes a cada probabilidade de falha (P10, P50 e P90) obtidas a partir das metodologias FOSM e SEAM respectivamente.

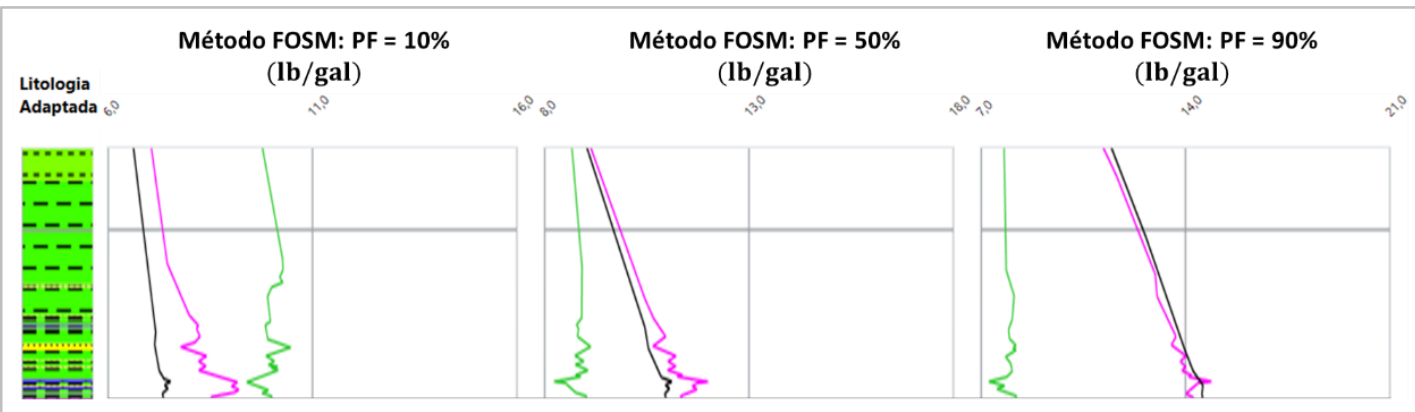

(A)

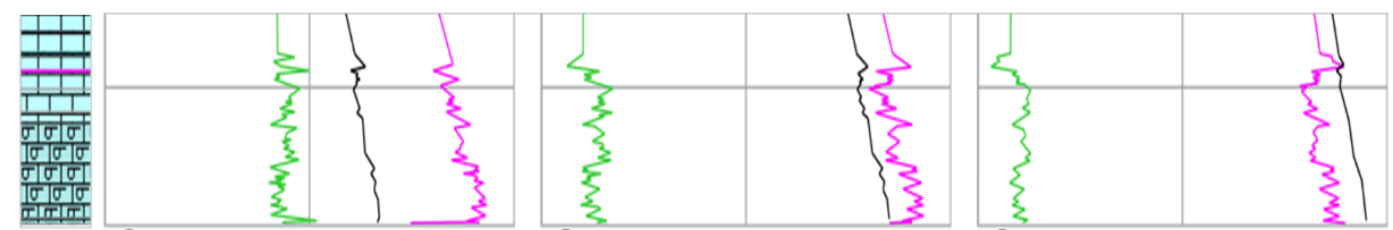

(B)

- Fratura superior

Colapso superior

Colapso inferior

Figura 38 - Janelas operacionais obtidas a partir do método FOSM, nas camadas (A) pós sal e (B) pré-sal, para as diferentes probabilidades de falha (PF) - com distribuição normal dos parâmetros de entrada. (SEST TR 2.0@). 


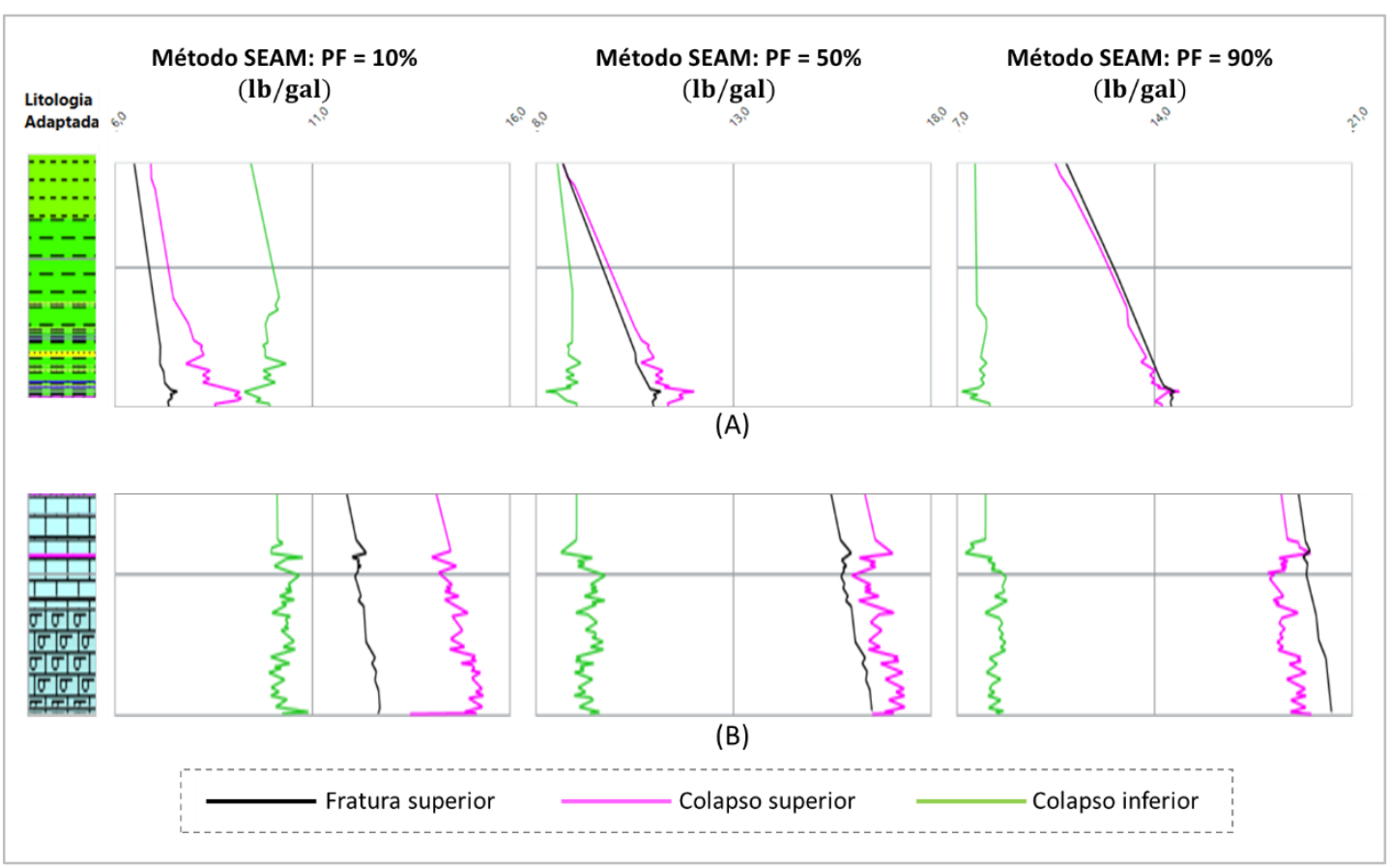

Figura 39 - Janelas operacionais obtidas a partir do método SEAM, nas camadas (A) pós sal e (B) pré-sal, para as diferentes probabilidades de falha (PF) - com distribuição normal dos parâmetros de entrada. (SEST TR 2.0@).

Com base nas Figura 37, Figura 38 e Figura 39, nota-se que para uma probabilidade de falha de $50 \%$, todos os resultados apresentados pelos métodos coincidem entre si. Isso ocorre devido ao fato de que tanto SEAM como FOSM utilizam a função padrão normal acumulada para o cálculo dos gradientes em função de uma probabilidade de falha, este método assume que os resultados probabilísticos dos gradientes apresentam uma distribuição normal. Este tipo de distribuição é caracterizado por apresentar resultados para P50 igual ao valor médio do parâmetro em questão. Portanto, nas duas metodologias, tem-se que P50 é igual ao valor médio dos gradientes obtidos deterministicamente.

\section{b) Distribuição Uniforme}

Baseando-se na hipótese simplificadora de que todos os parâmetros de entrada possuem uma distribuição uniforme com parâmetros a e b iguais a aproximadamente 
0.83 e 1.17 do seu valor médio, foi possível aplicar os dois métodos probabilísticos. Na Figura 40 são apresentados uma comparação entre os resultados obtidos a partir dos métodos FOSM e SEAM para cada gradiente (fratura superior, colapso superior e colapso inferior) e também considerando diferentes probabilidades de falha: $10 \%$ (P10), 50\% (P50) e 90\% (P90).

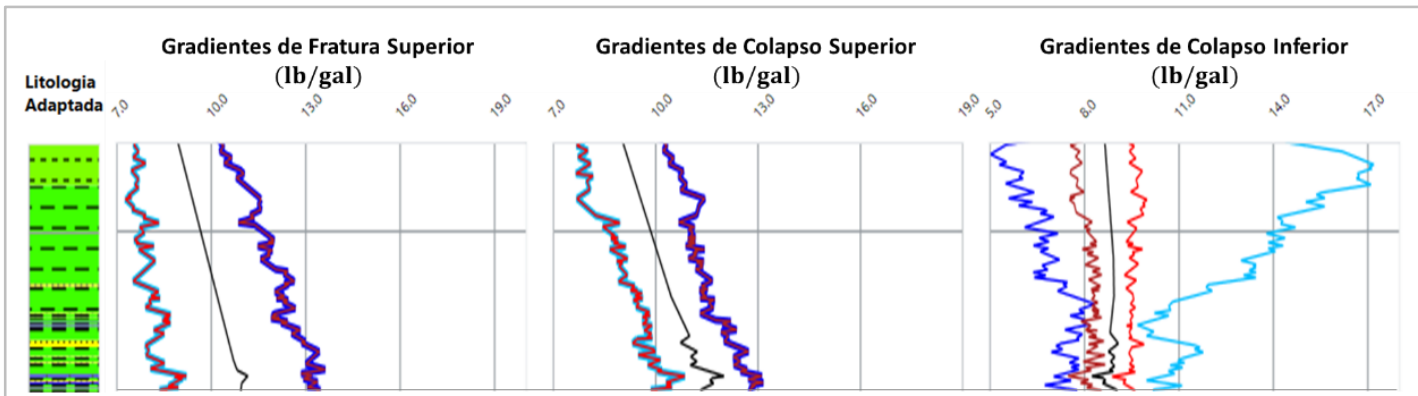

(A)

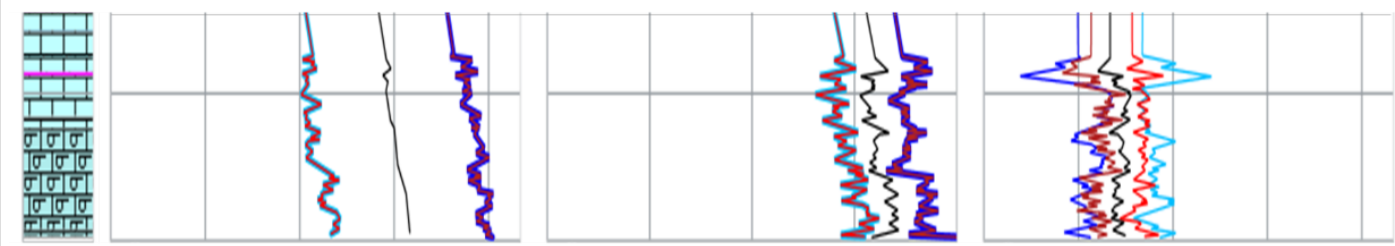

(B)

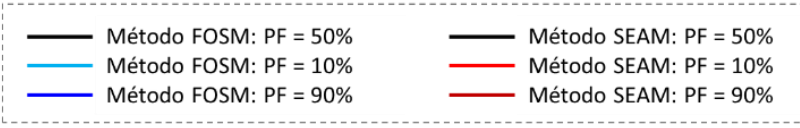

Figura 40 - Gradientes obtidos a partir dos métodos probabilísticos FOSM e SEAM, nas camadas $(A)$ pós sal e $(B)$ pré-sal, para as diferentes probabilidades de falha (PF) - com distribuição uniforme dos parâmetros de entrada. (SEST TR 2.0 C)

Assim como no caso da distribuição normal, é possível observar a partir da Figura 40, que os limites superiores apresentam muito próximos para os dois métodos probabilísticos ao passo que o limite inferior apresenta diferenças nos resultados para FOSM e SEAM.

Os resultados obtidos a partir da distribuição uniforme dos parâmetros de entrada apresentam uma tendência parecida com aqueles apresentados pela distribuição normal desses parâmetros. Entretanto, é verificada uma maior proximidade dos valores médios dos gradientes às soluções obtidas a partir da 
distribuição uniforme dos parâmetros de entrada. A janela em torno do valor determinístico é mais fechada e esse efeito se deve à diferença de variação do parâmetro de entrada para o cálculo das derivadas parciais.

No caso da distribuição normal, foi aplicada a variação fixa de $\pm 10 \%$ do valor médio de cada parâmetro. Já para o caso da distribuição uniforme, as variações foram selecionadas aleatoriamente para cada parâmetro em um intervalo delimitado pelo valor médio do parâmetro $\pm 11.8 \%$ desse mesmo valor. Sabe-se que na prática, não é de se esperar que todos os parâmetros de entrada para a estimativa dos gradientes apresentem o mesmo perfil de distribuição e nem a mesma taxa de desvio padrão. Portanto, apesar de considerar todos os parâmetros com distribuição uniforme, este cenário permite que seja escolhida de maneira aleatória a variação sofrida por cada parâmetro a cada profundidade.

A Figura 41 e a Figura 42 mostram as janelas operacionais referentes a cada probabilidade de falha obtidas a partir das metodologias FOSM e SEAM respectivamente.

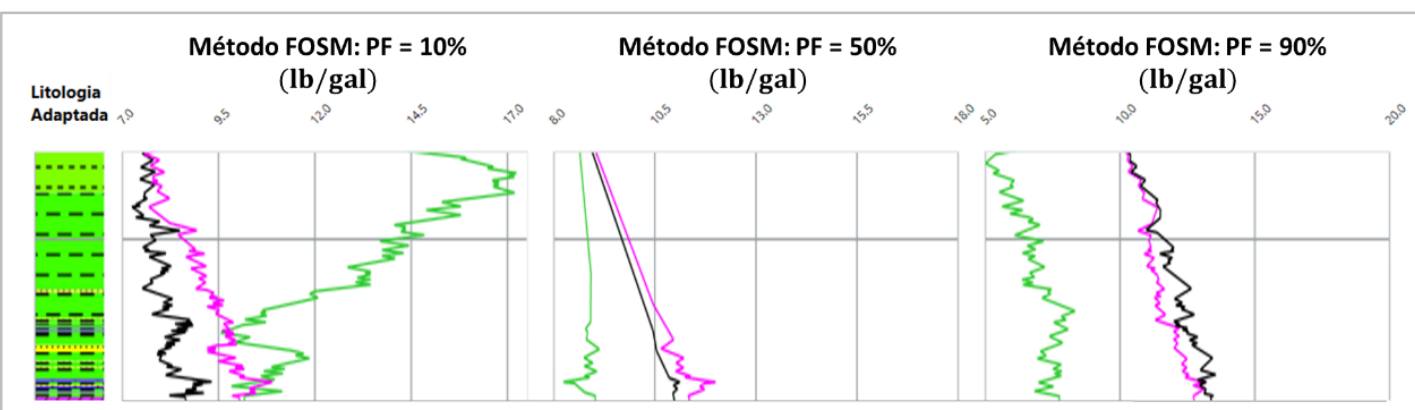

(A)

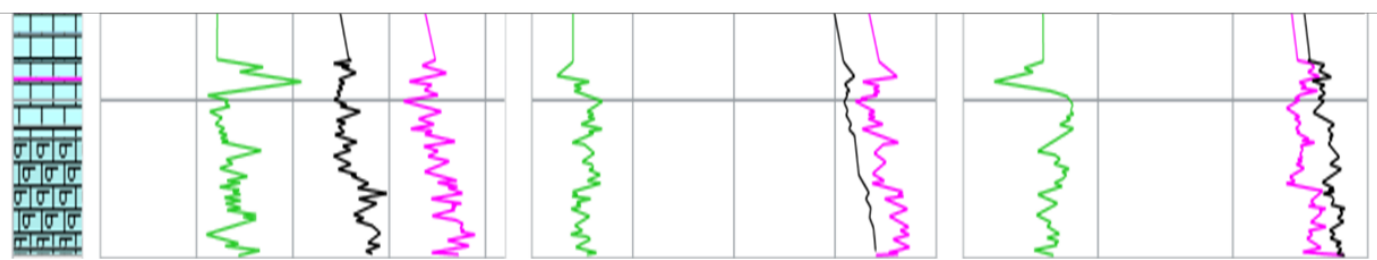

(B)

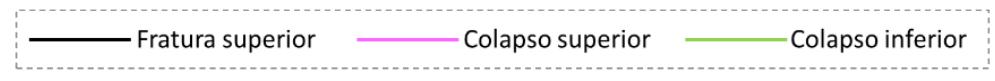

Figura 41 - Gradientes obtidos a partir da metodologia FOSM, nas camadas (A) pós sal e (B) pré-sal, com distribuição uniforme dos parâmetros de entrada. (SEST TR 2.0 (C) 


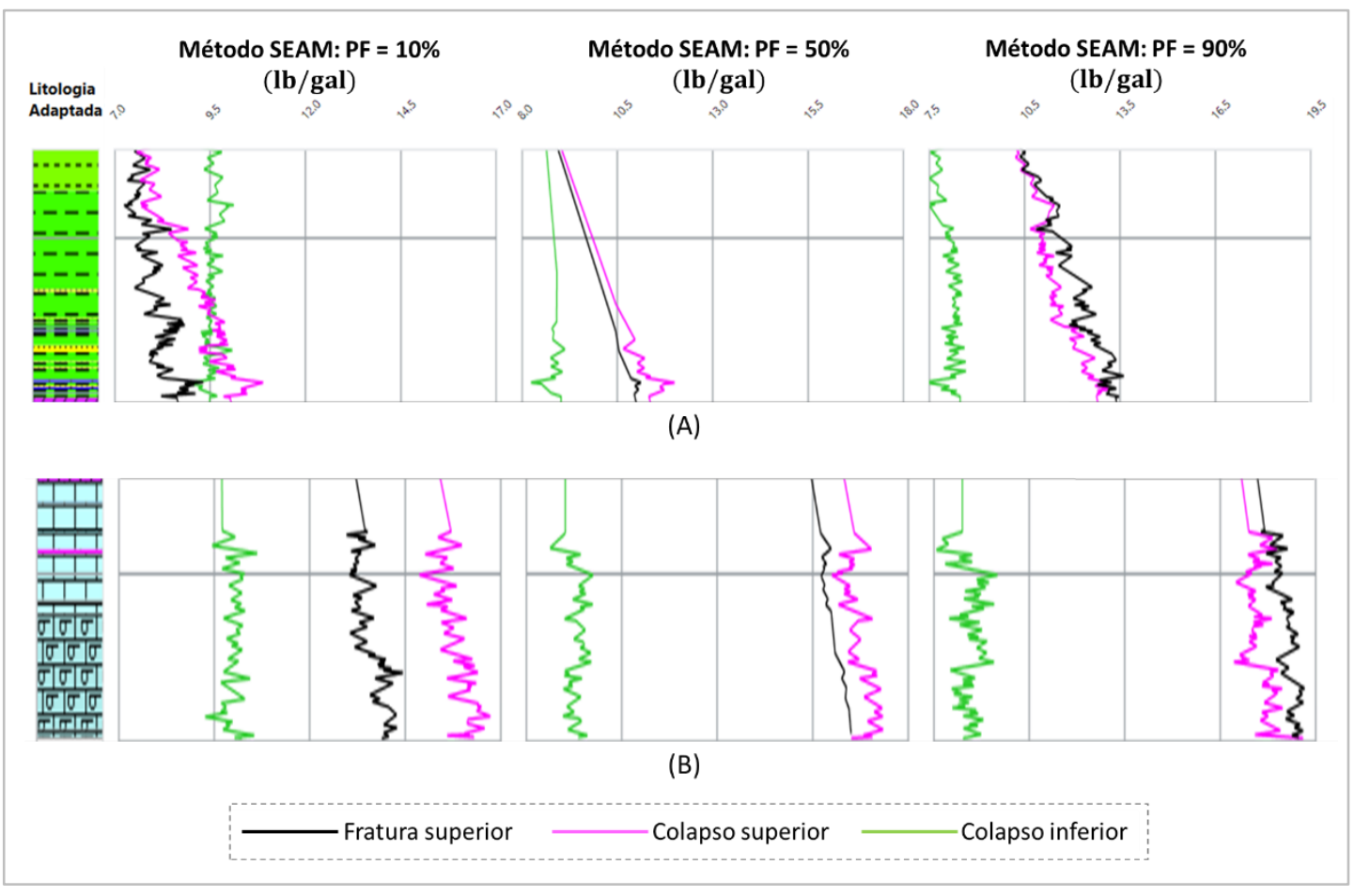

Figura 42 - Gradientes obtidos a partir da metodologia FOSM, nas camadas (A) pós sal e

(B) pré-sal, com distribuição uniforme dos parâmetros de entrada. (SEST TR 2.0@)

Ao comparar os dois métodos probabilísticos, verifica-se que uma vez definidos o desvio padrão e a taxa de variação que o parâmetro de entrada sofre, os dois métodos sempre proporcionarão resultados muito próximos para limites superiores. Portanto, o que pode influenciar na escolha de um método ou outro é o resultado obtido para o gradiente de colapso inferior.

Com os resultados obtidos nesse estudo de caso, nota-se que a diferença entre o tipo de distribuição dos parâmetros de entrada ocasionou uma diferença nos resultados também. Para o caso da distribuição normal, a metodologia FOSM resultou em valores levemente mais conservadores, pois tanto a curva obtida para P10 quanto aquela obtida para P90 estão acima das respectivas curvas obtidas a partir do método SEAM.

Já para o cenário onde a distribuição dos parâmetros de entrada é uniforme, essa configuração se modifica. Neste caso, a dispersão dos resultados fornecidos por SEAM é menor em relação a curva determinística do que aquela observada nos 
resultados fornecidos por FOSM. Portanto, para este caso, tem-se a configuração apresentada na Tabela 7.

Tabela 7 - Comparação entre nível de conservadorismo entre os métodos FOSM e SEAM considerando distribuição uniforme dos parâmetros de entrada.

\begin{tabular}{|c|c|c|}
\hline Metodologia & P10 & P90 \\
\hline FOSM & + conservador & - conservador \\
\hline SEAM & - conservador & + conservador \\
\hline
\end{tabular}

A partir da Figura 38, Figura 39, Figura 41 e Figura 42 é possível verificar que as janelas operacionais obtidas para uma probabilidades de falha de $10 \%$ apresentam um comportamento incomum. Nas camadas de pré-sal, a janela operacional existe, apesar de ser bem fechada. Esse resultado é intuitivo, uma vez que esta é uma probabilidade de falha bem conservadora.

Para as camadas de pós-sal, contudo, a janela não só é fechada, como os gradientes de limites superiores atingem valores mais baixos que o limite inferior. Esse fenômeno ocorre devido à hipótese de que os gradientes de fratura e colapsos seguem uma distribuição estatística normal. As formulações matemáticas podem permitir que sejam obtidos resultados que não são fisicamente possíveis, dessa forma, cabe ao analista interpretar esses resultados. Para a verificação das formulações matemáticas que levaram ao resultado fisicamente impossível, será analisado o cenário de distribuição normal dos parâmetros de entrada.

Para essa verificação, será definida a função de distribuição acumulada associada à distribuição normal de cada gradiente, a fim de observar para quais probabilidades de falha as metodologias apresentam resultados incoerentes. Esta função de distribuição acumulada é regida por uma função dos parâmetros $\mu$ (valor médio) e $\sigma$ (desvio padrão). Selecionando uma profundidade específica na camada de pós-sal (camada onde ocorre o referido resultado), é possível obter o valor médio dos gradientes para essa profundidade (valor determinístico). A partir do código MATLABC desenvolvido neste estudo, é possível também obter o desvio padrão de cada gradiente nesta profundidade. 
Dados esses parâmetros estatísticos, define-se a curva de distribuição normal acumulada - integral da equação 35 de distribuição normal de frequência - referente a cada gradiente na profundidade selecionada, conforme indicado na Figura 43. $\mathrm{O}$ mesmo processo pode ser feito para uma profundidade nas camadas de pré-sal (Figura 44).

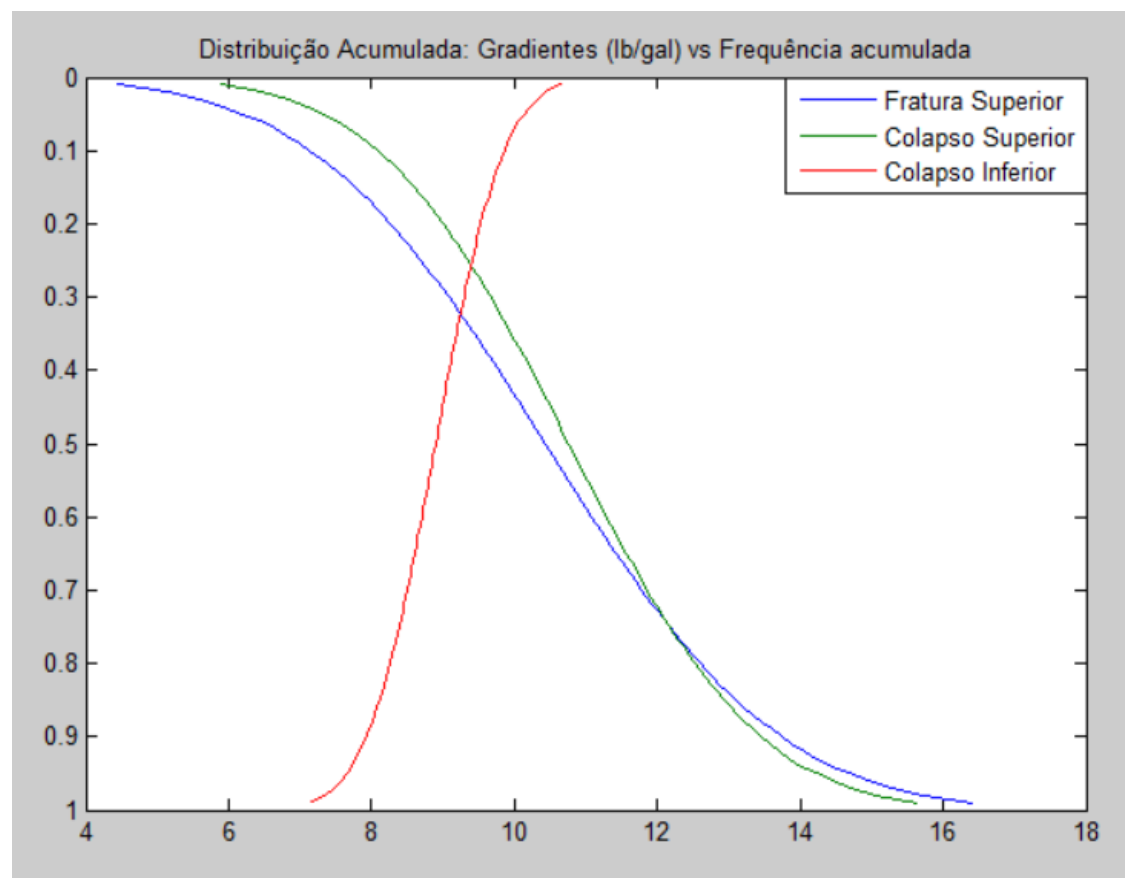

Figura 43 - Distribuição acumulada referente a uma produndidade na camada pós-sal. 0 eixo y refere-se a probabilidade de falha acumulada e o eixo $x$ refere-se aos valores de gradientes obtidos para cada probabilidade em lb/gal.

A partir da Figura 43 é possível observar que para uma probabilidade de falha de aproximadamente $32 \%$ as curvas de distribuição dos gradientes de limites superior e inferior se cruzam. Isso significa que para qualquer probabilidade de falha inferior a essa, a janela obtida será completamente fechada, ou seja, o método indica que não há um peso de fluido de perfuração que garanta a estabilidade do poço para uma probabilidade de falha nesse intervalo. Nesse caso, o analista deverá trabalhar com probabilidades menos conservadoras.

Este comportamento observado nos resultados obtidos para uma probabilidade de falha de $10 \%$ é esperado, visto que essa probabilidade é bem conservadora. 
Dependendo do cenário que se apresenta ao analista, mesmo para probabilidades de falha baixas, o poço a ser perfurado pode apresentar

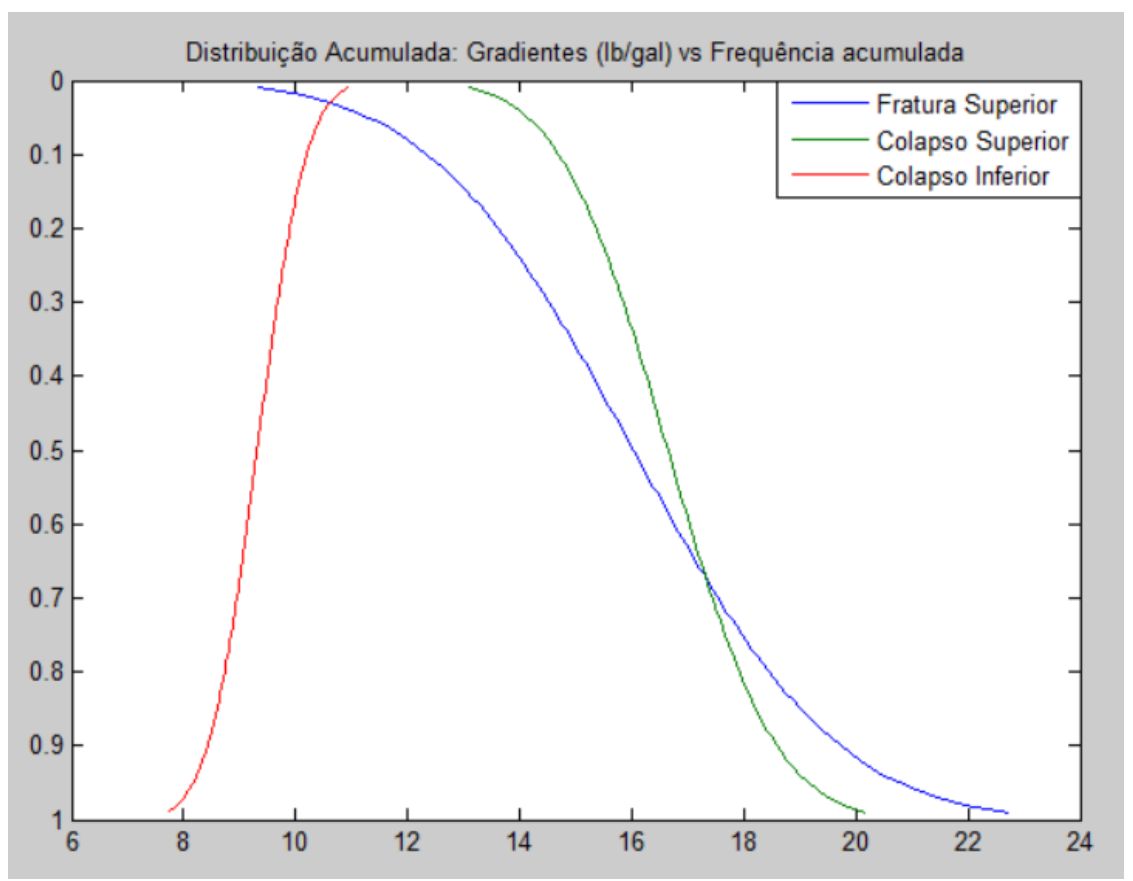

Figura 44 - Distribuição acumulada referente a uma profundidade na camada pré-sal. O eixo y refere-se a probabilidade de falha acumulada e o eixo $x$ refere-se aos valores de gradientes obtidos para cada probabilidade em $\mathrm{lb} / \mathrm{gal}$.

Já para as camadas de pré-sal (Figura 44), esse cenário muda havendo o cruzamento das curvas de limitantes superior e inferior da janela apenas para probabilidades de falha mais baixas. Dessa forma, para essa circunstância, é possível contar com estimativas conservadoras.

Fazendo-se uma comparação geral partir das Figura 38, Figura 39, Figura 41 e Figura 42 observa-se que conforme a probabilidade de falha diminui, a janela operacional calculada é mais conservadora, como era de se esperar. A escolha de uma probabilidade de falha para a estimativa dos gradientes dependerá sempre do cenário em que o poço está inserido.

Para campos onde observa-se uma grande ocorrência de eventos indesejados devido ao mau dimensionamento da densidade de fluido de perfuração, é preferível 
adotar probabilidades de falha mais baixas nos projetos de perfurações futuras, com a finalidade de restringir mais a faixa segura de densidade de fluido e evitar os problemas de perfuração. O estudo de caso apresentado neste trabalho ilustra esse cenário. No tópico 5.3.3 será feita uma análise integrada comparando os resultados probabilísticos e determinísticos obtidos para o projeto do poço PUC com os resultados determinísticos obtidos na retroanálise deste poço.

\subsection{3.}

\section{Análise Integrada com Resultados Reais Pós Perfuração}

O estudo de caso deste trabalho apresenta o projeto do Poço PUC, desenvolvido com base nos dados adaptados da correlação com um poço adjacente. Após o projeto realizado, o Poço PUC foi então perfurado e foi possível obter as estimativas de todos os parâmetros e, por fim, dos gradientes a partir de perfis iniciais corridos no próprio poço, como apresentado no item 4.3.

Atualmente, a estimativa da janela operacional em um projeto a partir de dados adaptados de poços adjacentes apresenta, muitas vezes, resultados satisfatórios e realistas. Entretanto, apesar da análise cuidadosa feita para cada projeto, ainda ocorrem muitos cenários de perfuração de poços com um elevado número de problemas que se apresentam durante essa perfuração, ocasionando o NTP - como verificado por Argote (2012) que analisou a ocorrência de eventos indesejados durante a perfuração de 4 poços de um mesmo campo e seus respectivos NPTs, obtendo para um deles uma taxa de $16 \%$ do tempo total da perfuração. Por isso, é importante que, ao final de cada operação de perfuração seja feita uma análise comparativa entre as estimativas realizadas a partir de dados adaptados e previstos no projeto com aquelas geradas a partir de dados originais do poço.

Devido à quantidade de eventos de perfuração ocorridos no Poço PUC - drag, perda de circulação e prisão em profundidades onde a densidade de fluido de perfuração estava abaixo ou muito próxima do colapso inferior -, conclui-se que o projeto não satisfez às condições necessárias para evitar a ocorrência de problemas e riscos durante a perfuração. A Figura 45 apresenta a comparação entre a janela operacional obtida deterministicamente no projeto do Poço PUC e aquela obtida 
também deterministicamente, mas dessa vez durante a retroanálise desse poço, considerando os dados reais do poço perfurado.

Observando a Figura 45, é possível constatar que o projeto forneceu uma janela operacional bem mais aberta em comparação com aquela obtida na retroanálise. De acordo com os gradientes de projeto, o peso de fluido de perfuração dimensionado está dentro dos limites aceitáveis para evitar tanto o colapso quanto a fratura da formação. Entretanto, quando se verifica a janela da retroanálise, constata-se que 0 fluido de perfuração possui um peso insuficiente para garantir a estabilidade da formação ao longo da perfuração.

É importante ressaltar que o modelo geomecânico utilizado para o projeto e retroanálise diferem no que diz respeito às tensões horizontais. Devido ao cenário que se apresentou ao longo das análises de estabilidade, a relação entre as tensões horizontais assim como as metodologias de obtenção desses parâmetros são diferentes, o que pode contribuir para a divergência de resultados entre as janelas operacionais de projeto e retroanálise do poço PUC. 


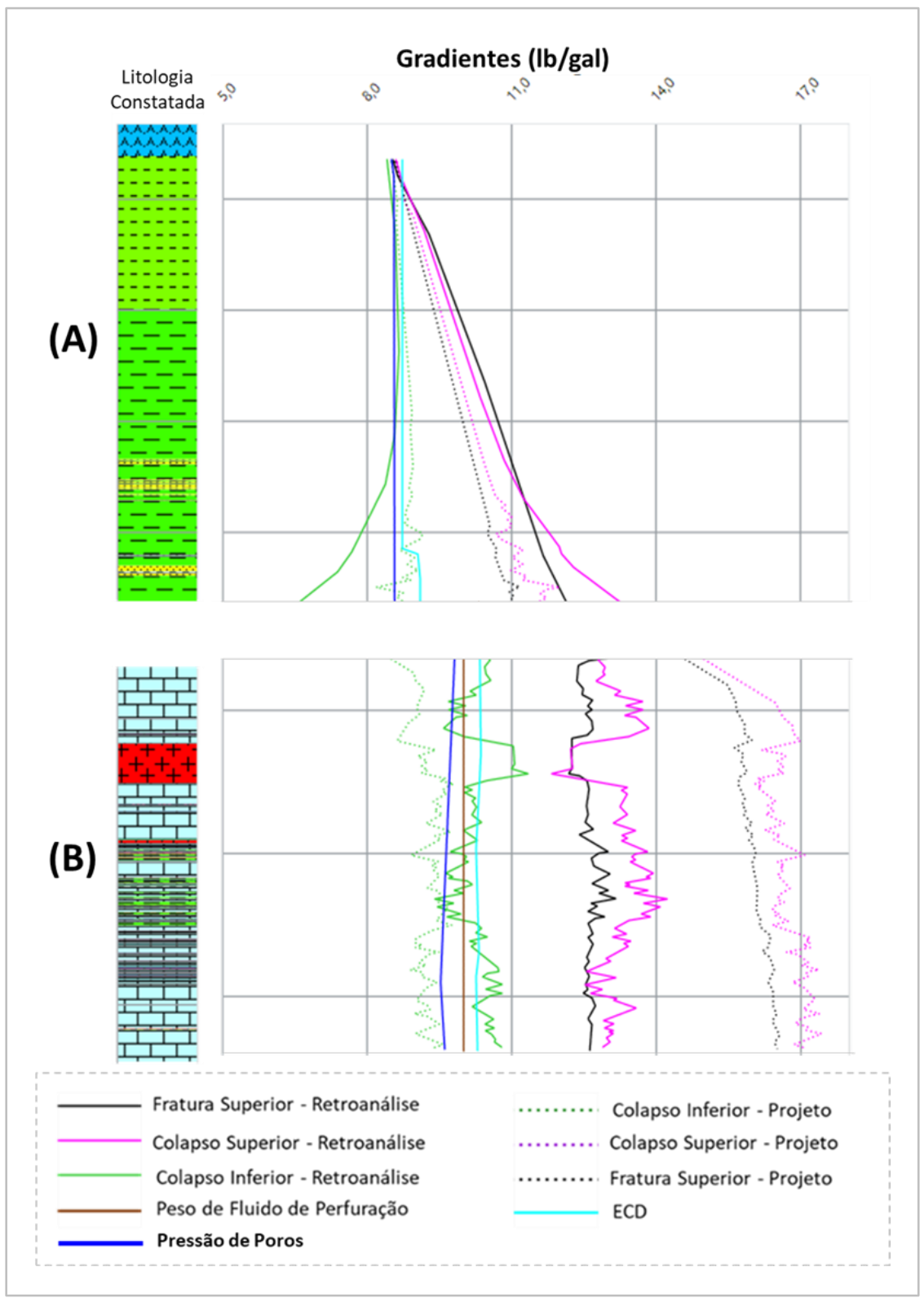

Figura 45 - Comparação entre as janelas operacionais obtidas deterministicamente, nas camadas $(A)$ pós sal e $(B)$ pré-sal, no projeto e retroanálise do estudo de caso. (SEST TR 2.0C)

Dessa forma, propõe-se que utilizando uma metodologia de análise probabilística e adotando probabilidades de falha mais seguras, é possível obter resultados satisfatórios e evitar a ocorrência de eventos de perfuração, riscos durante a perfuração e, consequentemente, gastos extras. 
A Figura 46 apresenta uma comparação entre a janela operacional de retroanálise do Poço PUC e aquela obtida a partir dos métodos probabilísticos SEAM e FOSM no projeto desse poço. Como discutido no tópico 5.3.2, os resultados para colapso superior e fratura superior são muito próximos, portanto, para maior clareza da figura, serão apresentados juntos.

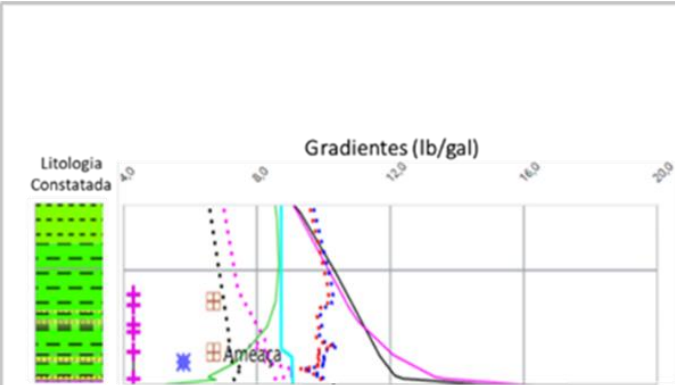

(A)

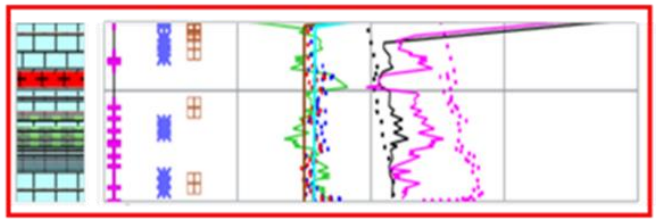

(B)

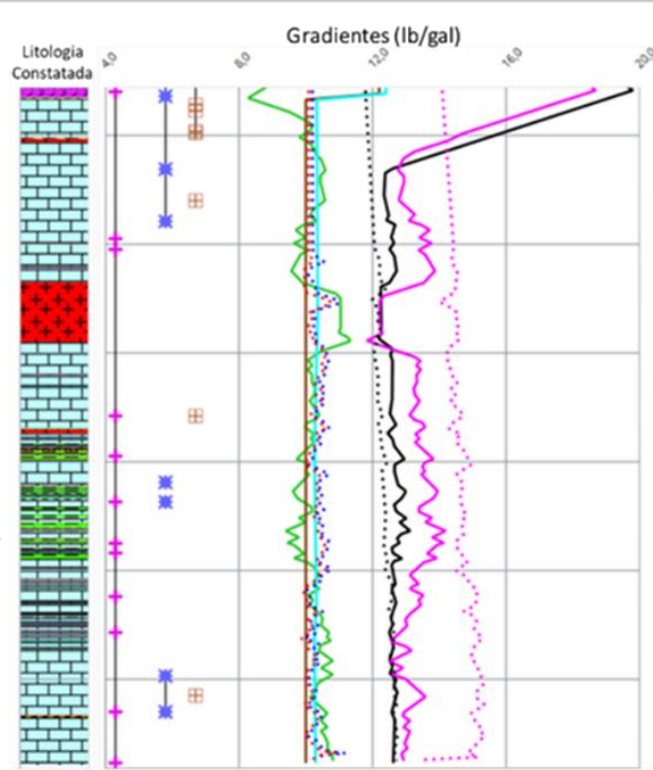

(C)

Colapso Inferior - determinístico Colapso Inferior - FOSM P10

Colapso Inferior - SEAM P10

Peso de Fluido de Perfuração ECD

Figura 46 - Comparação entre gradientes obtidos deterministicamente e gradientes obtidos probabilisticamente para uma probabilidade de falha de 10\%, nas camadas (A) pós sal e (B) pré-sal. (C) denota a comparação em detalhe na camada pré-sal. (SEST TR 2.0@)

A partir da Figura 46(C), observa-se que, para as camadas pré-sal, a janela operacional obtida probabilisticamente para uma probabilidade de falha de $10 \%$ é mais apropriada para esse estudo de caso do que aquela estimada deterministicamente. É possível verificar que os gradientes de colapso inferior obtidos 
por FOSM e SEAM, assim como o gradiente de fratura apresentam comportamento similar a janela operacional de retroanálise. O gradiente de colapso superior para P10 expressa um comportamento mais afastado da curva real do poço, porém, ainda se apresenta mais próxima do real do que a de projeto.

No caso do pós-sal, não foi possível fazer uma análise comparativa avaliando se os métodos probabilísticos foram eficazes. Isso porque, devido à falta de perfis lidos nas profundidades mais rasas, os parâmetros de entrada foram estimados por curvas de regressão que refletem apenas a tendência que o perfil poderia assumir nessas profundidades. Nesses casos em que não se dispõe de dados provenientes da montagem para as camadas mais superficiais do poço, uma abordagem alternativa é usar dados provenientes de levantamento sísmico. Esses dados, mesmo que suavizados, representam melhor o cenário para o poço de projeto.

Para este estudo, observa-se que a janela operacional probabilística de projeto que mais se adequa à janela operacional obtida na retroanálise é caracterizada por uma probabilidade de falha baixa (10\%). Essa conclusão mostra que dependendo do cenário de estabilidade que se apresenta para um poço, pode ser possível a ocorrência de eventos indesejados mesmo para probabilidades de falha conservadoras. Dessa forma, não se pode determinar uma faixa de probabilidade de falha que garanta a estabilidade de qualquer poço. Cada projeto deve ser analisado em conjunto com informações de outros poços do campo.

No estudo de caso apresentado, é possível observar que ao selecionar um cenário de probabilidade de falha de $10 \%$, a janela operacional obtida a partir das metodologias SEAM e FOSM apresentam resultados muito mais realistas. Essa é uma vantagem de utilizar metodologias probabilísticas para análises de estabilidade. De uma forma geral, para qualquer tipo de análise que se deseja fazer, os métodos probabilísticos fornecem resultados diferentes para diferentes cenários de probabilidade de insucesso, ao passo que os métodos determinísticos fornecem resultados para apenas um cenário, aquele mais provável. Entretanto, observa-se que para que seja feita uma análise probabilística, é necessário dispor de uma quantidade muito maior de dados, o que representa uma desvantagem, uma vez que nem sempre é simples obter essa quantidade de dados. 


\subsection{4.}

\section{Análise de Sensibilidade}

Com base nos resultados parciais obtidos a partir de uma pequena variação individual de cada parâmetro de entrada, é possível fazer uma análise de sensibilidade e determinar aqueles parâmetros que mais e menos influenciam no resultado final do cálculo de cada gradiente, tal como as análises de Gholami et al. (2015), Al-Ajmi \& Al- Harthy (2010) e Moos et al. (2003). Para esta análise de sensibilidade, foram utilizados os resultados de gradientes obtidos a partir da variação de $\pm 10 \%$ do valor médio do parâmetro, aqueles calculados quando considerou-se distribuição normal para os dados de entrada.

De uma maneira geral, notou-se que quatro parâmetros de entrada tiveram uma influência significativa para os resultados finais dos três gradientes abordados neste estudo: tensão horizontal maior, tensão horizontal menor, pressão de poros e coeficiente de Biot. Embora os quatro parâmetros atuem de maneira mais representativa que os demais para os três gradientes, individualmente esses parâmetros possuem relevâncias diferentes para os cálculos de fratura superior, colapso superior e colapso inferior.

A Figura 47 mostra graficamente a variação percebida no gradiente de fratura quando é aplicada uma variação positiva e negativa nas tensões horizontais, pressão de poros e coeficiente de Biot. Com base nesta figura, é possível concluir que o parâmetro que mais influenciou o resultado final desse gradiente foi a tensão horizontal menor seguida da tensão horizontal maior, esta última sendo encontrada também como o parâmetro de maior influência por Moos et al. (2003). A faixa de variação média de cada um dos 4 parâmetros mais influentes para os resultados de gradiente de fratura estão apresentados na Tabela 8. 


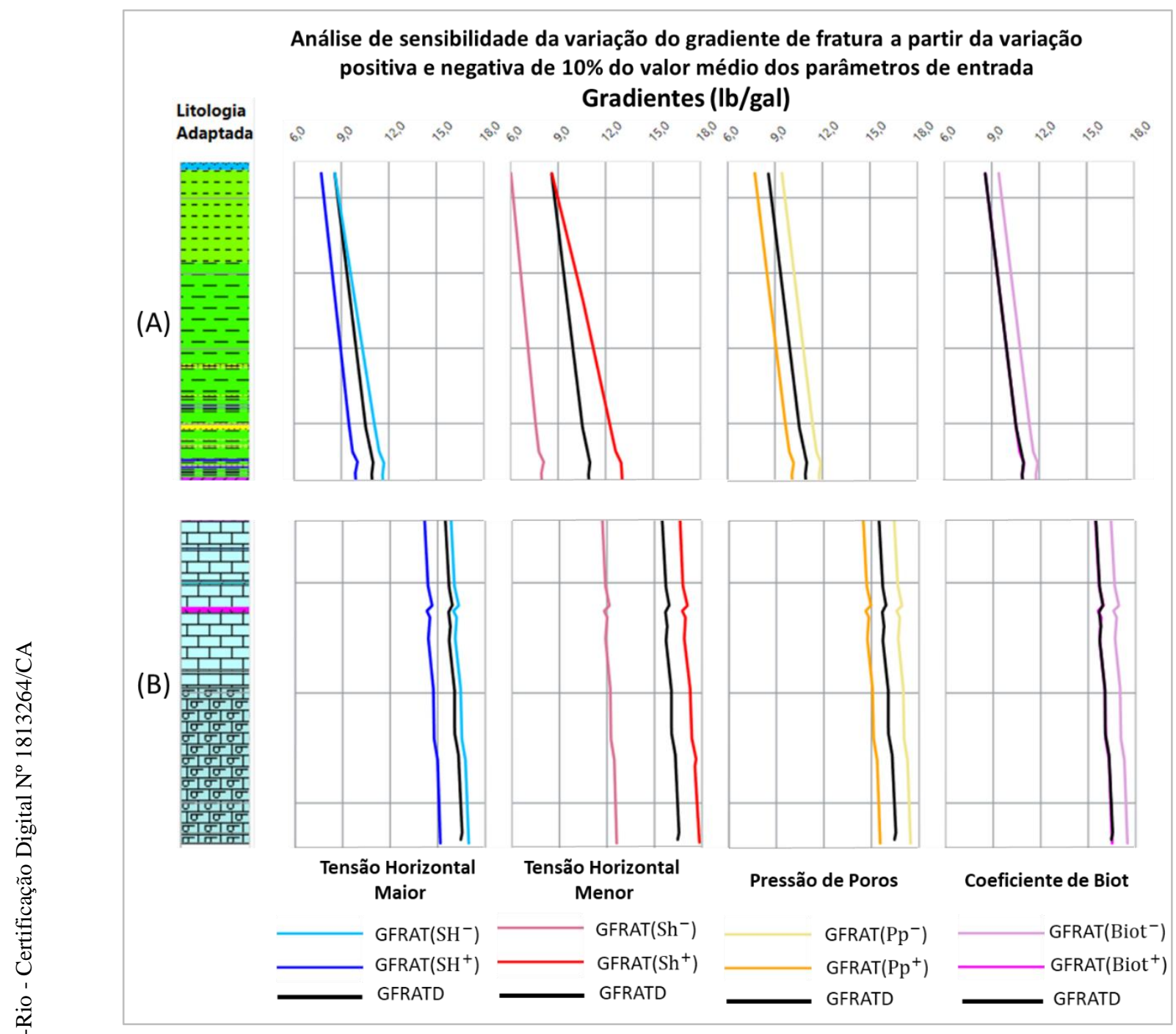

Figura 47 - Análise de sensibilidade dos parâmetros que mais influenciam o resultado para gradiente de fratura nas camadas $(A)$ pós sal e (B) pré-sal. GFRATD é o gradiente de fratura obtido deterministicamente. GFRAT $\left(\mathrm{X}^{+}\right)$é o resultado para o gradiente de fratura quando é imposta uma variação positiva no parâmetro X. GFRAT(X') é o resultado para o gradiente de fratura quando é imposta uma variação negativa no parâmetro X. (SEST TR 2.0@) 
Tabela 8 - Faixa de valores de gradiente de fratura (GFRAT) obtido em psi a partir do incremento positivo e negativo do parâmetro de entrada. GFRATD denota o gradiente de fratura médio em psi.

\begin{tabular}{|c|c|}
\hline Parâmetro & $\begin{array}{c}\text { Faixa de valores de gradiente de fratura obtido a partir da } \\
\text { variação positiva e negativa do parâmetro de entrada } \\
\text { (lb/gal) }\end{array}$ \\
\hline Tensão horizontal maior & GFRATD $-1.11>$ GFRAT $>$ GFRATD +0.375 \\
\hline Tensão horizontal menor & GFRATD $-3.23>$ GFRAT $>$ GFRATD +1.12 \\
\hline Pressão de poros & GFRATD $-0.90>$ GFRAT $>$ GFRATD +0.90 \\
\hline Coeficiente de Biot & GFRATD $>$ GFRAT $>$ GFRATD +0.90 \\
\hline
\end{tabular}

É possível notar também, que que a curva GFRAT $\left(\mathrm{Biot}^{+}\right)$coincide com a curva determinística. Isso devido às medidas tomadas para evitar resultados inconsistentes. Uma vez que nesse estudo foi adotado regime elástico, o valor médio do coeficiente de Biot já é o limite máximo que este parâmetro pode assumir. Portanto, a variação positiva desse parâmetro foi desconsiderada.

A Figura 48 apresenta graficamente a variação percebida no gradiente de colapso superior quando é aplicada uma variação positiva e negativa nas tensões horizontais, pressão de poros e coeficiente de Biot. Com base nesta figura, é possível concluir que o parâmetro que mais influenciou o resultado final desse gradiente foi a tensão horizontal menor seguida da pressão de poros. A faixa de variação média de cada um dos 4 parâmetros mais influentes para os resultados de gradiente de colapso superior estão apresentados na Tabela 9. 


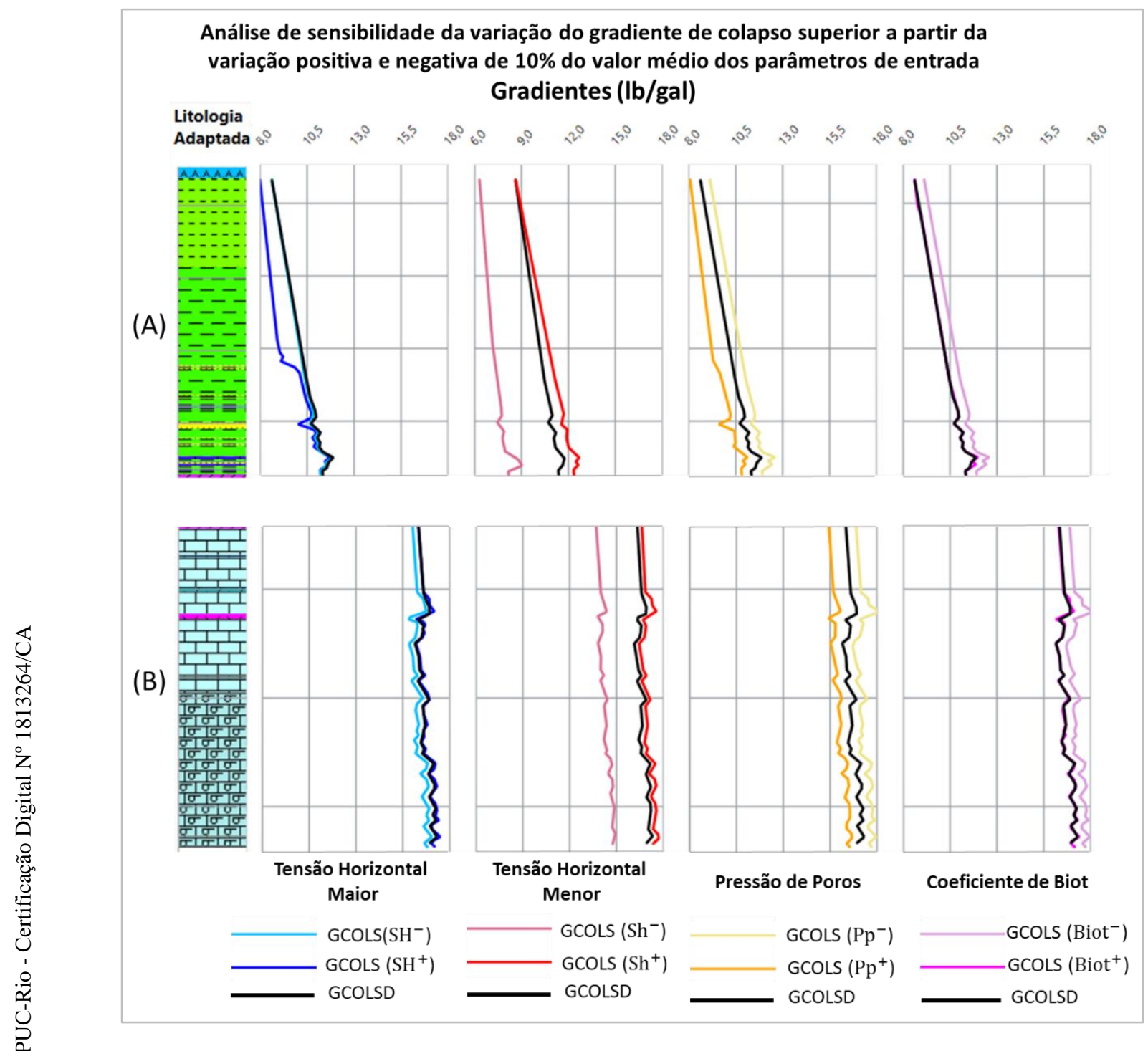

Figura 48 - Análise de sensibilidade dos parâmetros que mais influenciam o resultado para gradiente de colapso superior nas camadas (A) pós sal e (B) pré-sal. GCOLSD é o gradiente de fratura obtido deterministicamente. $\mathrm{GCOLS}\left(\mathrm{X}^{+}\right)$é o resultado para o gradiente de fratura quando é imposta uma variação positiva no parâmetro X. GCOLS(X) é o resultado para o gradiente de fratura quando é imposta uma variação negativa no parâmetro X. (SEST TR 2.0@)

Diferente do gradiente de fratura, apesar da tensão horizontal maior estar entre os quatro parâmetros mais representativos para o colapso superior, as variações verificadas no resultado final relativos ao incremento da pressão de poros e, também, ao coeficiente de Biot são mais significativas. A mesma observação referente ao 
resultado para a variação positiva do coeficiente de Biot feita para a análise de sensibilidade do gradiente de fratura se aplica para o gradiente de colapso.

Tabela 9 - Faixa de valores de gradiente de colapso superior (GCOLS) obtido em psi a partir do incremento positivo e negativo do parâmetro de entrada. GCOLSD denota o gradiente de colapso superior médio em psi.

\begin{tabular}{|c|c|}
\hline Parâmetro & $\begin{array}{c}\text { Faixa de valores de gradiente de colapso superior } \\
\text { obtido a partir da variação positiva e negativa do } \\
\text { parâmetro de entrada (lb/gal) }\end{array}$ \\
\hline Tensão horizontal maior & GCOLSD $-0.37>$ GCOLS $>$ GCOLSD \\
\hline Tensão horizontal menor & GCOLSD $-2.66>$ GCOLST $>$ GFRATSD + 0.43 \\
\hline Pressão de poros & GCOLSD $-0.75>$ GCOLS $>$ GCOLSD + 0.59 \\
\hline Coeficiente de Biot & GCOLSD $>$ GCOLS $>$ GCOLSD +0.59 \\
\hline
\end{tabular}

Gholami et al. (2015), Al-Ajmi \& Al- Harthy (2010) e Moos et al. (2003) apresentaram em seus estudos a análise de sensibilidade para o cálculo dos colapsos. Para Gholami et al., os parâmetros mais influentes foram tensão horizontal maior e pressão de poros, enquanto que para Al-Ajmi \& Al-Harthy, além da tensão horizontal maior, o ângulo de atrito e a coesão também apresentaram variações mais significativas nos resultados.

Moos et al. também apresentaram um estudo onde utilizou um método probabilístico para obter resultados de colapsos e a análise de sensibilidade apresentou a pressão de poros como o principal parâmetro de influência para esses cálculos. 


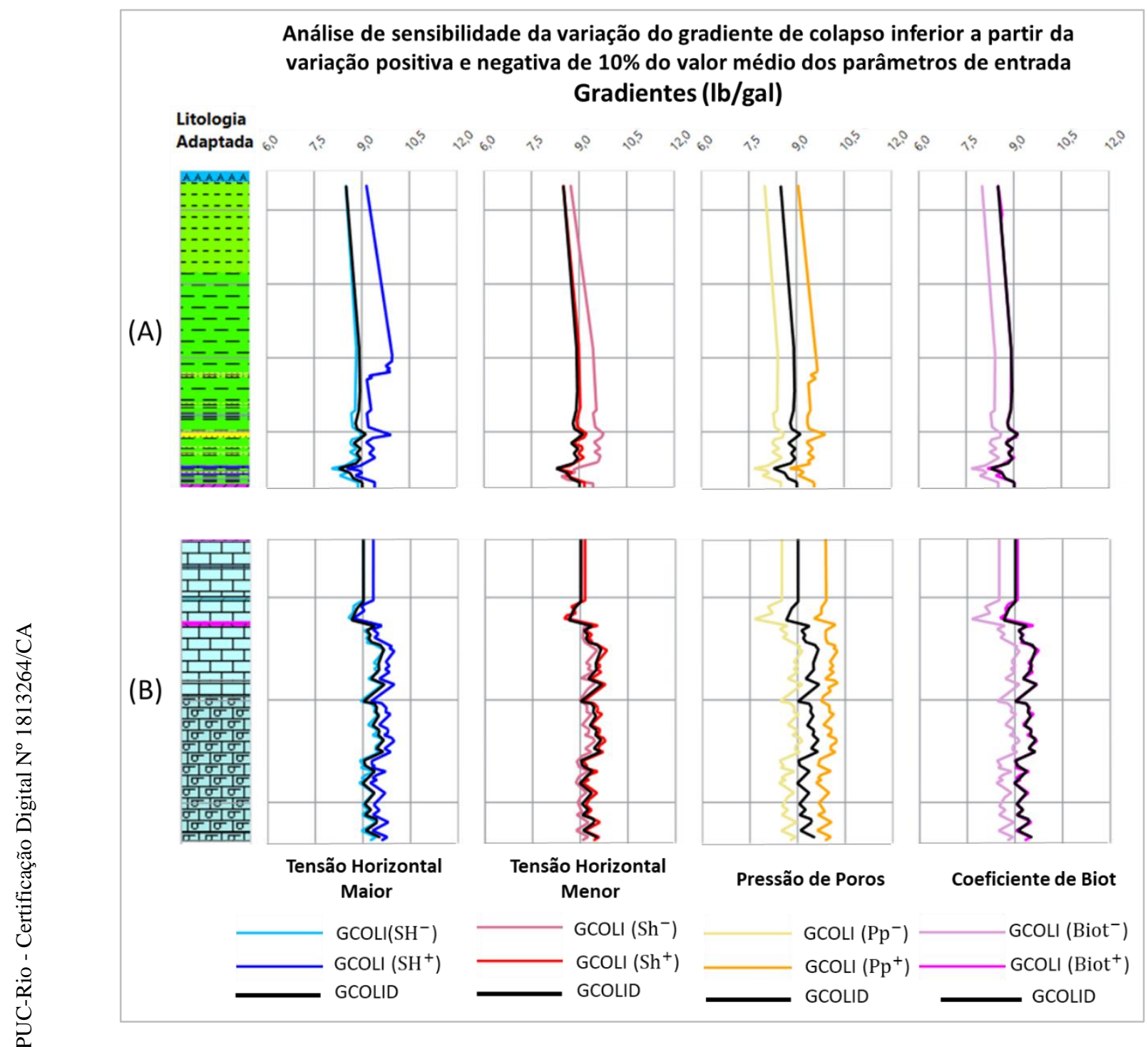

Figura 49 - Análise de sensibilidade dos parâmetros que mais influenciam o resultado para gradiente de colapso superior nas camadas (A) pós sal e (B) pré-sal. GCOLID o gradiente de fratura obtido deterministicamente. $\mathrm{GCOLI}\left(\mathrm{X}^{+}\right)$é o resultado para o gradiente de fratura quando é imposta uma variação positiva no parâmetro X. GCOLI(X-) é o resultado para o gradiente de fratura quando é imposta uma variação negativa no parâmetro X. (SEST TR 2.0@)

A Figura 49 apresenta graficamente a variação percebida no gradiente de colapso inferior quando é aplicada uma variação positiva e negativa nas tensões horizontais, pressão de poros e coeficiente de Biot. Com base nesta figura, é possível concluir que o parâmetro que mais influenciou o resultado final desse gradiente foi 
pressão de poros seguida do coeficiente de Biot e tensão horizontal maior. A faixa de variação média de cada um dos 4 parâmetros mais influentes para os resultados de gradiente de colapso inferior estão apresentados na Tabela 10.

Tabela 10 - Faixa de valores de gradiente de colapso inferior (GCOLI) obtido em psi a partir do incremento positivo e negativo do parâmetro de entrada. GCOLID denota o gradiente de colapso inferior médio médio em psi.

\begin{tabular}{|c|c|}
\hline Parâmetro & $\begin{array}{c}\text { Faixa de valores de gradiente de colapso inferior } \\
\text { obtido a partir da variação positiva e negativa do } \\
\text { parâmetro de entrada (Ib/gal) }\end{array}$ \\
\hline Tensão horizontal maior & GCOLID $-0.08>$ GCOLI $>$ GCOLID + 0.50 \\
\hline Tensão horizontal menor & GCOLID $>$ GCOLIT $>$ GFRATID + 0.21 \\
\hline Pressão de poros & GCOLID $-0.54>$ GCOLI $>$ GCOLID +0.62 \\
\hline Coeficiente de Biot & GCOLID $-0.54>$ GCOLI $>$ GCOLID \\
\hline
\end{tabular}

A mesma observação referente ao resultado para a variação positiva do coeficiente de Biot feita para a análise de sensibilidade do gradiente de fratura se aplica para o gradiente de colapso também.

Da mesma forma que foi apresentada para a análise de sensibilidade aplicada ao colapso superior, os estudos abordados por Gholami et al. (2015), Al-Ajmi \& AlHarthy (2010) e Moos et al. (2003) mostraram que a análise de sensibilidade indicou que no estudo de Gholami et al., os parâmetros mais influentes foram tensão horizontal maior e pressão de poros, enquanto que para Al-Ajmi \& Al-Harthy, além da tensão horizontal maior, o ângulo de atrito e a coesão também apresentaram variações mais significativas nos resultados, já Moos et al. mostraram que, em seu estudo, a pressão de poros foi o principal parâmetro de influência para o cálculo do colapso inferior, assim como o resultado obtido nessa dissertação.

De maneira resumida, a Tabela 11 apresenta os resultados da análise de sensibilidade obtidos para os gradientes de fratura superior, colapso superior e colapso inferior. Na Tabela 11, os parâmetros tensões horizontais maior $\left(\sigma_{\mathrm{H}}\right)$ e menor $\left(\sigma_{\mathrm{h}}\right)$, pressão de poros $\left(\mathrm{P}_{\mathrm{P}}\right)$ e coeficiente de Biot $(\alpha)$ são listados em ordem de maior relevância para menor relevância para o valor final daqueles gradientes. 
Tabela 11 - Resumo de análise de sensibilidade desse estudo de caso para os gradientes de fratura superior, colapso superior e colapso inferior.

\begin{tabular}{|c|c|c|c|}
\hline $\begin{array}{c}\text { Ordem de } \\
\text { relevância }\end{array}$ & $\begin{array}{c}\text { Gradiente de } \\
\text { Fratura Superior }\end{array}$ & $\begin{array}{c}\text { Gradiente de } \\
\text { Colapso Superior }\end{array}$ & $\begin{array}{c}\text { Gradiente de } \\
\text { Colapso Inferior }\end{array}$ \\
\hline $\mathbf{1}^{\circ}$ & $\sigma_{\mathrm{h}}$ & $\sigma_{\mathrm{h}}$ & $\mathrm{P}_{\mathrm{P}}$ \\
\hline $\mathbf{2}^{\mathbf{0}}$ & $\sigma_{\mathrm{H}}$ & $\mathrm{P}_{\mathrm{P}}$ & $\alpha$ \\
\hline 3ㅇ $^{\circ}$ & $\mathrm{P}_{\mathrm{P}}$ & $\alpha$ & $\sigma_{\mathrm{H}}$ \\
\hline $\mathbf{4}^{\circ}$ & $\alpha$ & $\sigma_{\mathrm{H}}$ & $\sigma_{\mathrm{h}}$ \\
\hline
\end{tabular}




\section{6. Conclusões e Recomendações para Trabalhos Futuros}

\section{1. Conclusões e comentários finais}

Duas metodologias de análise probabilística foram propostas para aplicação a estabilidade de poços: FOSM e SEAM. A análise probabilística visa considerar incertezas associadas aos parâmetros utilizados nas formulações que o método determinístico ignora. As incertezas podem ter diversas fontes, podem ser provenientes das correlações da literatura, utilizadas para a estimativa das propriedades mecânicas, podem ser carregadas também a partir de hipóteses simplificadores utilizadas para o cálculo das tensões e gradientes e também podem estar associadas ao fato de que os perfis iniciais utilizados para um projeto de poço são adaptados a partir de um poço correlato.

A partir dos métodos probabilísticos selecionados foi possível calcular os gradientes de fratura superior, colapso superior e colapso inferior para diferentes probabilidades de falha. Foi desenvolvido um código no MATLAB@ para a aplicação dessas metodologias ao longo de toda a trajetória de poço. Logo, foi possível obter a janela operacional probabilística para todas as profundidades. Neste trabalho foram apresentados os resultados para as probabilidades de falha de P10 e P90. As curvas para P50 também foram apresentadas, porém, as metodologias probabilísticas apresentadas assumem que as curvas de gradiente possuem uma distribuição normal, logo a P50 é equivalente aquelas obtidas deterministicamente.

Para a aplicação de uma metodologia probabilística, foi necessário fazer uma análise estatística e obter os parâmetros estatísticos referentes aos dados de entrada. Neste trabalho, foram considerados dois tipos de distribuição - normal e uniforme e assumiu-se por hipótese simplificadora que o desvio padrão associado a cada parâmetro de entrada equivale a $10 \%$ do seu valor médio para a distribuição normal e que os parâmetros a e b associados a cada parâmetro de entrada equivalem a 0.83 
e 1.17 do seu valor médio respectivamente. Para a distribuição normal, utilizou-se uma taxa de variação fixa igual ao desvio padrão nos parâmetros de entrada. Já na distribuição uniforme, a variação foi aleatória dentro de um intervalo de $\pm 11.8 \%$ do valor médio do parâmetro.

Para essa proposta de aplicação, observou-se que os resultados obtidos considerando distribuição normal dos parâmetros de entrada, foram mais afastados dos valores médios determinísticos tanto para o método SEAM quanto para FOSM, ou seja, esse cenário apresentou uma dispersão maior em relação aos resultados determinísticos. Entre as duas formulações, espera-se que aquela baseada na distribuição uniforme com variação aleatória dos parâmetros seja a mais realista. Isto porque na prática, os parâmetros não apresentam todos uma distribuição normal com taxa de variação fixa. Cada parâmetro apresenta sua própria distribuição e intervalo de variação. Portanto, apesar de considerar todos os parâmetros com distribuição uniforme, esse cenário permite que seja escolhida de maneira aleatória a variação sofrida por cada parâmetro.

O estudo de caso apresentado refere-se ao Poço PUC. O projeto de estabilidade feito para o Poço PUC foi comparado com a retroanálise de estabilidade feita após sua perfuração. Foi observada a ocorrência de vários eventos de perfuração. A comparação entre projeto e retroanálise mostrou que a janela operacional estimada no projeto representava um cenário muito mais abrangente para o dimensionamento de fluido de perfuração do que a janela real estimada na retroanálise, o que ocasionou os eventos indesejados.

A análise probabilística de estabilidade foi aplicada para o projeto do Poço PUC a fim de considerar as incertezas associadas aos parâmetros utilizados para a configuração da janela operacional e verificar para qual a probabilidade de falha os gradientes de fratura e colapso seriam estimados de maneira mais realista quando comparados com a janela de operação da retroanálise.

Como o intervalo de peso de fluido de perfuração que garante a estabilidade do poço obtido na retroanálise se mostrou estreito, os gradientes estimados com dados reais do Poço PUC foram comparados com aqueles obtidos probabilisticamente para uma probabilidade de falha de $10 \%$. Essa comparação mostrou que, para as camadas pré-sal, as curvas de P10 seriam uma boa estimativa para o projeto desse poço. Caso 
o projeto tivesse sido feito com base em metodologias probabilísticas e considerando uma probabilidade de falha de $10 \%$, os eventos de perfuração observados poderiam ter sido evitados.

O Poço PUC que foi usado para esse estudo de caso possui uma camada espessa de sal para a qual este estudo não se aplica. Entretanto, as análises foram feitas para as camadas pré-sal e pós-sal. Não foi possível obter conclusões a partir das informações fornecidas para as camadas pós-sal. Isso porque os perfis iniciais utilizados para o projeto foram estimados a partir de formulações de regressão potencial e não com base em perfis originais de correlação (montagem) ou provenientes de levantamento sísmico.

Foram feitas análises de sensibilidade relativas aos gradientes de fratura superior, colapso superior e colapso interior. Constatou-se que quatro parâmetros de entrada foram os mais expressivos para os três gradientes: tensão horizontal maior $\left(\sigma_{\mathrm{H}}\right)$, tensão horizontal menor $\left(\sigma_{\mathrm{h}}\right)$, pressão de poros $\left(\mathrm{P}_{\mathrm{P}}\right)$ e coeficiente de Biot $(\alpha)$. Dentre esses parâmetros, a variação da tensão horizontal menor foi aquela que mais afetou os limites superiores (fratura e colapso), enquanto que para o limite de colapso inferior, o parâmetro de maior relevância foi a pressão de poros.

\section{2. \\ Recomendações para trabalhos futuros}

As análises probabilísticas de estabilidade são uma boa alternativa para a estimativa das janelas operacionais em projetos de poços. Isso porque essas análises consideram as incertezas associadas aos parâmetros de entrada e por isso, podem apresentar janelas de operação mais realistas e consequentemente seguras, evitando assim a ocorrência de eventos indesejados, inclusive custos extras ocasionados devido ao NPT.

Inicialmente, os métodos probabilísticos podem ser aplicados em diversos projetos de poços que já foram perfurados em um mesmo campo, da mesma maneira que foi feito neste trabalho. Dessa forma, pode ser possível observar um padrão de probabilidade de falha que melhor se adequa para correlação entre poços desse campo. A finalidade dessa aplicação seria poder utilizar o método probabilístico para 
projetos de poços nesse campo utilizando uma probabilidade de falha média já prédefinida e avaliada.

Para a aplicação de métodos probabilísticos em uma análise, é necessário primeiramente, fazer uma análise estatística dos dados de entrada e obter os parâmetros estatísticos. Neste estudo, por hipótese simplificadora, foram abordados dois cenários: um onde todos os parâmetros apresentam uma distribuição normal e outro onde apresentam distribuição uniforme. Para ambas as distribuições, foi considerado que o desvio padrão é de $10 \%$ do valor médio dos dados de entrada. Uma abordagem alternativa e mais realista para essa análise estatística seria analisar os parâmetros de entrada individualmente e verificar o tipo de distribuição que melhor se adequa a cada um e obter o os parâmetros estatísticos associados a essa distribuição para depois aplicar o método probabilístico.

Uma aplicação também relevante da análise probabilística de estabilidade é a análise de risco. A análise de risco é importante para fazer uma associação integrada entre eventos não desejados, suas probabilidades de ocorrência e suas possíveis consequências - financeiras, ambientais e humanas. Uma vez que a análise de risco aborda a probabilidade de ocorrência de um evento não desejado, é importante dispor de metodologias probabilísticas a sua aplicação. Dessa forma, uma abordagem interessante dos métodos probabilísticos apresentados seria propor uma metodologia de análise de risco aplicada a estabilidade de poços com base nos métodos probabilísticos apresentados. 


\section{Referências}

AL-AJMI, A. M. \& AL-HARTHY, M. H. 2010. Probabilistic wellbore collapse analysis. Journal of Petroleum Science and Engineering. Res. 74 (2010), 171 - 177.

ALDRED, W., et al. 1999. Managing Drilling Risk. Oilfield Review, v.11, (2), pp. 219.

ALDRED, W., PLUMB, D., BRADFORD, I., COOK, J., GHOLKAR, V., COUSINS, L., MINTON, R., FULLER, J., GORAYA, S., TUCKER, D. Managing Drilling Risk. Oilfield Review, v.11, (2), pp. 2-19, Summer, 1999.

ARGOTE, S. M. R. Modelo Geomecânico Aplicado à Análise de Estabilidade de Poços com Ênfase em Folhelhos. Dissertação de Mestrado - Departamento de Engenharia Civil (Geotecnia), Pontifícia Universidade Católica do Rio de Janeiro. Rio de Janeiro, 2012. 129p.

CARDOSO JUNIOR, J. V. L. Diagnóstico de problemas em poços direcionais durante as manobras. Dissertação de Mestrado - Faculdade de Engenharia Mecânica (Departamento de Engenharia de Petróleo), Universidade Estadual de Campinas, São Paulo, 1992, 90p.

CHIEZA, C. P. Diagnósticos de problemas operacionais durante a perfuração de poços de petróleo. Dissertação de Mestrado - Departamento de Engenharia mecânica, Pontifícia Universidade Católica do Rio de Janeiro, Rio de Janeiro, 2011, $151 \mathrm{p}$.

CHIPINDU, N. S. CH. Pós-análise em problemas de perfuração de poços marítimos de desenvolvimento. Dissertação de Mestrado. Faculdade de Engenharia Mecânica e Instituto de Geociências, Universidade Estadual de Campinas, São Paulo, 2010, 113p.

CHRISTIAN, T. J., LADD, C. C., BAECHER ,B. G. Reliability and Probability in Stability Analysis, Invited Lecture. Stability and Performance of Slopes and Embankments-II, A 25 Year Perspective. ASCE Geotechnical Special Publication No. 31, Vol. 2, pp.1071-1111, 1992.

CONDOL, F. S. \& CORRÊA, L. L. B. Análise Estatística do Custo Métrico de Perfuração de Poços de Petróleo. Monografia - Faculdade de Engenharia de Petróleo, Universidade Federal do Rio de Janeiro. Rio de Janeiro, 2012. 93p.

EATON, B. A. The Equation for Geopressure Prediction from Well Logs. Society of Petroleum Engineers. SPE, 1975.

FJÆER, E.; HOLT, R.; HORSRUD, P.; RAAEN, A. E RISNES, R. Petroleum Related Rock Mechanics, Elsevier Science Publishers, 2008. Second Edition. 
FONTOURA, S. A. B., HOLZBERG, B. B. TEIXEIRA, E. C., FRYDMAN, M. 2002 Probabilistic Analysis of Wellbore Stability During Drilling. Rock Mechanics Conference. Irving, 20-23 de Outubro, 2002.

FREITAS, L. O. 2018. Análise Econômica de um Projeto de Perfuração de Poços Marítimos. Monografia - Faculdade de Engenharia de Petróleo, Universidade Federal Fluminense, Rio de Janeiro, 2018, 74p.

GHOLAMI, R., RABIEI, M., RASOULI, V., AADNOY, B., FAKHARI, N. 2015. Application of quantitative risk assessment in wellbore stability analysis. Journal of Petroleum Science and Engineering. Res. 135 (2015), 185 - 200.

GTEP, Modelo Geomecânico e Estudo de Estabilidade, Rio de Janeiro, 2016, 36p. Relatório Técnico.

GUIMARÂES, I. O. Operações Especiais de Perfuração. Trabalho de pós graduação da disciplina de Engenharia de Poço - Programa de Pós-Graduação Ciências e Engenharia de Materiais, Universidade Federal de Campina Grande, Campina Grande, 2010, 25p.

HOUTCHENS, B., FOSTER, J., TESSARI, R. 2007. Applying risk analysis to casing while drilling. SPE/IADC Drilling Conference. Amsterdam, 20-22 de Fevereiro, 2007.

JAVERI, S. M., HAINDADE, Z. W., JERE, C. B. Mitigating Loss Circulation and Differential Sticking Problems Using Silicon Nanoparticles. SPE/IADC Middle East Drilling Technology Conference and Exhibition. Oman, 24-26 de Outubro, 2011.

KIRSCH, E.G., "Die Theorie der Elastizität und die Bedürfnisse der Festigkeitslehre, Zeitschrift des Vereines deutscher Ingenieure, Vol. 42, pp. 797807, 1898.

MILITZER, H. \& STOLL, R. Einige Beitrageder geophysics zur primadatenerfassung im Bergbau. Neue Bergbautechnik , 3, 21-25. 1973.

MOOS, D., PESKA, P., FINKBEINER, T., ZOBACK, M. 2003. Comprehensive wellbore stability analysis utilizing Quantitative Risk Assessment. J. of Petroleum Science and Engineering. Res. 38 (2010), 97 - 109.

MORITA, N. Uncertainty Analysis of Borehole Stability Problems. Society of Petroleum Engineers. SPE. Dallas, 22-25 de Outubro, 1995.

MURTHA, J. A. Decisions involving uncertainty: a risk tutorial for the petroleum industry. $2^{\text {nd }}$ ed. New York: Palisade Corporation, 2008, 142p.

PINHEIRO, J. I. D., CUNHA, S. B. (2012) Probability and statistics: quantifying uncertainties, 1st ed.; Elsevier hs - education, Brazil, (in Portuguese).

PORTAL ACTION $\circledast$, São Carlos, SP. Disponível em: <http://www.portalaction.com.br/probabilidades/62-distribuicao-normal>. Acesso em: 20, setembro e 2020. 
RABELO, C. A. C. Metodologia para análise de dados de perfuração. Dissertação de Mestrado - Faculdade de Engenharia Mecânica e Institudo de Geociências, Universidade Estadual de Campinas, São Paulo, 2008, 114p.

REID, D., ROSENBERG, S., MONTGOMERY, M., SUTHERLAND, M., YORK, P. Drilling-Hazard Mitigation-Reducing Nonproductive Time by Application of Common Sense and High-Value-Well Construction techniques. Offshore Technology Conference. Houston, 1-4 de Maio, 2006.

SCHLUMBERGER MECPRO Mechanical Properties, 1985.

SEST TR 2.0@ - Simulador de Estabilidade em Tempo Real, versão2.0, GTEP/PUCRIO e CENPES/PDDP/PCP PETROBRAS, 2018.

SEST TR 2.0C - Simulador de Estabilidade em Tempo Real, versão2.0, Manual Teórico, 2018.

SESTC - Sistema de Estabilidade, versão 5.72, GTEP/PUC-RIO e TEP/CENPES/PETROBRAS, 2012.

TAVARES, R. M. Interpretação e Análise de dados de Perfuração em poços de petróleos. Dissertação de Mestrado - Faculdade de Engenharia Mecânica e Institudo de Geociências, Universidade Estadual de Campinas, São Paulo, 2006, 145p.

TEIKOKU-Vp. Technical Reference and User's Manual. GMI WellCheckTM Version 3.2. 2007.

TERZAGHI, K. V. The shearing resistance of saturated soils and the angle between the planes of shear. In: Casgrande, A.; Rutledge, P. C.; Watson; J. D. (eds.) Proc. Int. Conf. Soil Mechanics and Foundation Engineering, Vol. I, pp. 54-56. Harvard University, 1936.

VECCI, A. N., SAYÃO, S. F. J. Probabilistic Analysis of Mine Slope Stability. XVI Pan-American Conference on Soil Mechanics and Geotechnical Engineering. Cancun, 17-20 de Novembro, 2019.

ZOBACK, M. D. (2007) Reservoir Geomechanics. New York: Cambidge University Press, 2007, 505p.

ZOBACK, M. D., et al., 2003. Determination of Stress Orientation and Magnitude in Deep Wells. International Journal of Rock Mechanics \& Mining Sciences: 40 (2003) 1049-1076 


\section{Apêndice A}

\section{Equivalência Amostral entre os Métodos Estatísticos}

No item 3.2 foi mencionado que, para fins de comparação entre os resultados obtidos a partir da distribuição normal dos parâmetros de entrada e aqueles obtidos a partir da distribuição uniforme, deveria ser feita uma equivalência amostral.

A distribuição amostral ao longo da curva de distribuição normal de um parâmetro e delimitada como indicado na Figura 19, ou seja, uma vez que, por hipótese simplidicadora, definiu-se o desvio padrão é $10 \%$ do valor médio do parâmetro, e que a variação aplicada ao parâmetro para o uso do método probabilístico será equivalente a um desvio padrão, significa que a amostragem associada a esse caso será de aproximadamente $68.3 \%$

Por hipótese simplificadora, foi definido para a aplicação da distribuição uniforme, que o desvio padrão também seria de $10 \%$ do valor médio do parâmetro de entrada. Dessa forma, é preciso estipular o intervalo ao redor do valor médio do dado de entrada que será equivalente a uma amostragem de $68.3 \%$.

As hipóteses simplificadoras sugerem que $\sigma=10 \% * \mu$, portanto, se as equações 37 e 38 forem aplicadas nessa hipótese, tem-se a equação 56 e desenvolvendo esta equação chega-se a equação 57.

$$
\begin{aligned}
& \frac{\mathrm{b}-\mathrm{a}}{\sqrt{12}}=\frac{10}{100} * \frac{\mathrm{a}+\mathrm{b}}{2} \\
& \mathrm{~b}=\frac{10+\sqrt{3}}{10-\sqrt{3}} * \mathrm{a}
\end{aligned}
$$

Uma vez que se tem uma relação entre a e b, é possível aplicar essa correlação na equação 37 e obter os parâmetros a e b em função de $\mu$. A sequencia de cálculos para a definição de a e b em função de $\mu$ está representada nas equações 58 e 59.

- Aplica-se a equação 55 na equação 52 e obtem-se a em função de $\mu$ : 
$\mu=\frac{\mathrm{a}+\frac{10+\sqrt{3}}{10-\sqrt{3}} * \mathrm{a}}{2} \Rightarrow \mathrm{a}=\frac{(10-\sqrt{3})}{10} * \mu$

- Aplica-se a equação 56 na equação 55 e obtem-se b em função de $\mu$ :

$\mathrm{b}=\frac{10+\sqrt{3}}{10-\sqrt{3}} * \frac{(10-\sqrt{3})}{10} * \mu \Rightarrow \mathrm{b}=\frac{(10+\sqrt{3})}{10} * \mu$

Uma vez que os limites da distribuição uniforme foram definidos, é possível definir o intervalo que abrange $68.3 \%$ da amostragem. A intenção é que o intervalo de variação que atende a amostragem requerida seja simétrico em relação ao valor médio $\mu$. Sabe-se o intervalo [a , b] abrange 100\% da amostragem. A Figura 50 apresenta um esquema do que seria um intervalo de amostragem de 68.3\%. NA Figura 50, pé a taxa de variação ao redor do valor médio da distribuição que assegura uma amostragem de $68 \%$.

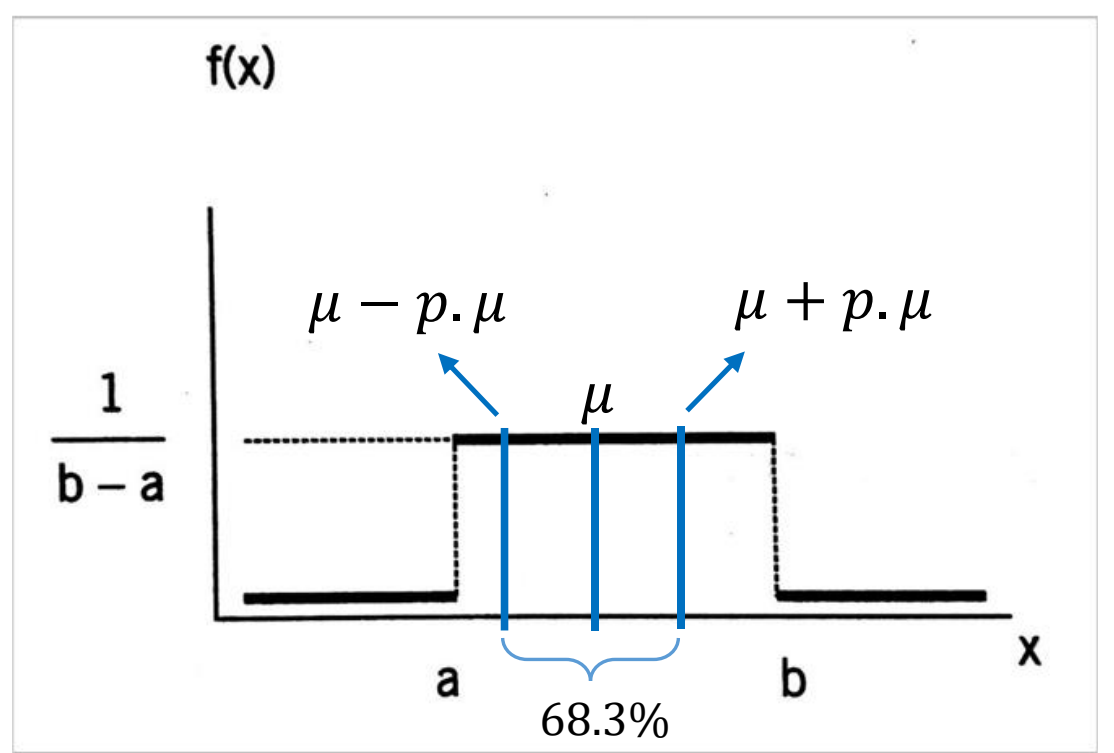

Figura 50 - Esquema para definição do intervalo da distribuição uniforme que abrange 68.3\% da amostragem. (Pinheiro et al., 2012, modificada)

Para definir o valor de $p$, pode ser feita uma regra de 3 simples da seguinte maneira:

$\frac{\mathrm{b}-\mathrm{a}}{100}=\frac{\mu+\mathrm{p} . \mu-(\mu-\mathrm{p} . \mu)}{68.3}$ 
Aplica-se as equações 58 e 59 na equação 60:

$\frac{\frac{(10+\sqrt{3})}{10} \mu-\frac{(10-\sqrt{3})}{10} \mu}{100}=\frac{2 . p}{68.3} * \mu$

A partir da equação 59 obtem-se $\mathrm{p}=6.83 * \sqrt{3} \% \approx 11.8 \%$. 


\section{Apêndice $B$ \\ Metodologia geral do Código Desenvolvido em MATLAB@ para Aplicação dos Métodos Probabilísticos}

Para a realização deste trabalho, foi desenvolvido um código no MATLAB@ para a aplicação dos métodos probabilísticos ao longo de todo o poço.

\section{Entradas para o código}

Ambas as metodologias abordadas abordam o conceito de derivada parcial. As derivadas parciais são obtidas a partir do cálculo dos gradientes variando-se um parâmetro de entrada por vez.

Para a aplicação das metodologias, 11 parâmetros de entrada foram considerados com incertezas associadas e para cada parâmetro foram calculadas deterministicamente dois gradientes de fratura, dois gradientes de colapso superior $\mathrm{e}$ dois gradientes de colapso inferior (considerando a variação positiva e negativa do parâmetro) ao longo de toda a trajetória de poço. Todos esses gradientes foram entradas para o código desenvolvido.

Os gradientes médios, obtidos a partir dos valores médios de cada parâmetro também foram entradas para o código.

\section{Organização}

Após a entrada desses gradientes, o código foi organizado da seguinte maneira:

1. Definição dos gradientes médios

2. Método FOSM: passo a passo para gradiente de fratura, colapso superior e colapso inferior

2.1. Definição do desvio padrão adotado; 
2.2. Definição da variação empregada aos parâmetros;

2.3. Definição dos pares de gradientes (gradiente obtido a partir da variação positiva e negativa) referentes a cada parâmetro;

2.4. Cálculo das derivadas parciais referentes a cada parâmetro;

2.5. Cálculo do somatório das derivadas parciais;

2.6. Cálculo do desvio padrão do fator de segurança;

2.7. Definição das probabilidades de falha que serão calculadas;

2.8. Aplicação das equações para gradientes probabilísticos.

3. Método SEAM: passo a passo para gradiente de fratura, colapso superior e colapso inferior

3.1. Definição do desvio padrão adotado;

3.2. Definição da variação empregada aos parâmetros;

3.3. Definição dos pares de gradientes (gradiente obtido a partir da variação positiva e negativa) referentes a cada parâmetro;

3.4. Cálculo das derivadas parciais referentes a cada parâmetro;

3.5. Cálculo do somatório das derivadas parciais;

3.6. Cálculo do desvio padrão da pressão interna do poço;

3.7. Definição das probabilidades de falha que serão calculadas;

3.8. Aplicação das equações para gradientes probabilísticos. 